\title{
COMPATIBILITY OF REFRIGERANTS AND LUBRICANTS WITH ENGINEERING PLASTICS
}

\author{
Quarterly Technology Progress Reports
}

1 July 1992 - 30 September 1992

1 October 1992 - 31 December 1992

\author{
Richard C. Cavestri, Ph. D. \\ Imagination Resources, Inc. \\ 5130 Blazer Memorial Parkway \\ Dublin, Ohio 43017
}

January 1993

Prepared for

The Air-Conditioning and Refrigeration Technology Institute

Under

ARTI MCLR Project Number 650-50800

This project is supported, in whole or in part, by U.S. Department of Energy grant number DE-FG02-91CE23810: Materials Compatibility and Lubricants Research (MCLR) on CFC-Refrigerant Substitutes. Federal funding supporting this project constitutes $\mathbf{9 3 . 6 7 \%}$ of allowable costs. Funding from non-government sources supporting this project consists of direct cost sharing of $6.33 \%$ of allowable costs; and in-kind contributions from the air-conditioning and refrigeration industry.

\section{MASTER}




\section{DISCLAIMER}

The U.S. Department of Energy's and the air-conditioning industry's support for the Materials Compatibility and Lubricants Research (MCLR) program does not constitute an endorsement by the U.S. Department of Energy, nor by the air-conditioning and refrigeration industry, of the views expressed herein.

\section{NO'TICE}

This report was prepared on account of work sponsored by the United States Government. Neither the United States Government, nor the Department of Energy, nor the Air-Conditioning and Refrigeration Technology Institute, nor any of their employees, nor of any of their contractors, subcontractors, or their employees, makes any warranty, expressed or implied, or assumes any legal liability or responsibility for the accuracy, completeness, or usefulness of any information, apparatus, product or process disclosed or represents that its use would not infringe privately-owned rights.

\section{COPYRIGHT NOTICE \\ (for journal publication submissions)}

By acceptance of this article, the publisher and/or recipient acknowledges the right of the U.S. Government and the Air-Conditioning and Refrigeration Technology Institutes, Inc. (ARTI) to retain a non-exclusive, royalty-free license in and to any copyrights covering this paper. 
TABLE OF CONTENTS

ABSTRACT

SCOPE

SIGNIFICANT RESULTS 1

PHYSICAL AND CHEMICAL PROPERTIES OF 1 ENGINEERING PLASTICS

PLASTIC MOLD

ENGINEERING PLASTICS

LUBRICANT PREPARATION

LUBRICANT IMMERSION STUDIES

REFRIGERANT QUALITY

REFRIGERANT IMMERSION STUDIES

TENSILE AND PERCENT ELONGATION MEASUREMENTS 3

STRESS CRACK - CREEP RUPTURE TEST CELLS 4

THERMAL AGING OF PLASTICS WITH REFRIGERANT 6

$\begin{array}{ll}\text { COMPLIANCE WITH AGREEMENT } & 8\end{array}$

$\begin{array}{ll}\text { PRINCIPAL INVESTIGATOR EFFORT } & 8\end{array}$

$\begin{array}{ll}\text { APPENDIX INDEX AND CONTENTS } & 9\end{array}$

LIST OF ILLUSTRATIONS

FIGURE 1. TYPICAL CREEP CURVE 5 


\section{ABSTRACT}

Seven oil immersion studies were completed at both $20^{\circ} \mathrm{C}$ and $60^{\circ} \mathrm{C}$. Test bars used in this study fall within the manufacturer specification limits of physical consistency and integrity. Refrigerant Immersion studies at ambient and $60^{\circ} \mathrm{C}$ are also complete. Equilibrium refrigerant gas solubilities of the 32 ISO VG branched acid polyolester with all ten refrigerants have been determined and completed at $20^{\circ} \mathrm{C}$. Finally, the thermal aging of plastics at constant refrigerant pressure exposure with seventeen refrigerant lubricant combinations have been completed.

\section{SCOPE}

The scope of this research provides compatibility information regarding plastics exposed to a wide variety of lubricant and refrigerant combinations. Data on the dimensional changes of plastic polymers were measured and the immersion and tensile properties were determined. Physical changes will be measured after ambient aging, under stress and after thermal aging for various lubricant and refrigerant combinations at constant pressure.

\section{SIGNIFICANT RESULTS}

\section{PHYSICAL AND CHEMICAL PROPERTIES OF ENGINEERING PLASTICS AND LUBRICANTS}

Physical and chemical changes in plastics exposed to differing chemical environments are generally specific to polymer type, processing and synthesis. Individual manufacturers, generally, have their own patent or proprietary methods for polymer synthesis and are not directly identified by generic name alone. As a result, molded polymers from different companies will often perform differently. Molecular weight, molecular weight distributions, polymer structure, chain length, density and processing may account for some of the observed differences. Data contained in this report reflect changes in properties of generic plastics obtained from specific manufactures.

Table A-1 identifies trademarks, registered trademarks or copyrighted names of plastics used in this study. In addition table A-1 identifies each plastic by an assigned number, referred to throughout the Appendixes.

The lubricants identified in Appendix A-1 are listed by manufacturer and generic name. This study only reflects the physical changes caused by the specific lubricant used and does not constitute a universal answer that all lubricants in the general category will have the identical behavior.

Table A-2 identifies the processing conditions used to mold the plastic test bars according to manufactures' specifications. Plastics are categorized by plastic number, name brand, manufacturer and generic type. Manufacturer specifications are used as starting guide lines for molders. Therefore, cylinders and molded temperatures may differ slightly to obtain the best mold test bars.

\section{PLASTIC MOLD}

A production quality steel thermoplastic/thermoset injection mold design was approved in February, 1992. The mold was completed on March 15, 1992. The first test material, a nylon 6/6 material, was tested and performed as expected. Each cavity has been numbered. Originally each cavity had two ejector pins located at opposite ends of the mold. Two additional ejector pins were included in later versions to improve straightness. Without these additional ejector pins, bending occurred in the gage area of the test bars. The quality of the 
mold finish in the gage area was improved to a $6 \mathrm{~F}$ stone. Original test bars had smooth extension tabs. To minimize possible slippage during testing $0.005^{\prime \prime}$ molded nipples are now included on each side of the tab.

Also included in this study are effects on thermoset phenolic materials exposed to differing lubricant/refrigerant combinations. Unlike thermoplastic materials, injection thermoset materials require a longer mold residence time under increased pressure and temperature. Injection ports, sprues and gates are made larger than normal to improve plastic homogeneity and reduce and physical degradation of the plastics.

The thermoplastic mold was designed to handle both types of plastics materials. Provisions were made for a large cartridge heater necessary for a phenolic thermoset curing reaction. The phenolic used in this study was almost completely cured in the mold prior to ejection. The final test parts will be post cured for the recommended time, as required for completion of the reaction.

\section{ENGINEERING PLASTICS}

With the exceptions of DuPont PTFE and DuPont Vespel DF and DF-ISO, which were used as received, the test plastics were molded into the modified type 5 ASTM test bars. These DuPont plastics required special molding operations and sintering equipment not available to this laboratory. The DuPont Teflon PTFE test bars were rule die cut from sheet grade virgin PTFE. The supplied test bars were cut as specified in ASTM D 1457-91a, "Standard Specification for Polytetrafluoroethylene (PTFE) Molding and Extrusion Materials" and as defined in Figure 13, Microtensile Test Bars.

DuPont Vespel DF products are produced from granulated polyimide powder and formed to near net shapes by a very high pressure compaction process. DuPont Vespel DF-ISO products are also compaction molded but are also densified by sintering under pressure in liquid metal. Vespel test bars were compression molded, by DuPont, as per the ASTM E8-91 "Standard Test Methods of Tension Testing of Metallic Materials" and produced to shape as defined in Figure 16.

Due to its high creep cold flow properties, the Teflon PTFE plastic will not be tested in the creep rigs. All plastics have been molded as close to manufactures specifications as possible, see Table A-2. Consistency among test specimens was determined by tensile measurements of five individual unaged test bars. All unaged test bars met the manufacturers reported tensile properties of the molded engineering plastic. The unaged data is presented as an average of five test bars in Appendix F. The creep loads are $25 \%$ of ultimate tensile.

\section{LUBRICANT PREPARATION}

The lubricants used in this testing program were degassed and dried by heating quantities of the bulk fluid to $60^{\circ} \mathrm{C}\left(140^{\circ} \mathrm{F}\right)$ under vacuum for at least $24 \mathrm{hrs}$. Moisture content did not exceed $50 \mathrm{ppm}$, while the total acid number of the flui is were below $0.05 \mathrm{mg} . \mathrm{KOH} / \mathrm{gm}$.

\section{LUBRICANT IMMERSION STUDIES}

Evaluation of the plastic test specimens at the required temperatures $\left(60^{\circ} \mathrm{C}\right.$ and $\left.100^{\circ} \mathrm{C}\right)$ have been completed, and is presented in Appendix B. All plastics were immersed in the test lubricant in screw cap sealed vials under nitrogen cover at the specified aging temperature for 14 days. The dimensional property changes observed indicated that all of the plastics were affected by the lubricants in some way. Tables for each lubricant at the two temperatures are provided in Appendix B, which summarizes the average percent affect on measured parameters. 
Dimensional property changes did not reflect changes in tensile properties. However, changes in dimension does suggest that some lubricant absorption has taken place, possibly impacting physical properties of the plastic.

\section{REFRIGERANT QUALITY}

Refrigerants received for use in this study were checked by packed column gas chromatography for contaminant content by other refrigerant gases. The refrigerants were found to have little, if any, contamination. Moisture content in the refrigerants was not determined.

\section{REFRIGERANT IMIMERSION STUDIES}

The liquid refrigerant immersion studies were performed in separate stainless steel pressure tubes equipped with a gas space and a metering needle valve. The tubes were filled using a special low volume, low loss, stainless steel manifold. Prior to filling, the tubes were evacuated to 20-30 millitorr for several minutes and then chilled in ice water before filling. The valves were closed and then sequentially opened for filling with liquid refrigerant. Typically the plastic specimens were exposed to about 20 grams of liquid refrigerant.

At the end of the exposure time, the refrigerants were exhausted from the stainless steel tube as liquid into $\mathrm{LN}_{2}$ cooled tared test tubes. The residues, if any, were then concentrated by boiling off the refrigerant. The amount of extractables generally ranged between 5 to $15 \mathrm{mg}$.

All refrigerants were found to affect the plastic parts in some way. A weight gain and some softening in the plastic was usually observed. With clear plastics the polymer takes on a silvery appearance. Generally the HFC refrigerants appear to least affect the plastics. The three plastics that seem to be most severely affected are ABS, polyphenylene ether, and polycarbonate. Although these results suggest the three plastics should not be tested in the 32 ISO VG branched acid polyolester with $40 \%$ refrigerant concentrations the presence of polyolester oil may allow the materials to survive the creep testing.

Aging for 14 days at ambient and $60^{\circ} \mathrm{C}\left(140^{\circ} \mathrm{F}\right)$ in pure refrigerant was performed at the refrigerant saturation pressure. The thermal aging of the plastics with selected refrigerant lubricant combinations was performed at $150^{\circ} \mathrm{C}\left(300^{\circ} \mathrm{F}\right)$. The pressure of the refrigerant was controlled to fall within 275-300 psia (19-20bar).

\section{TENSILE AND PERCENT ELONGATION MEASUREMENTS}

The tensile tests were conducted using an Instron Model 1122 with a modified ASTM type 5 tensile bar. The plastics were placed vertically in test grips attached to the crosshead via a self-aligning universal yoke. The crosshead movement was set at the specified ASTM D678 pull rates and were between 0.2 and $1.2 \mathrm{~mm} / \mathrm{min}$. The load cell resolution is $0.5 \%$ of the observed force and has a load range of 0 to $120 \mathrm{Kg}$.

The physical property values of aged test bars reported in Appendix $F$ are derived from two samples of test bars exposed to the selected refrigerant/lubricant environment, where as the unaged properties are from five test pieces. Percent elongation and ultimite tensile were calculated from the physical test data provided by the Instron measurements. Percent elongation is the total change in length divided by the one inch $(25.4 \mathrm{~mm})$ necked down length. The change in length is measured by the amount the crosshead moves from the original position until the instant the plastic bar breaks. Ultimate tensile is the maximum recorded load divided 
by the cross-sectional area of the gage region of the plastic test piece. Plastics thermally aged in different oil and refrigerant environments are then compared to the values of nontreated plastics. Relative percent changes are calculated and examined for significant changes.

\section{STRESS CRACK-CREEP RUPTURE TEST CELLS}

Currently all test cells are complete. Creep stress is currently being performed at $25 \%$ of the ultimate tensile load. Previous experiments at lighter loads, indicated that nylon test bars were insufficiently stressed. At lighter loads the nylon samples were in a purely elastic region resulting in spring-like behavior. Experiments with $25 \%$ load gave the best creep curve function and provided sufficient load to stress the gage area of the test bar within the 14 day test period.

\section{Creep Measurement Process}

The principal of creep rupture measurement required the use of sensitive, long term noise free electronics. Initially a commercial LVDT computer board system was used to measure creep. However unacceptable oscillatory noise was observed in test specimens using the $25 \%$ of dead weight loads. The origin of this unwanted noise seemed to originate with the sampling board.

It was determined that powering each LVDT with individual amplifiers and frequency source eliminated the noise. Unfortunately the required amplifiers were not immediaiely available. Thus, all boards presently in use for this study were designed, built and tested by IRI.

The use of individual amplifiers has allowed us to sample each cell at an hourly rate using four separate 15 second sample times averaged as a single test point. This increase in averaging further improves accuracy by eliminating random noise. Using individual amplifiers allows for rapid change out in the event of channel failure. Currently the sensitivity of the measurement is $1.5 \times 10^{-4}$ inches; an improvement from the $2.5 \times 10^{-4}$ inches stated in the last report. It is believed that this measurement level represents the best compromise between movement, position and reduced measurement noise.

We are not planning, at this time, any changes in the sensitivity of the creep rupture experiment. However, depending on the progression of the experiment we may wish to increase the sensitivity. Any change would be on the order of $75 \times 10^{6}$ inches which would improve measurements in plastics showing minimal creep.

\section{Creep Modulus}

The plastics used in refrigeration and compressor systems are expected to have high reliability and long-term stable qualities. The compressor and systemi design engineer requires information regarding physical property changes for proper engineering usage. The property of plastics under long-term load and at varying conditions provide measurable changes that are essential for an understanding of material behavior. Such material behavior is described in terms of creep properties.

The phenomenon of deformation under load is referred to as creep. In ihis study creep was measured for plastics submerged in a $32 \mathrm{cSt}$ synthetic lubricant, 32 ISO VG branched acid polyolester, with selected refrigerants maintained at $40 \%$ concentration by weight at $20^{\circ} \mathrm{C}$. $\left(68^{\circ} \mathrm{F}\right)$. 
The plastic test bars were held in screw clamped stainless steel jaws. The clamping procedure consisted of first centering the test piece between the jaws and firmly squeezing the plastic tabs. An hour after the initial tightening the jaws are retightened to take up any cold flow which may have occurred in the jaw area.

Prior to loading, the test bars are immersed in the lubricant in a 100 millitorr vacuum for severai hours removing any air. Liquid refrigerant is added to the bottom of the test cylinder through a needle valve. The cylinders are charged to a previously calculated gas pressure known to yield $40 \%$ refrigerant by weight.

The sample is loaded by slowly releasing a predetermined dead weight providing $25 \%$ of the samples ultimate tensile strength. When the plastic part is loaded, it rapidly deforms to a strain roughly predicted by its previously determined stress-strain modulus. With time and/or temperature the plastic part continues to deform until rupture or yielding causes failure.

Figure 1, illustrates a typical creep curve of the test plastics and shows four distinct regions on the creep curve. The first stage shows the near instantaneous elastic deformation of the gage area. The second stage, called primary creep, is more easily seen and is the strain which occurs much more rapidly but at a decreasing rate. The third stage, sometimes called cold flow, is the linear region of the curve and is characterized by a constant rate of creep. In most of our plastics so far we have not seen the fourth stage which is failure or rupture. The exceptions are the acrylonitrile-butadiene-styrene terpolymer and the modified polyphenylene oxide which fail within one hour in lubricant and refrigerant, (Table D-1,-2,-3).

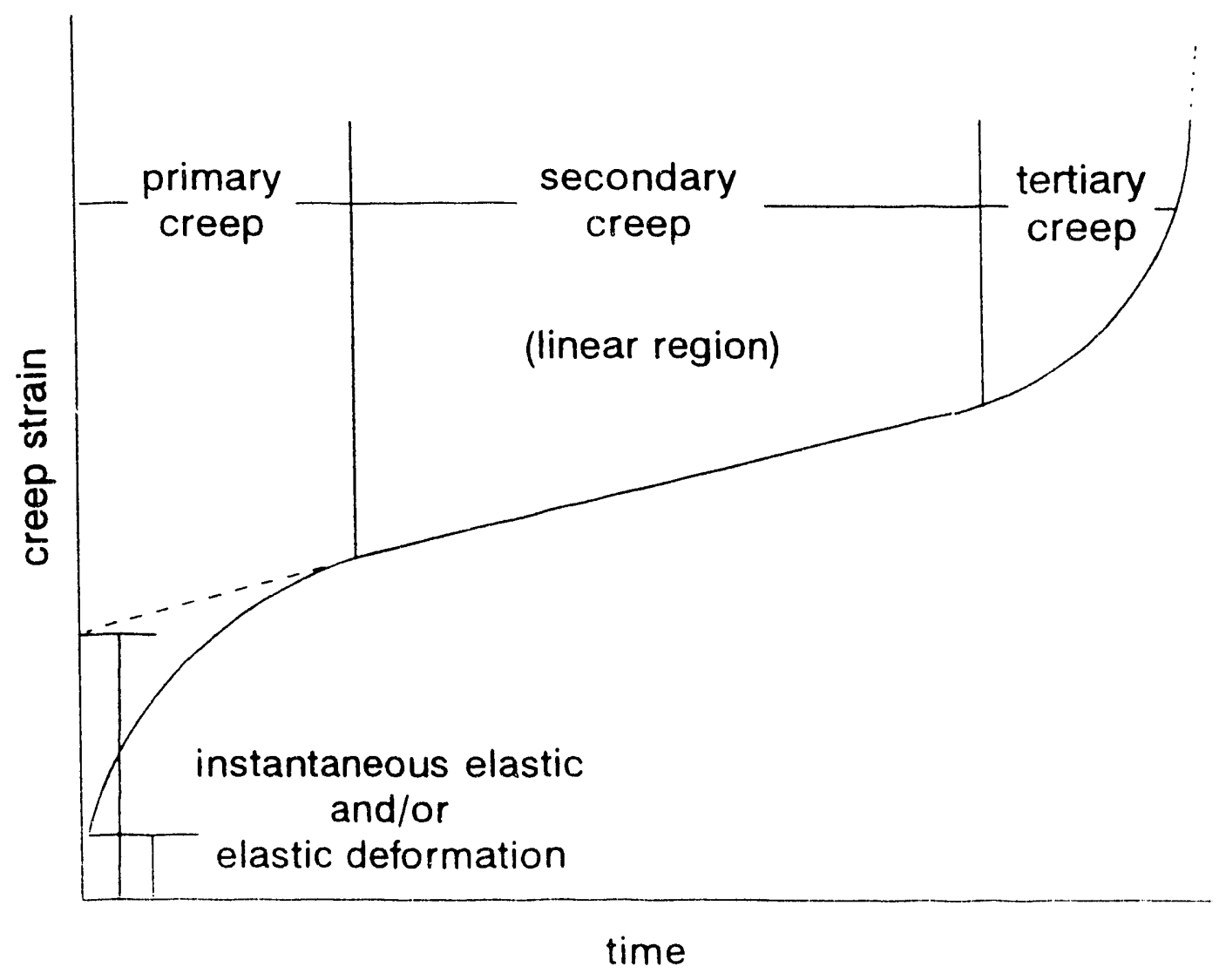

Figure 1. Typical Creep Curve

Appendix $\mathrm{D}$ is devoted to the analysis of the first three sections on the creep curve as described above. The charts in Appendix $\mathrm{D}$ list the creep modulus, $\left(\mathrm{ksi}, \mathrm{Kg} / \mathrm{M}^{2}\right)$, at five 
different times in hours $(10,50,100200$ and 300$)$ along with a remarks column. The remarks column describes the fourth section of the curve where the actual failure occurs.

Creep measurements are generally a long term experimental process that can take months or years of examination. During this time period a much larger dimensional change takes place and all three phases of the creep curve can be properly defined. We are currently trying to identify a creep value and the environmental affects of synthetic lubricant and differing refrigerants on plastic parts under stress, within a 14 day time frame. The sensitivity of the measurement, the smallest amount of movement measurable, becomes paramount as it is related to long term environmental chemical exposure. It is not entirely unlikely that what is currently being identified as the second and third regions on the creep curve may be primary, and not long term creep.

Most manufacturers publish plastic creep values as several different temperatures and loads. In this study, we initially considered creep testing at $60^{\circ} \mathrm{C}\left(140^{\circ} \mathrm{F}\right)$ with refrigerant at a specific pressure, thus allowing the refrigerant concentration to be whatever it is at a specified pressure. However in order to have the plastic exposed to a greater amount of refrigerant a temperature reduction was necessary. Due to equilibrium gas solubility limitations of some of the HFC's it was decided to limit the concentration to $40 \%$ by weight since this was achievable with the $32 \mathrm{cSt}$ branched acid, polyolester at $20^{\circ} \mathrm{C}\left(68^{\circ} \mathrm{F}\right)$ and not at $60^{\circ} \mathrm{C}\left(140^{\circ} \mathrm{F}\right)$.

Using a temperature of $60^{\circ} \mathrm{C}\left(140^{\circ} \mathrm{F}\right)$ with the $32 \mathrm{cSt}$ branched acid polyolester, would require the pressure of the creep rigs to be limited to 300 psia for safety reasons similar to the thermal aging portion of this study. Vapor equilibrium concentration determinati' ns are needed to determine the exact concentration of refrigerant in lubricant at this elevated temperature.

\section{THERMAL AGING OF PLASTICS WITH REFRIGERANT AND LUBRICANT}

The thermal aging of plastic test bars at $150^{\circ} \mathrm{C}\left(300^{\circ} \mathrm{F}\right)$ for 14 days with selected refrigerants and lubricant combinations, was conducted in stainless steel pressure tubes (as described previously) with refrigerant pressure not to exceed 275-300 psia. Following 14 days of thermal and pressure aging, the plastic test bars were pulled for tensile strength retention. The seventeen combinations required are now complete. Detailed results of each refrigerant and lubricant combination are included in the tables of physical change data appearing in Appendix's $\mathrm{E}$ and $\mathrm{F}$.

At the onset of the thermal aging experiment, it was decided to eliminate ABS, Polycarbonate and modified Polyphenyleneoxide since very poor results in the refrigerant exposure examinations were observed. These plastics are, however, still being used in the creep-rupture experimentation.

It was decided to age plastic test bars in HCFC-123 (R-123) at $125^{\circ} \mathrm{C}\left(257^{\circ} \mathrm{F}\right)$ instead of the specticis $150^{\circ} \mathrm{C}\left(300^{\circ} \mathrm{F}\right)$ since there is a known degree of reactivity or instability of this refrigeran: and lubricant combination at the higher temperature. Unfortunately this temperature may still have been to high since most of the plastics specimens failed. After some discussion with the MCLR advisory committee it was decided to rerun the experiments with aging temperatures of $105^{\circ} \mathrm{C}\left(221^{\circ} \mathrm{F}\right)$. This data, along with the higher temperature, is included in appendix $\mathrm{E}$ and $\mathrm{F}$.

\section{Discussion of Results}

The second portion of this study entails evaluating the end result of property changes in plastics at elevated pressure and temperature conditions. Using a test temperature of $150^{\circ} \mathrm{C}$ 
$\left(300^{\circ} \mathrm{F}\right)$ for all plastics except the polypropylene homopolymer [exposed at $100^{\circ} \mathrm{C}\left(212^{\circ} \mathrm{F}\right)$ ] precludes the assumption that all plastics are stable at these temperatures. Two lower temperatures of $105^{\circ} \mathrm{C}\left(221^{\circ} \mathrm{F}\right)$ and $125^{\circ} \mathrm{C}\left(257^{\circ} \mathrm{F}\right)$ were used with $\mathrm{HCFC}-123(\mathrm{R}-123)$ due to the refrigerant being more reactive than the other HFC and HCFC's.

Plastic test bars are tested at conditions similar to production situations. Simılating production conditions, plastics were allowed to equilibrate at ambient moisture levei conditions. Generally, plastics pick up moisture of hydration or adsorption. The moisture level can vary dramatically. Lubricants used in this study were dried to less than $50 \mathrm{ppm}$ water. The ratio of plastic to lubricant weight was approximately 50:50 in all of the cases, which is not typical in product refrigeration systems. However, the use of larger quantities of lubricant would require larger quantities of limited refrigerants. Polyolesters can be hydrolyized by water. The rate of hydrolysis is dependant on water concentration, time and temperature as well as the types of catalysis present. Therefore, we must remain cautious when interrupting elevated temperature immersion data with potentially "wet" plastics.

With the exception of the hydrocarbon lubricants of mineral oil and alkylbenzene, the polyalkylene glycols (PAG) and polyolesters are less stable and can be reactive to released water from the plastic. During the 14 day test, some polyols seem to have produced carboxylic acids and an assortment of other compounds; some more aggressive than the lubricant.

The current study involved plastics in the presence of refrigerants and lubricants at elevated temperatures and pressures. However, some mechanism of identifying the affects contributed by the refrigerant alone would be beneficial.

The Acetal (3), Polybutylene terephthalate [PBT] (18) and Polyethylene terephthalate [PET] (10) left a floculant precipitate when the oil was at room temperature for several days. This material is an extractable component, possibly an oligemer of some kind, that can be a circulating contaminant. In small hermetic appliance systems a PBT and PET extractable is not removed from the lubricant by descant beads or the more polar aluminas due to its size. Instead, the materials can separate from the oil in a cool place like in a bullet drier exit port and provide a means for plugging capillary tubes. In larger quantities of lubricant, the extractable amount probably will remain in solution but separable when high amounts of HFC's are present. The PET plastic and extractable are dependent on manufacture and the retrograding process that occurs with temperature. The extractable of PET's are increased with time and temperature. Depending on the polyolester lubricant used this process may be accelerated.

The acetal (3) plastic evaluated in this study belongs to a family of materials that have acquired food-grade use status. The samples of lubricant used for the acetal (3) exposure were reexamined because of the drastic loss in tensile retention of the plastic part. The retained lubricant sample had a very strong odor of formaldehyde. The acetal (3) product literature indicated that when acetal (3) is heated to $120^{\circ} \mathrm{C}$ for any length of time, formaldehyde is released. The presence of formaldehyde was confirmed by trapping formaldehyde with benzyl ethanol amine and detecting its presence as the 3-benzyl oxazolidine derivative by gas chromatography. The fromaldehyde was removed from the lubricant by purging a portion of the lubricant sample with nitrogen and trapping the effluent gas on chromasorb coated with benzyl ethanol amine, followed by extraction with methylene chloride and confirmed by gas chromatography.

Appendix E, which details physical dimensional changes, indicate that most plastics show only minimal changes in size. However in Appendix F, which details the tensile properties of the test plastics, it is clear that all of the plastics are affected to some degree. The exact reason for tensile retention loss in test plastics after thermal aging, without knowing the individual affects caused by temperature, lubricant and refrigerant, is not known. 


\section{COMPLIANCE WITH AGREEMENT}

Imagination Resources has complied with all requirements of the agreement.

\section{PRINCIPAL INVESTIGATOR EFFORT}

Richard Cavestri (Principle Investigator) has devoted 1240 hours on this program. Technicians and other investigators have worked approximately 2340 hours on this project since the beginning of the research project. 
APPENDIX A CONTENTS

\section{APPENDIX}

Registered and Registered Trade Marks of Suppliers

PAGE

Engineering Plastics Molding Specifications and Molding Conditions

\section{APPENDIX B CONTENTS}

\section{LUBRICANTS}

Table, Plastic Immersion in 32 ISO VG Mineral Oil

B-1

Table, Plastic Immersion in 32 ISO VG Modified Polyglycol

B-2

Table, Plastic Immersion in 32 ISO VG Polypropylene Glycol Diol

B-3

Table, Plastic Immersion in 32 ISO VG Branched Acid Polyolester

B-4

Table, Plastic Immersion in 22 ISO VG Mixed-Acid Polyolester

B-5

Table, Plastic Immersion in 32 ISO VG Polypropylene Glycol Buty! Mono Ether

B-6

Table, Plastic Immersion in 32 ISO VG Alky enzene

B-7

\section{APPENDIY C CONTENTS}

\section{REFRIGERANTS}

Table, Plastic Immersion in HCFC-22 (R-22)

C-1

Table, Plastic Immersion in HFC-32 (R-32)

C-2

Table, Plastic Immersion in HCFC-123 (R-123)

C-3

Table, Plastic Immersion in HCFC-124 (R-124)

C-4

Table, Plastic Immersion in HFC-125 (R-125)

C-5

Table, Plastic Immersion in HFC-134 (R-134)

C-6

Table, Plastic Immersion in HFC-134a (R-134a)

C-7

Table, Plastic Immersion in HCFC-142b (R-142b)

C-8

Table, Plastic Immersion in HFC-143a (R-143a)

C-9

Table, Plastic Immersion in HFC-152a (R-152a)

\section{APPENDIX D CONTENTS}

\section{STRESS CRACK - CREEP RUPTURE OF PLASTICS IN}

32 ISO VG BRANCHED ACID POLYOLESTER WITH REFRIGERANT.

Table, Creep modulus of plastics with HCFC-22 (R-22)

D-1

Table, Creep modulus of plastics with HFC-152a (R-152a)

D-2

Table, Creep modulus of plastics with HFC-134a (R-134a)

D-3 
THERMAL AGING, PHYSICAL CHANGES

Table, 32 ISO VG Mineral Oil and HCFC-22 (R-22) E-1

Table, 32 ISO VG Branched Acid Polyolester and HFC-32 (R-32) E-2

Table, 32 ISO VG Polypropylene Glycol Butyl Mono Ether and HFC-32 (R-32) E-3

Table, 32 ISO VG Mineral Oil and HCFC-123 (R-123) at $105^{\circ} \mathrm{C} \quad \mathrm{E}-4 \mathrm{a}$

Table, 32 ISO VG Mineral Oil and HCFC-123 (R-123) at $125^{\circ} \mathrm{C} \quad$ E-4b

Table, 32 ISO VG Alkylbenzene and HCFC-124 (R-124) E-5

Table, 32 ISO VG Modified Polyglycol and HFC-125 (R-125) E-6

Table, 32 ISO VG Branched Acid Polyolester and HFC-125 (R-125) E-7

Table, 32 ISO VG Polypropylene Glycol Butyl Mono Ether and HFC-125 (R-125) E-8

Table, 32 ISO VG Rranched Acid Polyolester and HFC-134 (R-134) E-9

Table, 32 IS $)$ VG Modified Polyglycol and HFC-134a (R-134a) E-10

Table, 22 ISO VG Polypropylene Glycol Diol and HFC.134a (R-134a) E-11

Table, 32 ISO VG Branched Acid Polyglycol and HFC-134a (R-134a) E-12

Table, 22 ISO VG Mixed-Acid Polyolester and HFC-134a (R-134a) E-13

Table, 32 ISO VG Polypropylene Glycol Butyl Mono Ether and HFC-134a (R-134a) E-14

Table, 32 ISO VG Alkylbenzene and HCFC-142b (R-142b) E-15

Table, 32 ISO VG Branched Acid Polyolester and HFC-143a (R-1:3a) E-16

Table, 32 ISO VG Alkylbenzene and HFC-152a (R-152a) E-17

\section{APPENDDX F CONTENTS}

\section{PHASE II THERMAL AGING, TENSILE CHANGES}

Table, 32 ISO VG Mineral Oil and HCFC-22 (R-22)

Table, 32 ISO VG Branched Acid Polyolester and HFC-32 (R-32) F-2

Table, 32 ISO VG Polypropylene Glycol Butyl Mono Ether and HFC-32 (R-32) F-3

Table, 32 ISO VG Mineral Oil and HCFC-123 (R-123) at $105^{\circ} \mathrm{C} \quad \mathrm{F}-4 \mathrm{a}$

Table, 32 ISO VG Mineral Oil and HCFC-123 (R-123) at $125^{\circ} \mathrm{C} \quad \mathrm{F}-4 \mathrm{~b}$

Table, 32 ISO VG Alkylbenzene and HC,FC-124 (R-124) F-5

Table, 32 ISO VG Branched Acid Polyoiester and HFC-125 (R-125) F-6

Table, 32 ISO VG Polypropylene Glycol Butyl Mono Ether and HFC-125 (R-125) F-7

Table, 32 ISO VG Modified Polyglycol and HFC-125 (R-125) F-8

Table, 32 ISO VG Branched Acid Polyolester and HFC-134 (R-134) F-9

Table, 32 ISO VG Branched Acid Polyolester and HFC-134a (R-134a) F-10

Table, 22 ISO VG Mixed-Acid Polyolester and HFC-134a (R-134a) F-11

Table, 32 ISO VG Polypropylene Glycol Butyl Mono Ether and HFC-134a (R-134a) F-12

Table, 32 ISO VG Modified Polyglycol and HFC-134a (R-134a) F-13

Table, 32 ISO VG Polypropylene Glycol Diol and HFC-134a (R-134a) F-14

Table, 32 ISO VG Alkylbenzene and HCFC-142b (R-142b) F-15

Table, 32 ISO VG Branched Acid Polyoleter and HFC-143a (R-143a) F-16

Table, 32 ISO VG Alkylbenzene and HFC-152a (R-152a) F-17 
THE ENGINEERING PLASTICS USED IN THIS TESTING PROGRAM ARE REgISTERED TRADEMARKS, TRADEMARKS, OR ARE NONE OF THE RESPECTIVE MANUFAETUAER

\begin{tabular}{|c|c|c|c|c|}
\hline \multicolumn{4}{|c|}{ ENGINEEING PLASTIC } & \multirow{2}{*}{ 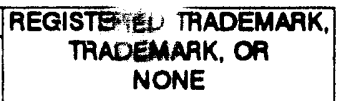 } \\
\hline NO. & TRADENAME & GENEAIC NAME & MANUFACTUAEA & \\
\hline 1 & AMODEL AD-1000 HS & POLYPHTHALAMIDE & AMOCO & REGISTERED TRADEMAAK \\
\hline 2 & CYCOLAC GPM 4700 & ACAYLONITRILE-BUTADIENE-STYRENE TERPOLYMER & G.E. & AEGISTERED TRADEMAAK \\
\hline 3 & DURIN II 11500 & ACETAL & DUPONT & REGISTERED TRADEMAFK \\
\hline 4 & DUAEZ & PHENQUC & HOOKEA & REGISTERED TRADEMAAK \\
\hline 5 & KMNA720 & POLYNNUDENE FLUOAIDE & ATOCHEM & RER 'T, TRED TRADEMAAK \\
\hline 6 & LEXAN 161 & POLYCARBONATE & G.E. & AF SEED TRADEMAAK \\
\hline 7 & NOAY 731 & MODIFIED POLYPHENYENE OXIDE & G.E. & RECU STERED TRADEMARK \\
\hline 8 & PAOFAX 6331 NW & POLYPAOPYLNE & HIMONT & TRADEMARK \\
\hline 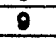 & RADEL $A-200$ & POLYAAYSUUFONE & AMOCO & AEGISTERED TRADEMAGK \\
\hline 10 & ARNITE 530 & POLYETIVENE TEREPHTHALATE & DUPONT & REGISTERED TRADEMARK \\
\hline 11 & SUPEC G401 & POLYPHENMENESULFIDE & G.E. & REGISTEAED TAADEMARK \\
\hline 12 & TEFLON & POLV KAFLUOAOETHVENE & DUPONT & REGISTERED TAADEMARK \\
\hline 13 & TORLON 4ROSL & POLYANIDE-!MIDE & AMOCO & REGISTEAED TRADEMAAK \\
\hline 14 & TOALON 4301 & POLYAMIDE-IMIDE & AMOCO & REGISTERED TRADEMAAK \\
\hline 15 & ULTEM 1000 & POLYETHERIMIDE & G.E. & REGISTERED TRADEMAAK \\
\hline 16 & ULTEM CAS 5001 & MODIFIED POLVTHERIMIDE & G.E. & REGISTERED TRADEMAAK \\
\hline 17 & ULTAAPEK (PAEK) & POLYARYETHEAKETONE & BASF & AEGISTEAED TRADEMARK \\
\hline 18 & VALOX 325 PBT & POLYBUTYLENE TEREPHTHALATE & G.E. & REGISTERED TRADEMARK \\
\hline 10 & VESPEL-DF & POLYIMIDE-DF & DUPONT & REGISTERED TRADEMARK \\
\hline 20 & VESPEL- DF-ISO & POLVMIDE-DF-1SO & DUPONT & REGISTEAED TRADEMARK \\
\hline 21 & VCTREX PEEK 4 SOG & POLY(AีILSTHEAETHEAKETONE) & $\mid \mathrm{CI}$ & TRADEMAAK \\
\hline 22 & XYDAR MG 460 & UQUID CAYSTAL POLMEA & AMOCO & REGISTEAED TRADEMAAK \\
\hline 23 & ZYIEL 101 & CONYLON, POLYAMIDE & DUPONT & IREGISTERED TRADEMARK \\
\hline
\end{tabular}

THE SYNTHETIC LUBRICANTS USED IN THIS TESTING PROGRAM ARE REGISTEAED TRADEMARKS, TRADEMARKS, OR ARE NONE OF THE RESPECTIVE MANUFACTURER

\begin{tabular}{|c|c|c|c|}
\hline NAME & TYPE & NANUFACTURER & $\begin{array}{c}\text { TEGISTERED TRADEMARK, } \\
\text { TRADEMARK, OR } \\
\text { NONE }\end{array}$ \\
\hline AUED SIGNAL, HAD & MODIFIED POLYGLYCOL & AUEED-SIG. & NONE \\
\hline B-VRO-15 & MINERAL OIL & BV ASSOC. & NONE \\
\hline EMET & BAANCHED ACID POLYOLESTEA & HENKEL & AEGISTEAED TRADEMARK \\
\hline EMKARATE RLQASA & MIXED-ACID POLYOLESTEA & $\mathrm{ICl}$ & TRADEMAAK \\
\hline ENKAROX VGS2 & PP GLYCOL BUTM MONO ETHEA & $\mathrm{ICI}$ & REGISTEAED TRADEMARK \\
\hline POLYGLYCOLP -425 & POLYPAOPYLENE GLYCOL DIOL & DOW CHEMICAL & NONE \\
\hline SHRIEVE ZAQ 150 & ALMMBENZSNE & SHAIEVE CHEM. & REGISTEAED TRADEMAAK \\
\hline
\end{tabular}




\begin{tabular}{|c|c|c|c|c|c|c|c|c|c|c|c|c|c|c|c|c|c|c|c|c|c|c|c|}
\hline 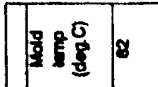 & F & $y$ & $E$ & 8 & : & & 8 & $E$ & $=$ & $\tilde{\underline{\Xi}}$ & & & ע & 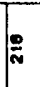 & $\tilde{z}$ & $\approx$ & $\tilde{\Xi}$ & $\underline{E}$ & 8 & & 8 & 8 & $\approx$ \\
\hline 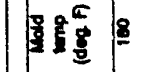 & $\underline{-2}$ & $z$ & 8 & 8 & 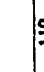 & & $\underline{8}$ & 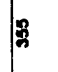 & 8 & 8 & ? & & 8 & 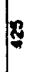 & $\$$ & 8 & $\nexists$ & $\stackrel{\Omega}{n}$ & $\cong$ & & \% & 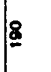 & 8 \\
\hline$\frac{R}{n}$ & 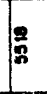 & 8 & R & 8 & 8 & & 8 & $\frac{9}{6}$ & 8 & శ్ & & & $\frac{R}{n}$ & $\underline{R}$ & $\underline{R}$ & 8 & 8 & 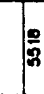 & ह్రి & & 8 & 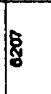 & $\frac{8}{7}$ \\
\hline 8 & 8 & 8 & 号 & 8 & 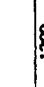 & & 8 & 年 & 8 & 8 & & & 8 & 8 & 8 & 8 & 8 & 8 & 8 & & 8 & 8 & 8 \\
\hline$[1$ & $=$ & $=$ & 8 & $=$ & $:$ & : & $=$ & 8 & 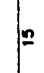 & $\bar{N}$ & & & \& & $\&$ & 8 & $\bar{\kappa}$ & $\bar{n}$ & $=$ & $=$ & & 2 & $=$ & $\approx$ \\
\hline 㩆 & $\tilde{\approx}$ & $\stackrel{\frac{O}{N}}{\pi}$ & $F$ & $\tilde{\tilde{A}}$ & 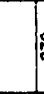 & 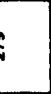 & 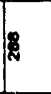 & F & 行 & 8 & & & $\frac{2}{n}$ & I & $\xi$ & $\hat{\xi}$ & $\bar{q}$ & 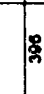 & $\approx$ & & 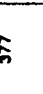 & $\dot{n}$ & $\tilde{\approx}$ \\
\hline 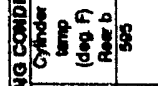 & 8 & $\%$ & 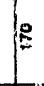 & $\xi$ & 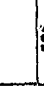 & 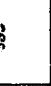 & \% & $E$ & 现 & 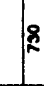 & & & 8 & 8 & 8 & 8 & 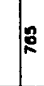 & 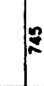 & 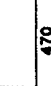 & & $\stackrel{\circ}{\circ}$ & $\S$ & 号 \\
\hline$=$ & 禺 & $\stackrel{\rho}{\%}$ & $E$ & | & 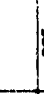 & B & $\bar{\alpha}$ & $F$ & $\bar{\jmath}$ & $\bar{D}$ & & & 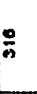 & मे & $\xi$ & 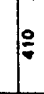 & $\because$ & ₹ & $\approx$ & & 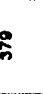 & $\hat{\sigma}$ & 象 \\
\hline 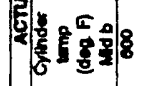 & $p$ & 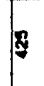 & $\because$ & $\beta$ & : & 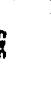 & 8 & $\approx$ & 8 & $g$ & & & 8 & 8 & $\$$ & 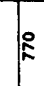 & $F^{2}$ & 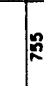 & $\approx$ & & $\frac{2}{2}$ & 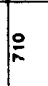 & $\frac{8}{3}$ \\
\hline 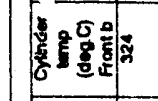 & $\mathbb{Z}$ & $\overline{\tilde{x}}$ & $F$ & శ్ & 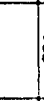 & 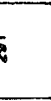 & $\hat{\tilde{z}}$ & $E$ & $\frac{\partial}{\tilde{N}}$ & $\stackrel{8}{\Omega}$ & & & กี & $\hat{n}$ & $\hat{g}$ & $\widehat{\vartheta}$ & 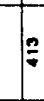 & 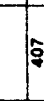 & 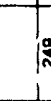 & & 8 & 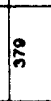 & 8 \\
\hline 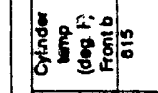 & 8 & 8 & $\approx$ & 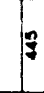 & 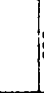 & h. & $\not$ & $\stackrel{?}{2}$ & 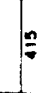 & 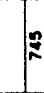 & & & $\stackrel{n}{0}$ & $:$ & s & $E$ & $E^{n}$ & 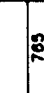 & $\S$ & & $\approx$ & $\frac{n}{n}$ & $h_{n}$ \\
\hline 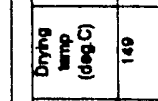 & 8 & 8 & & & & & 8 & 量 & & q & & & $\Phi$ & $E$ & $E$ & 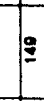 & $\$$ & $\Phi$ & 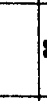 & & 8 & 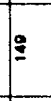 & 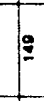 \\
\hline 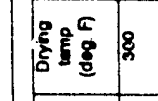 & $\mathbf{8}$ & 8 & 5 & & 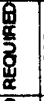 & & $\$$ & 跣 & 5 & 8 & & & $\S$ & 8 & $g$ & $\S$ & 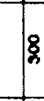 & 2 & $\varepsilon$ & & 8 & 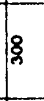 & ళ్ \\
\hline 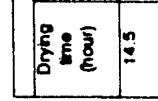 & $=$ & 8 & 12 & 5 & & & $=$ & 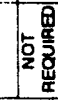 & 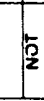 & 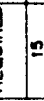 & & & & $=$ & 10 & I & & & & & 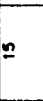 & $\equiv$ & 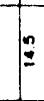 \\
\hline
\end{tabular}

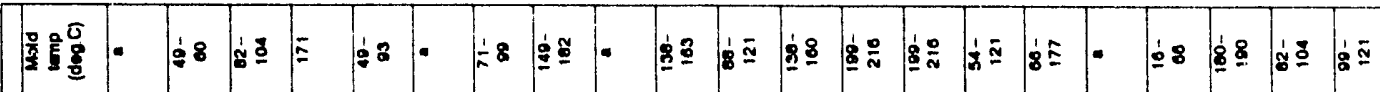

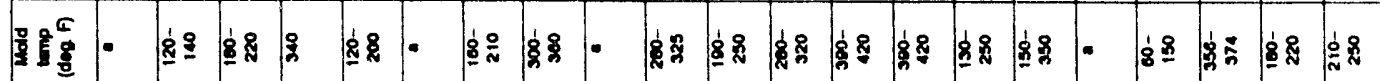

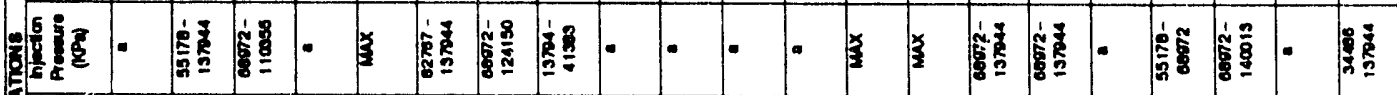

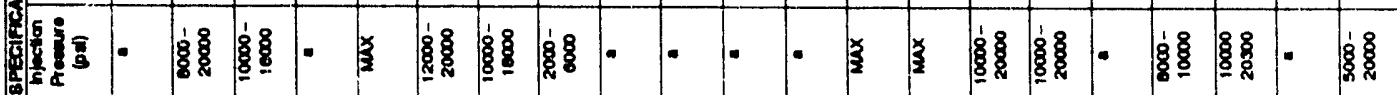

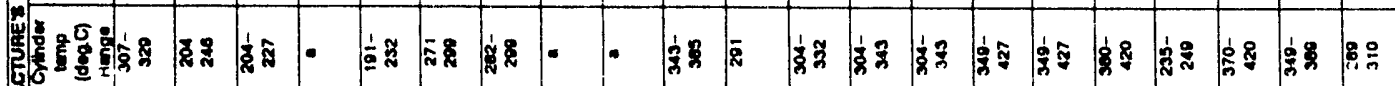

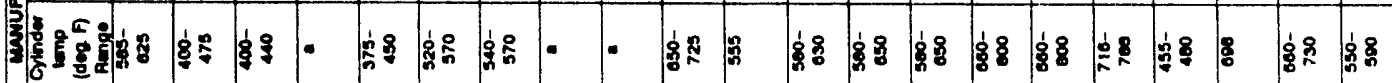

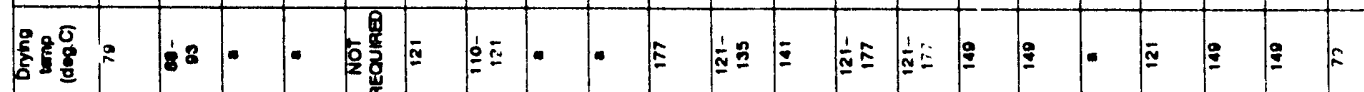

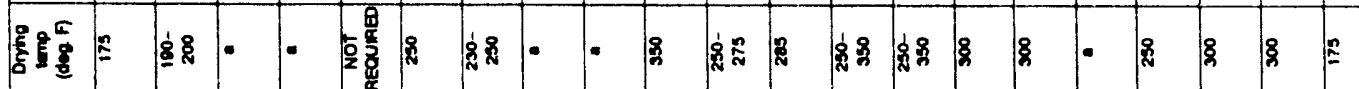

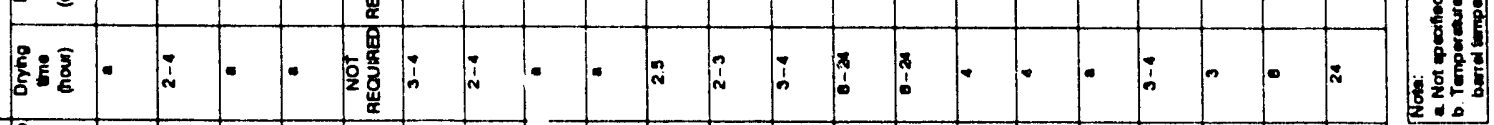

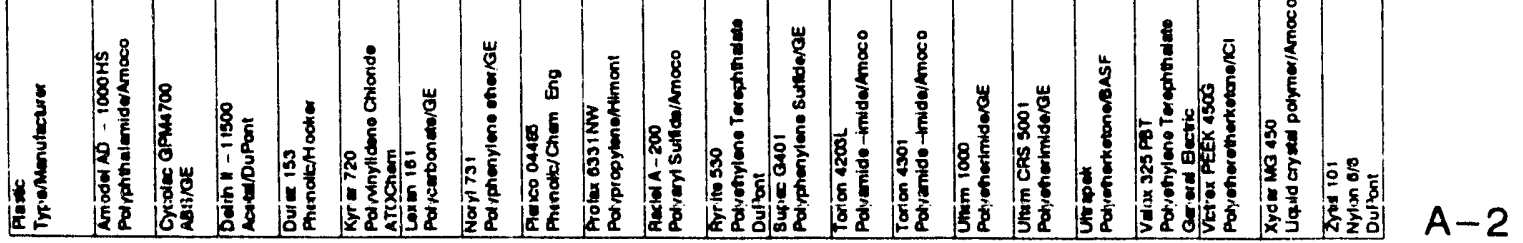




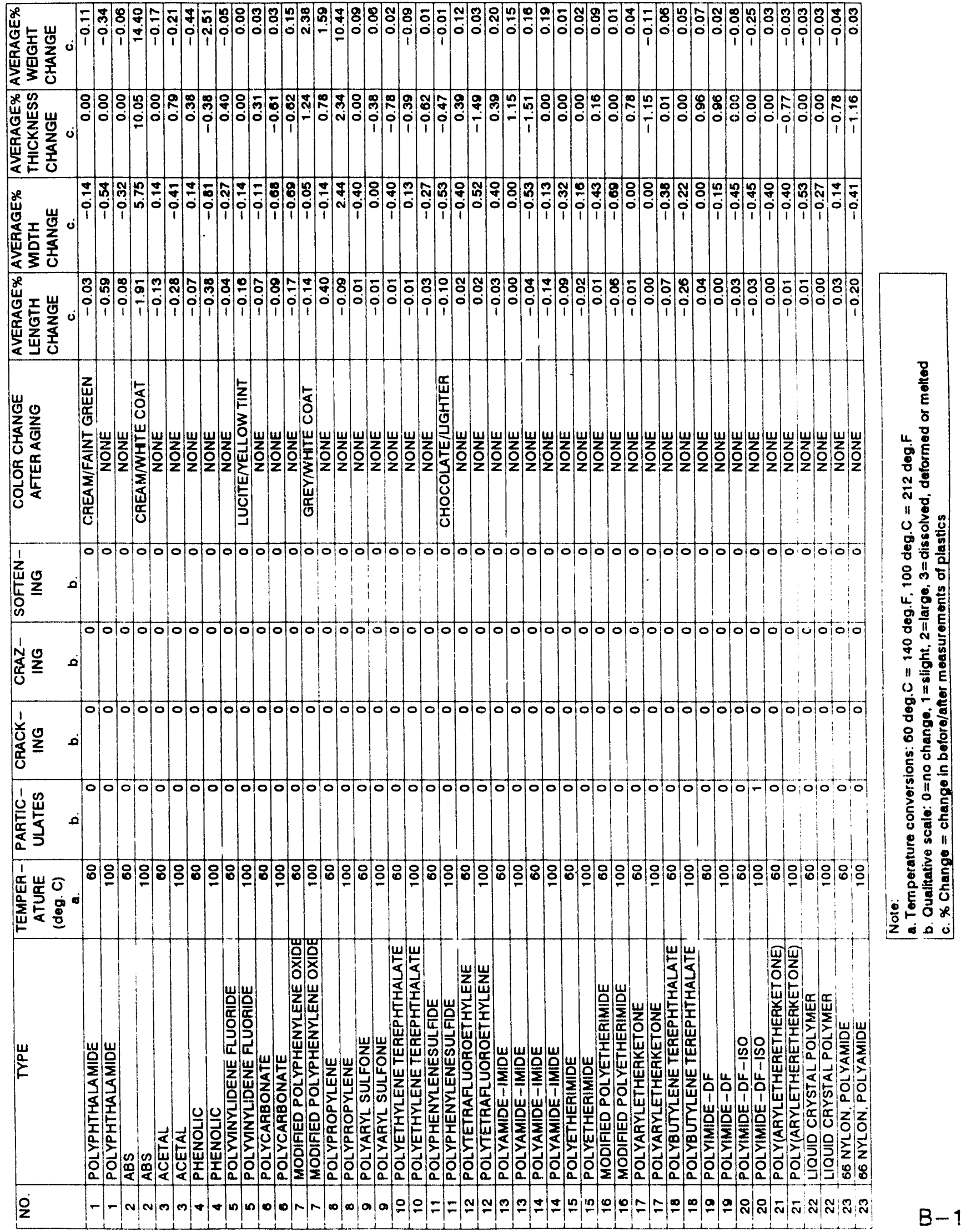




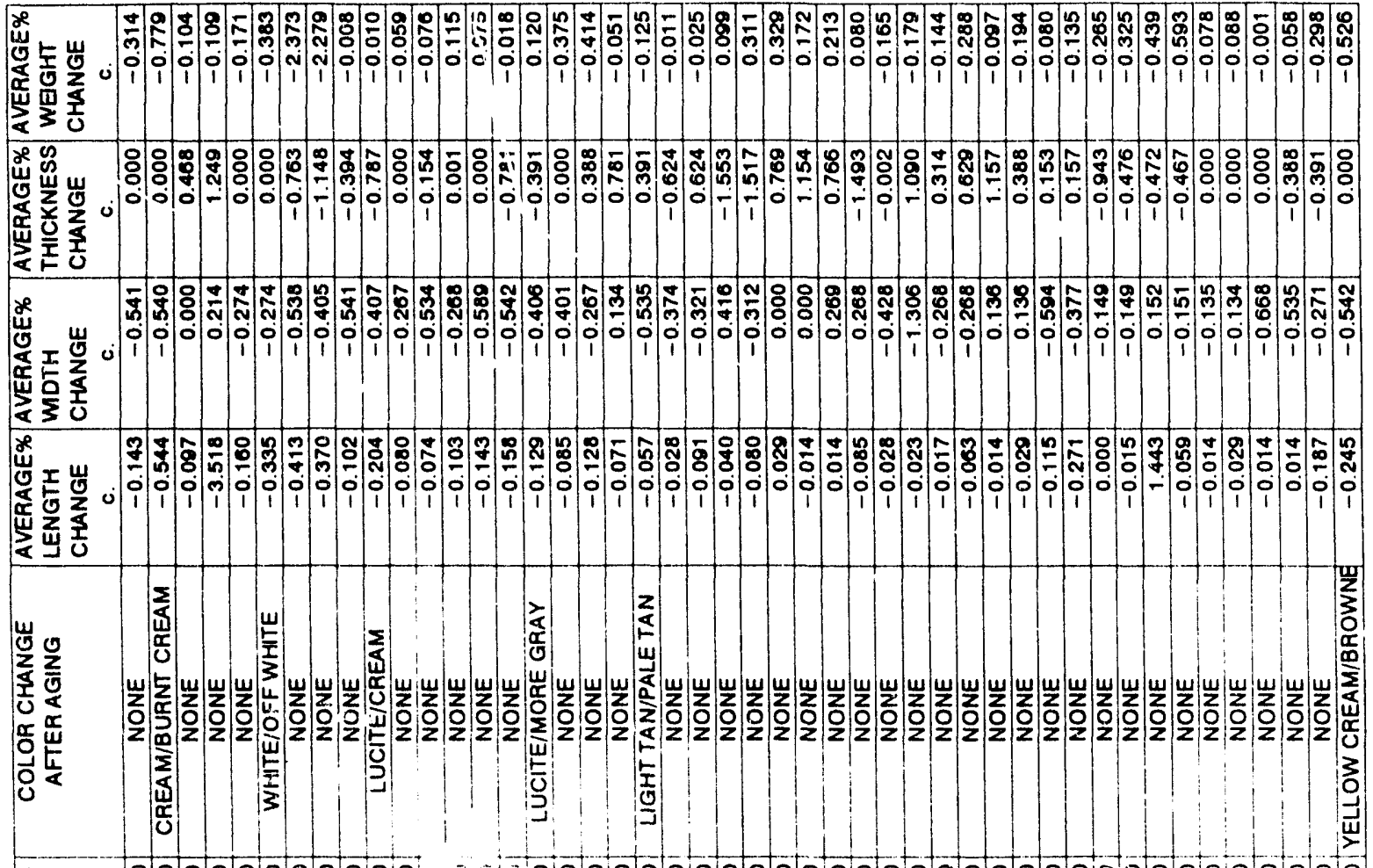

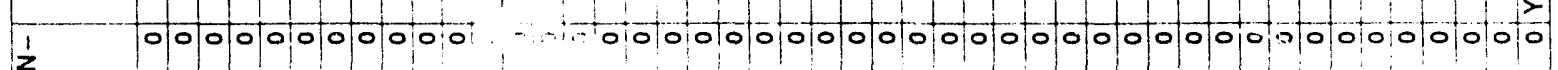
崖导

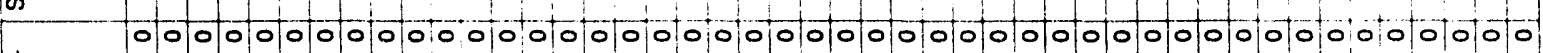

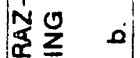

1

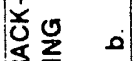

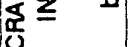

i 00000000000000000000000000000000000000000000000

黛兽 系出

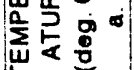

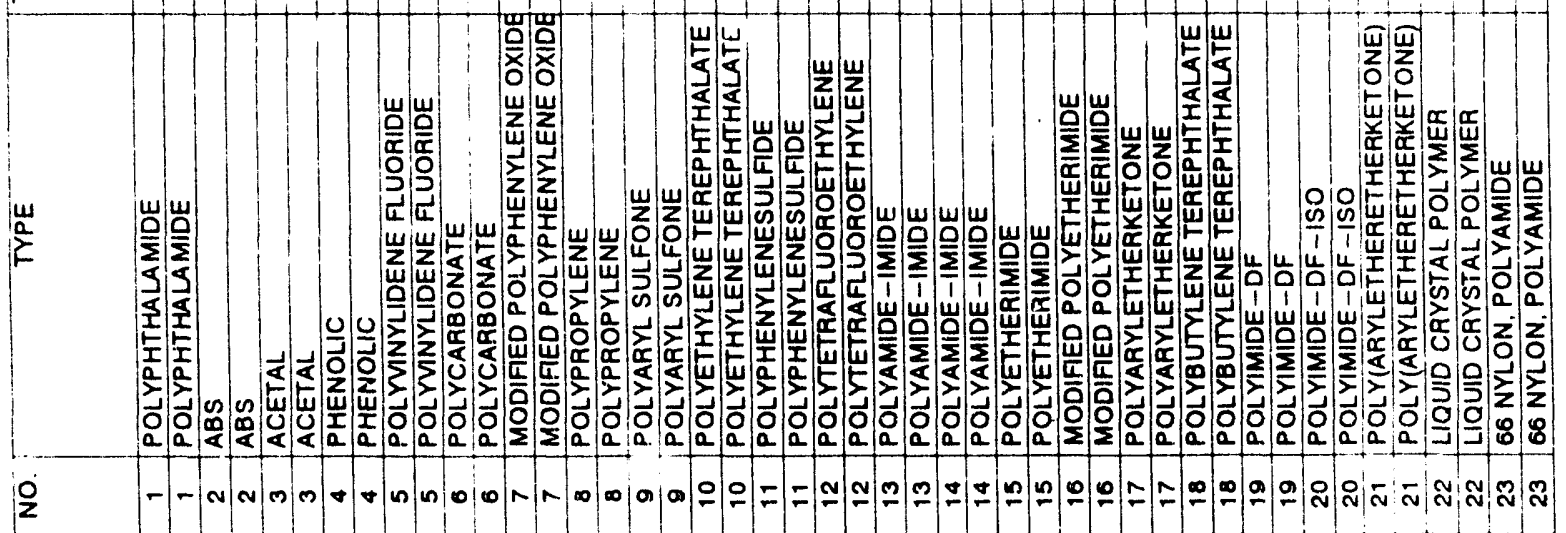




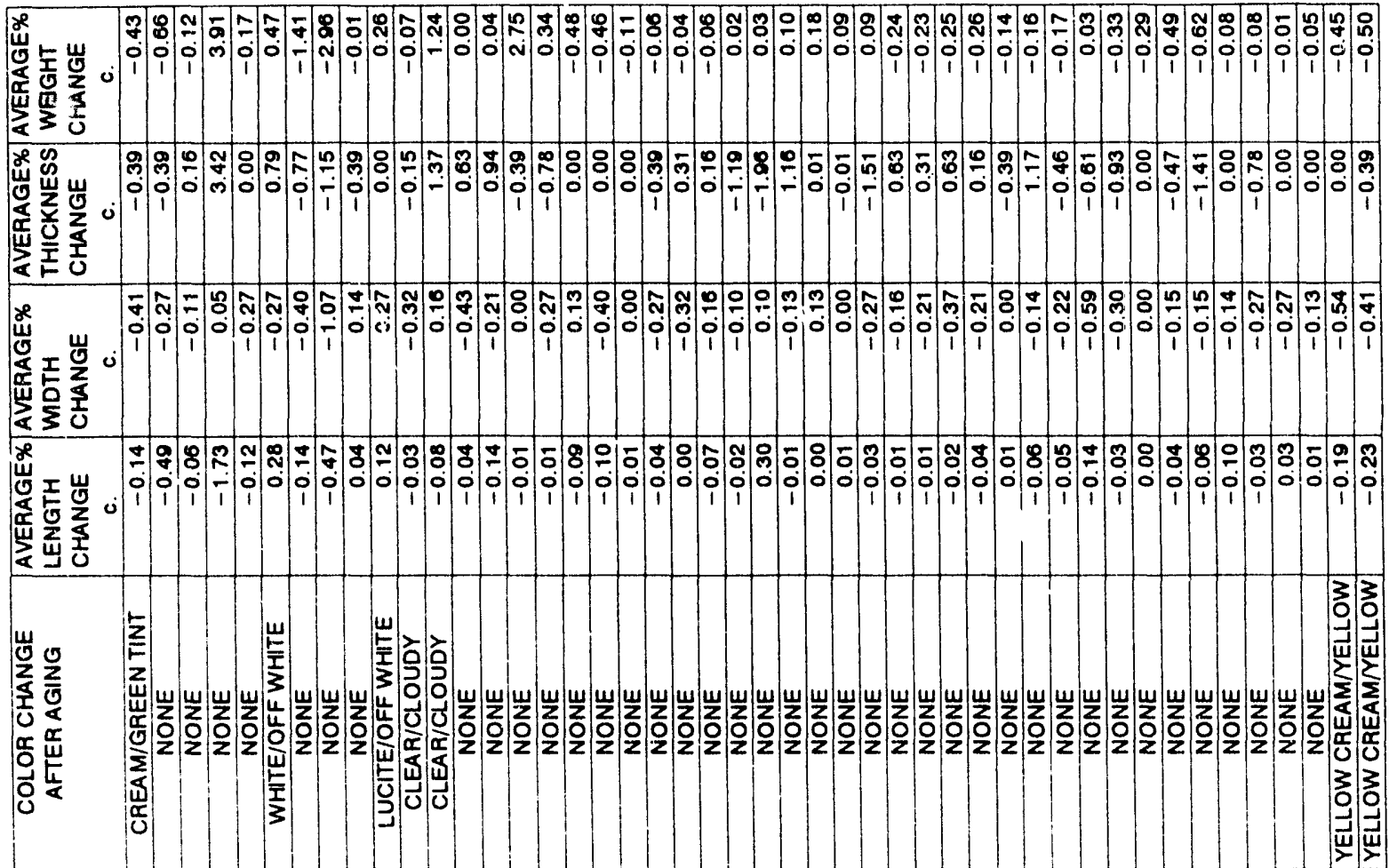

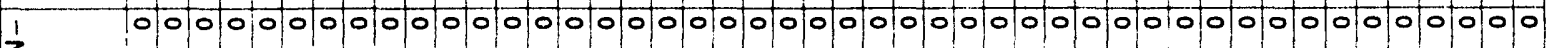
蓆岕

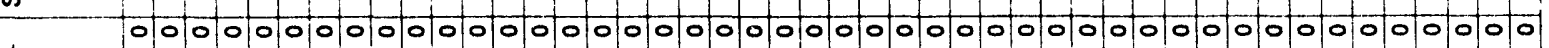
$\stackrel{1}{s}$ 通

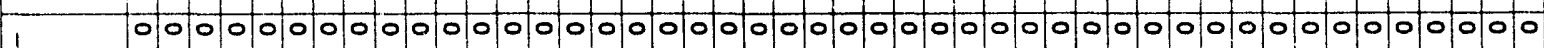
ปั 空

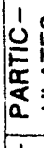
延

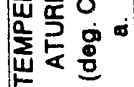

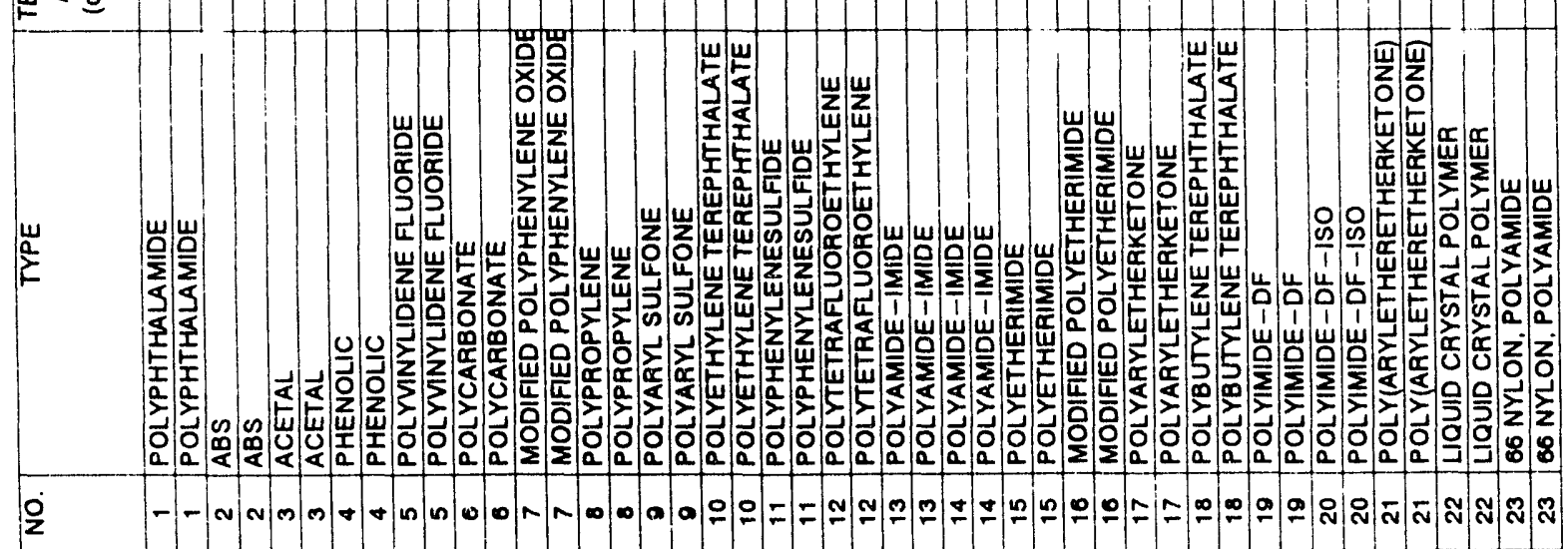




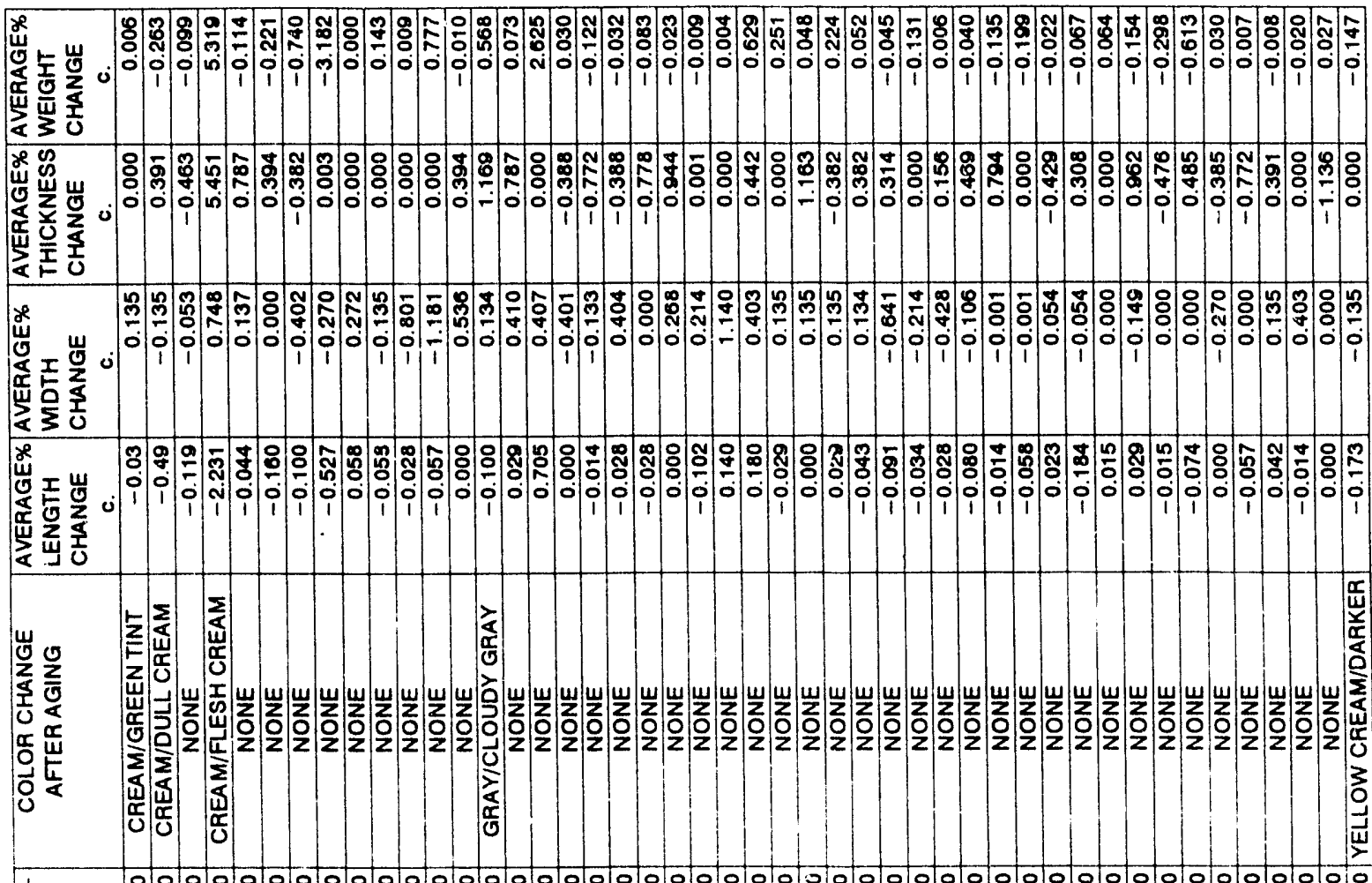

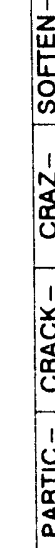

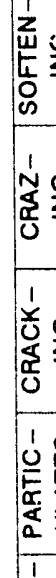

岳岸

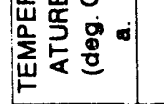

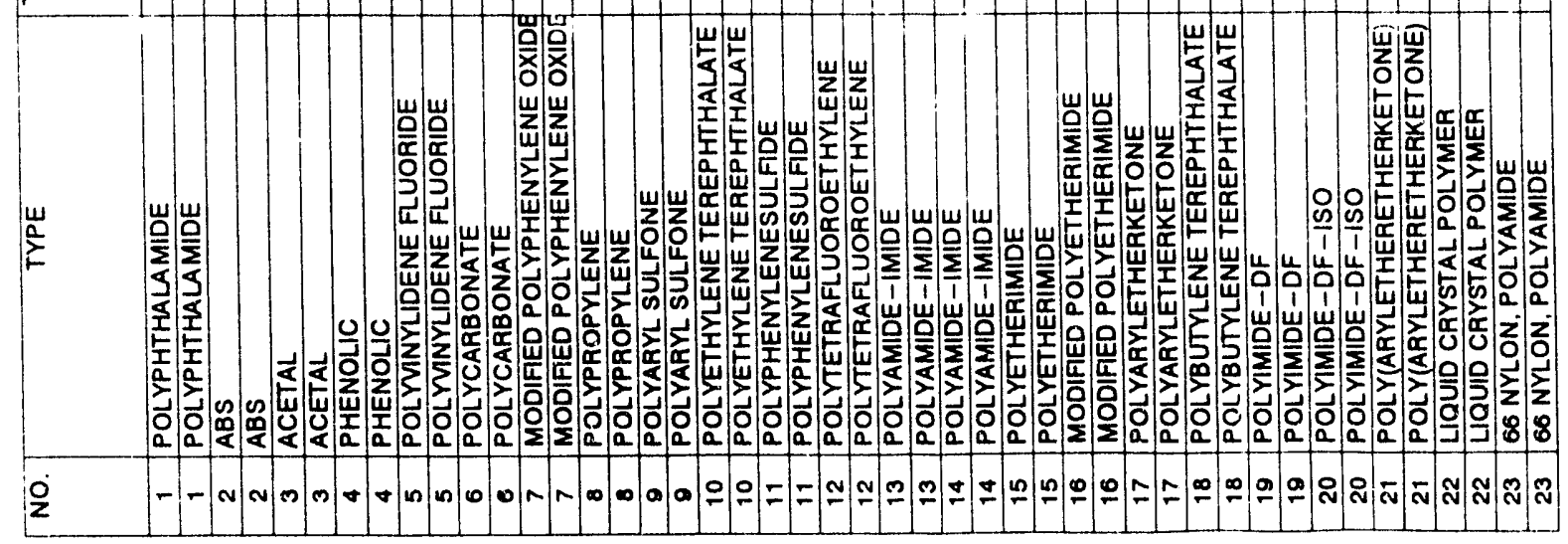




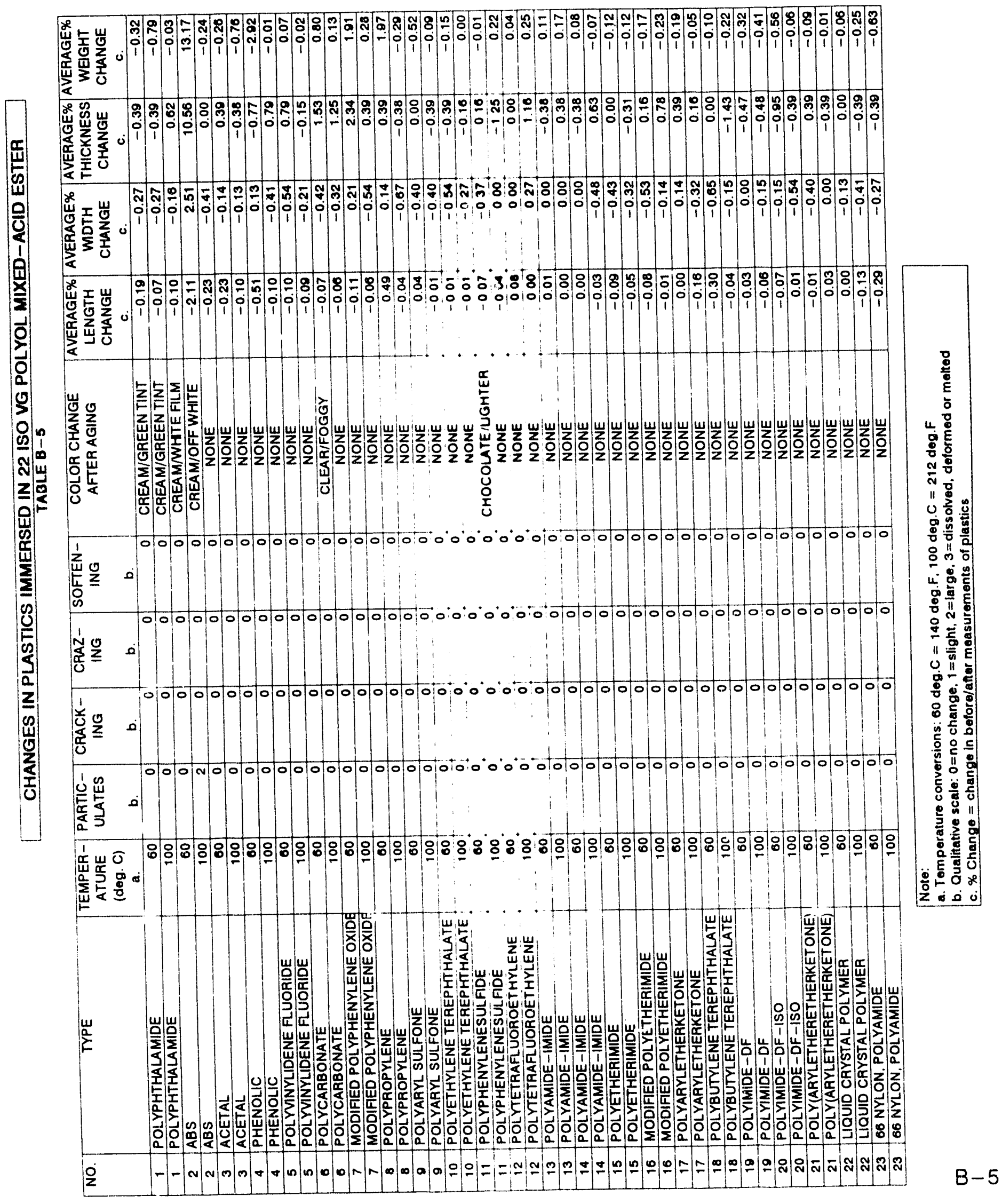




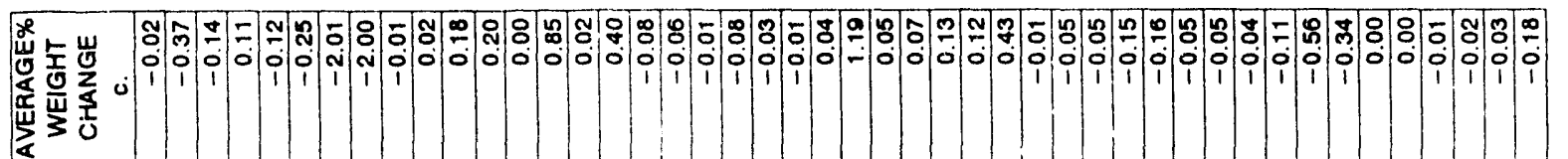

$\alpha$

冓

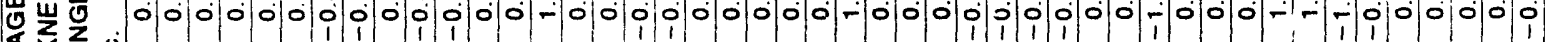

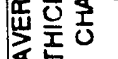

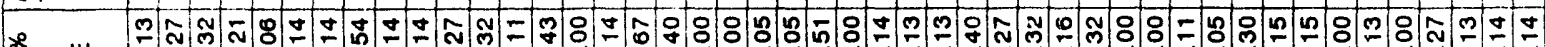

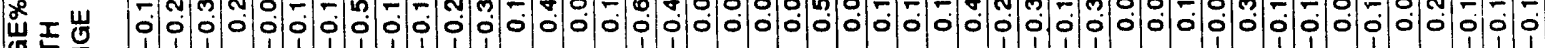

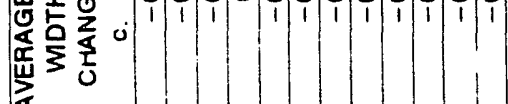

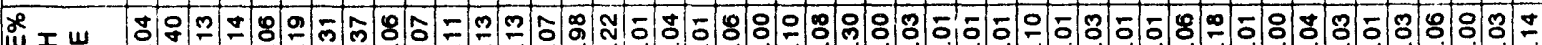

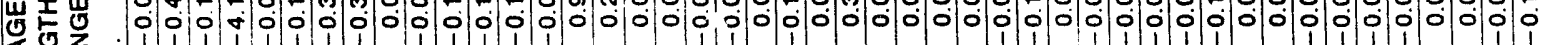

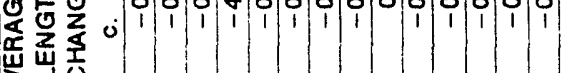

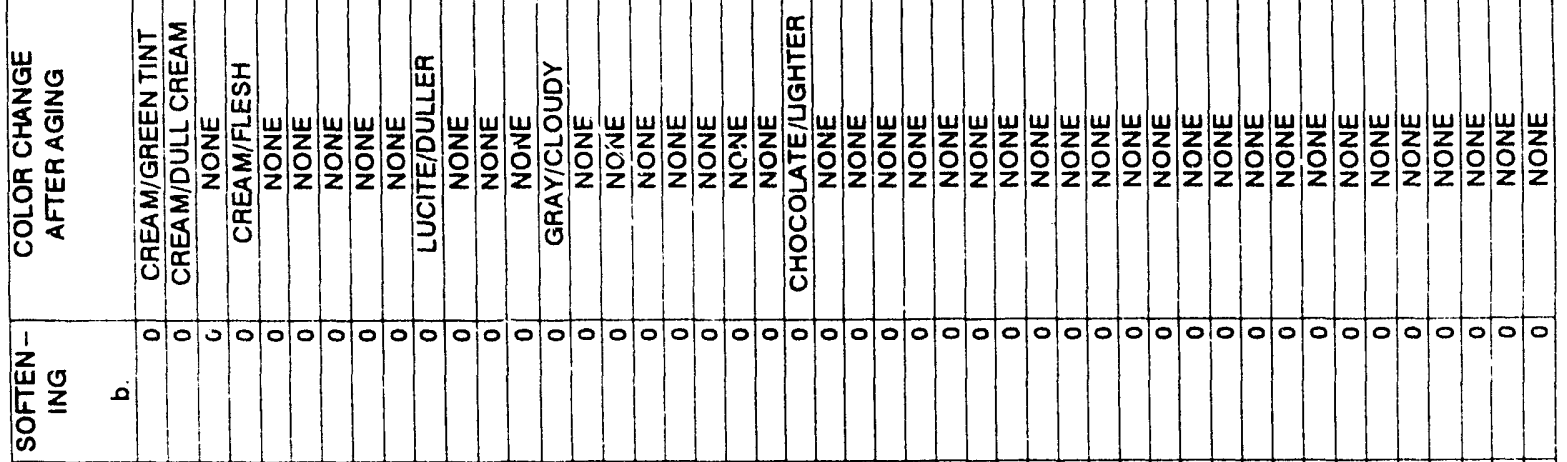

10000000000000000000000000000000000000000000000

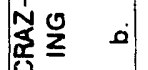

10000000000000000000000000000000000000000000000

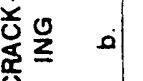

.

in 00000000000000000000000000000000000000000000000

紫写

延

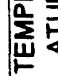

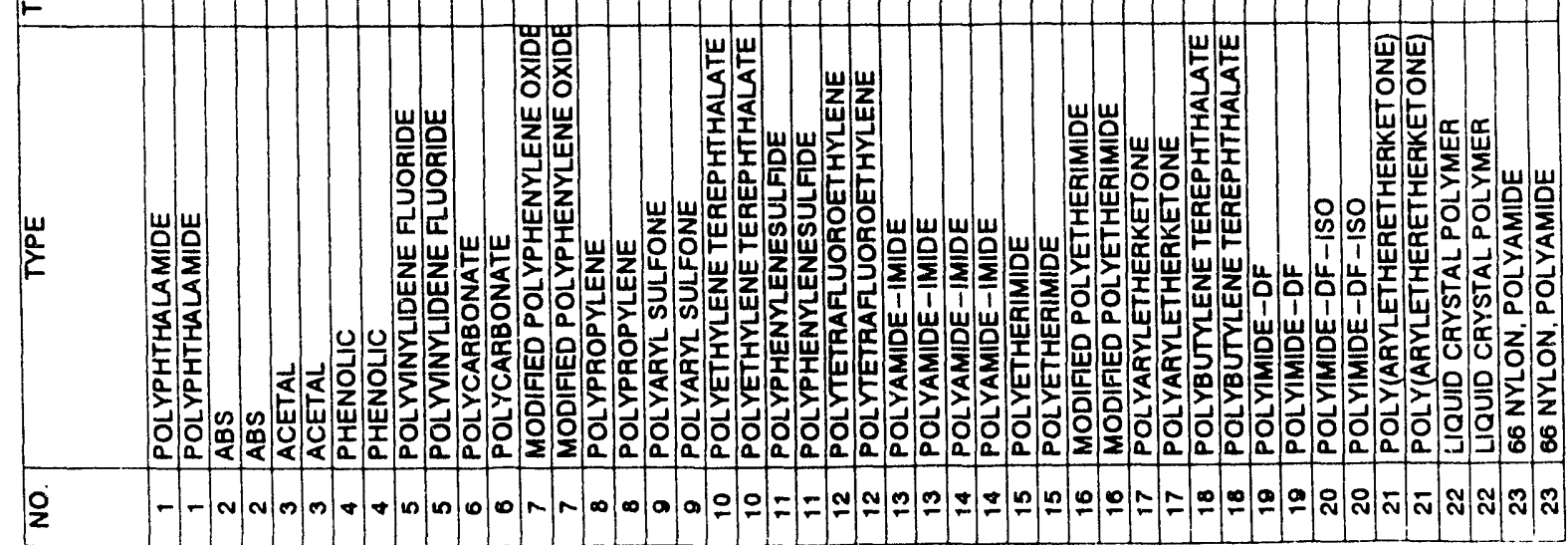




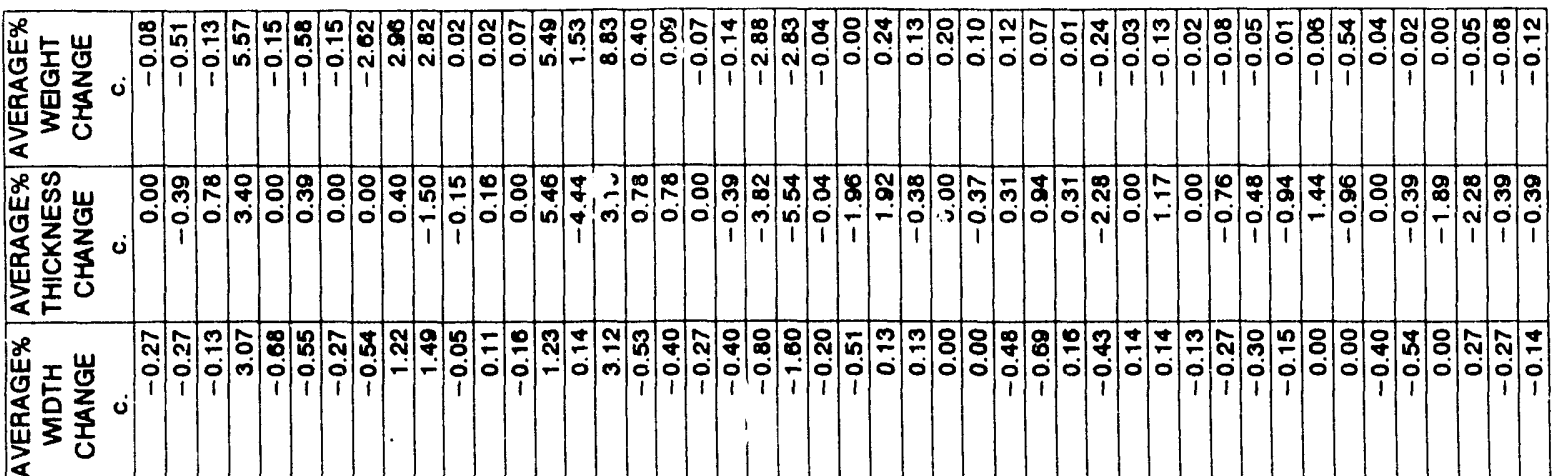

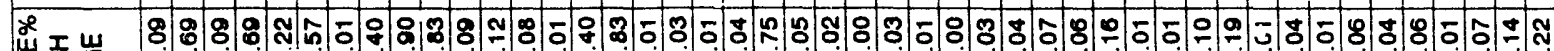

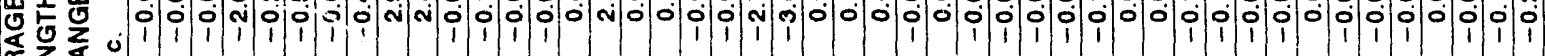
离
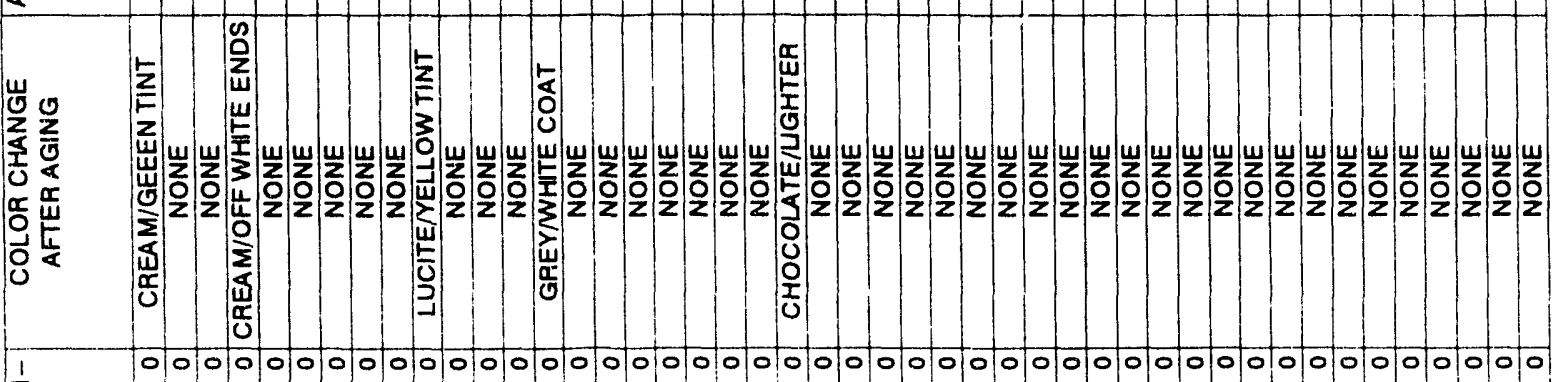

总

倠是:

0

安

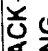

蛋

1 000-00000000000000000000000000000000000000000000

는

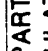

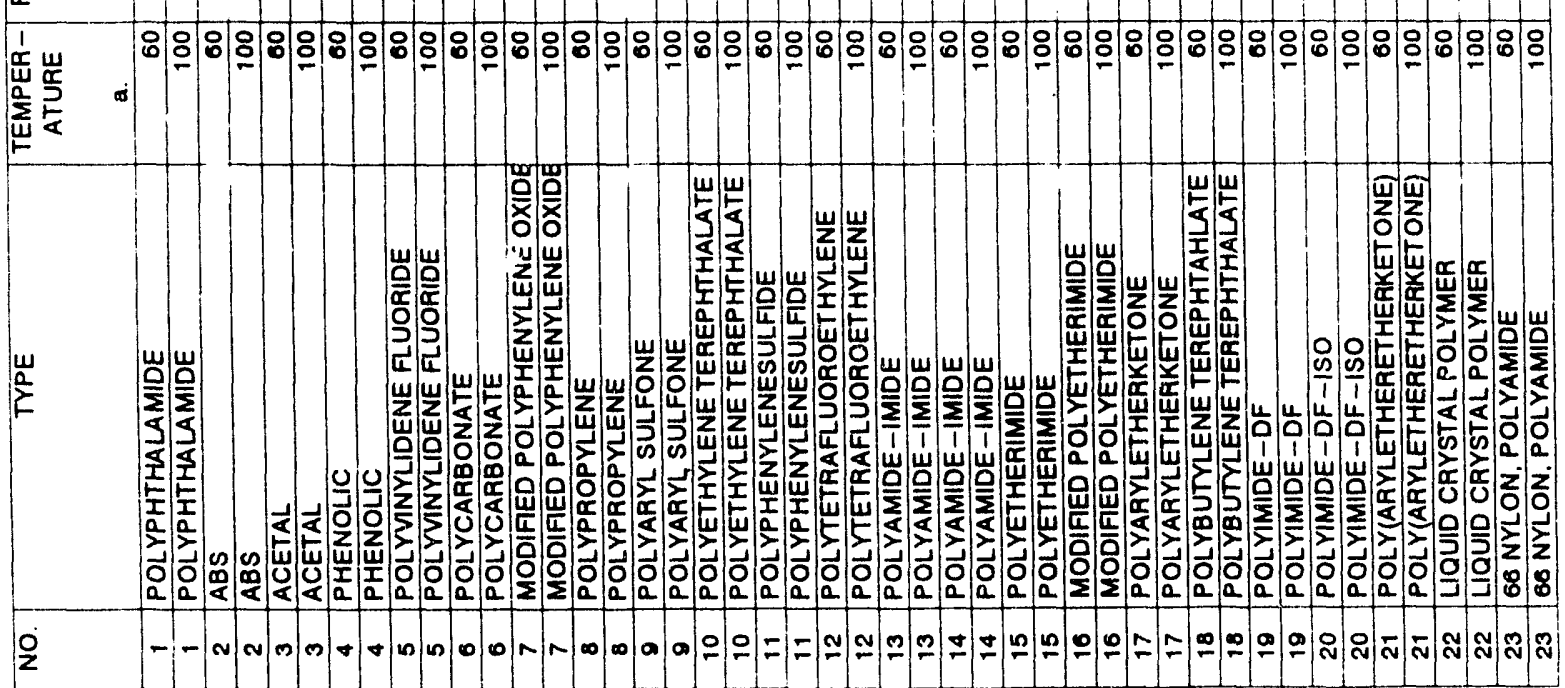



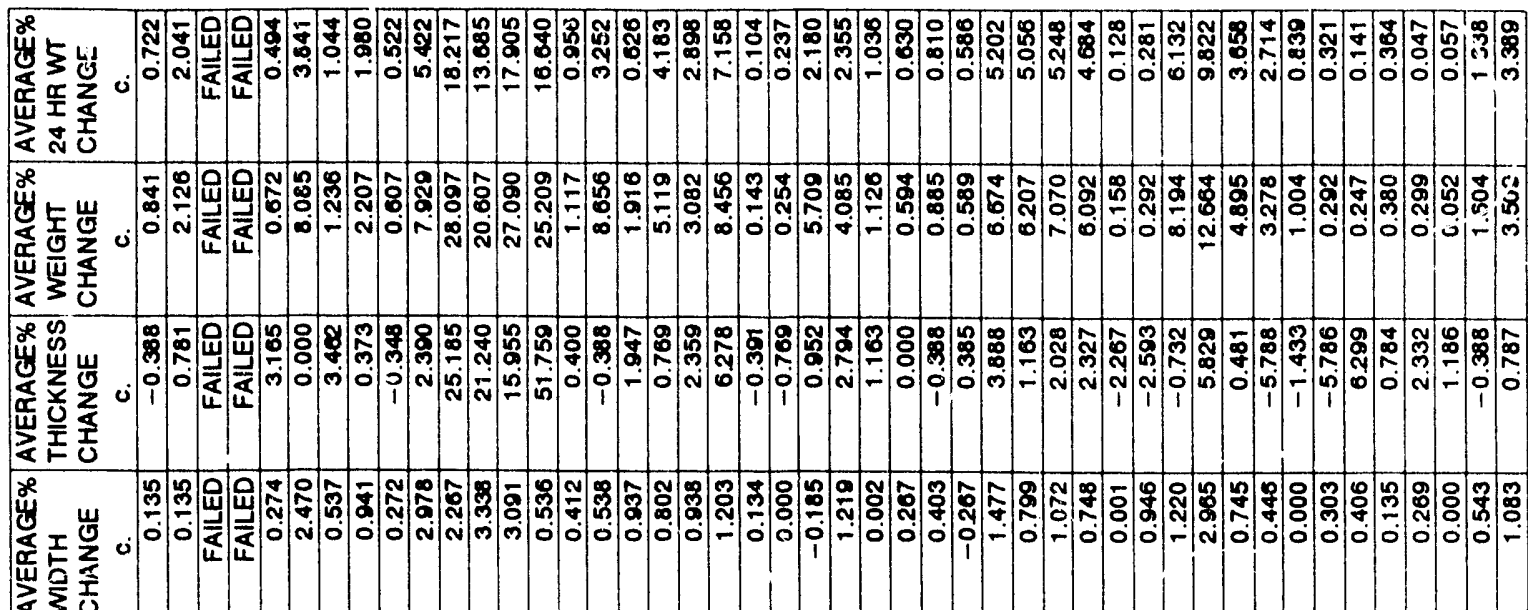

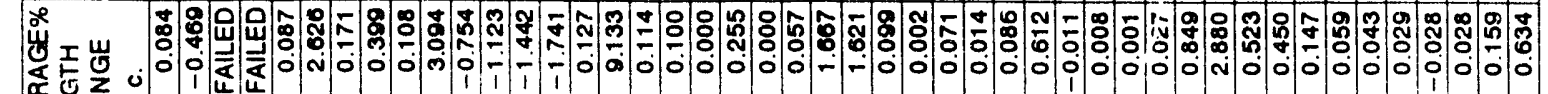

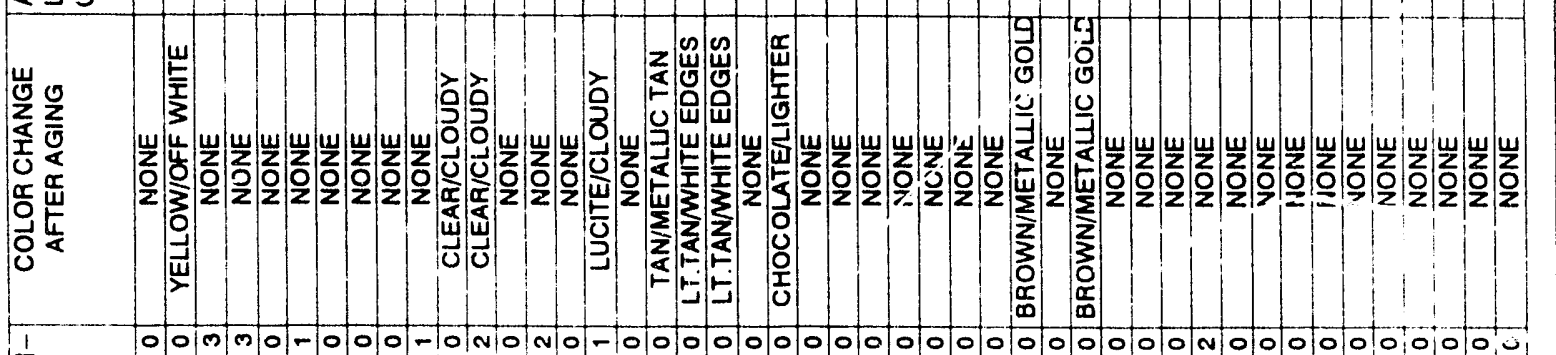

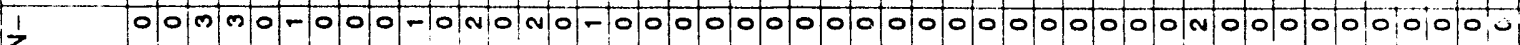
崖枈

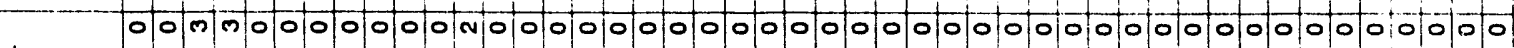

$\sum_{\substack{c \\ 0}}$

遅

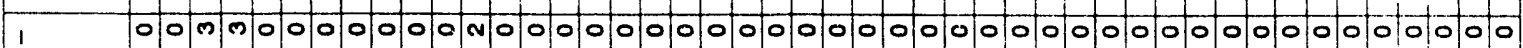

过

离

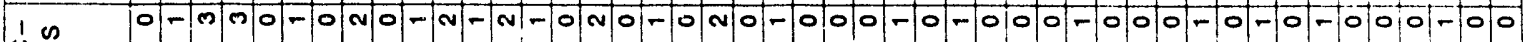

怘

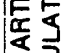

采楸 崖苋

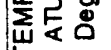

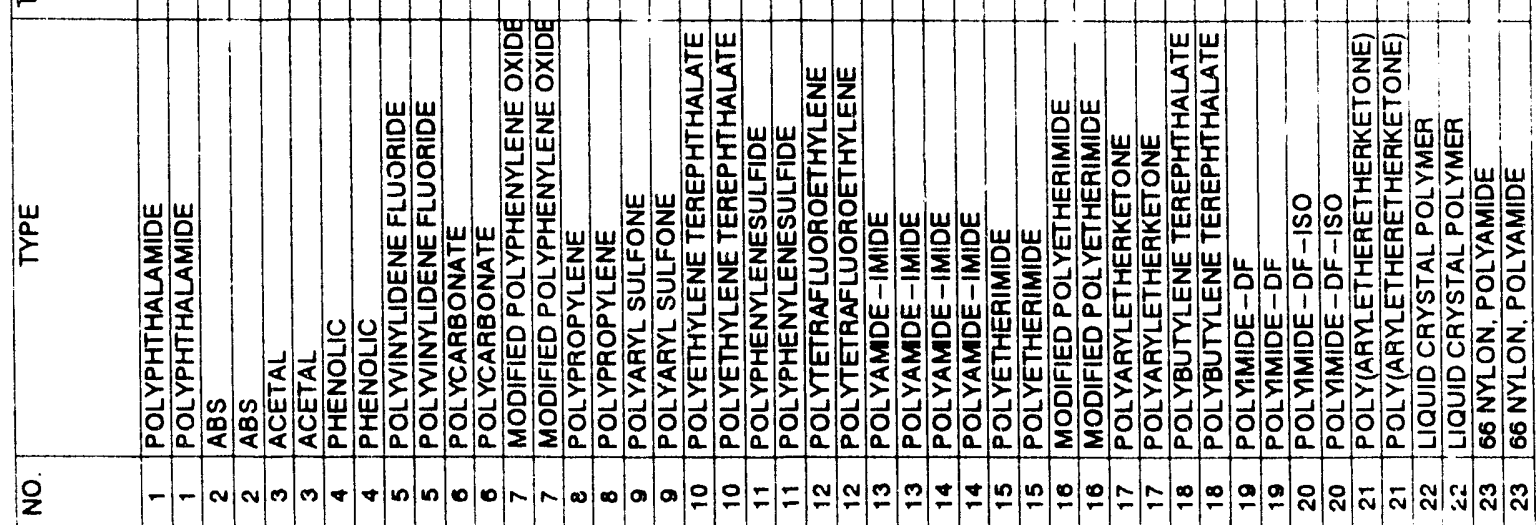




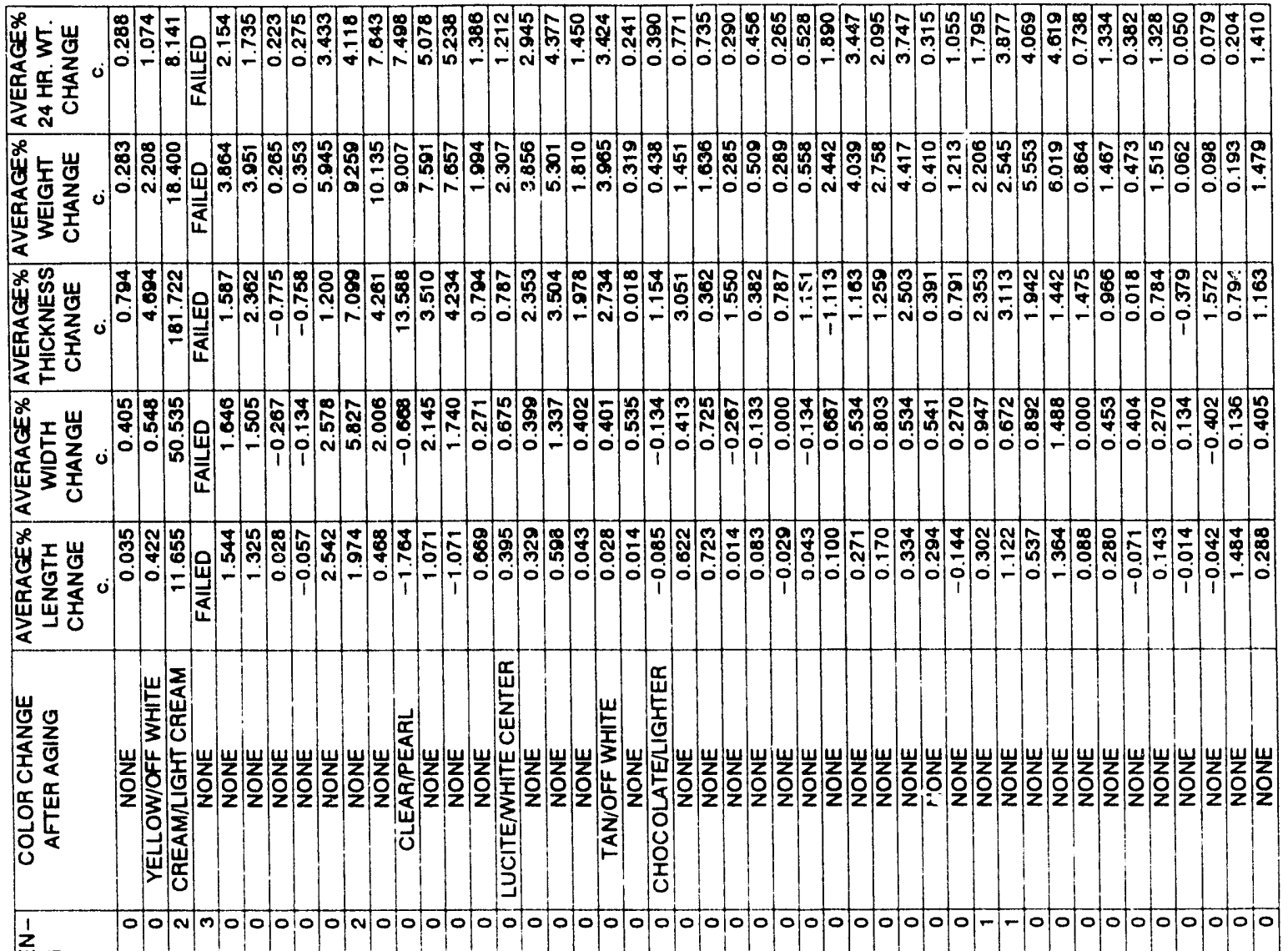

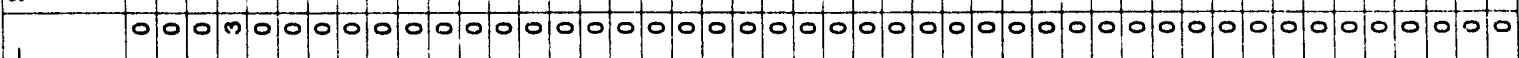

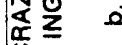

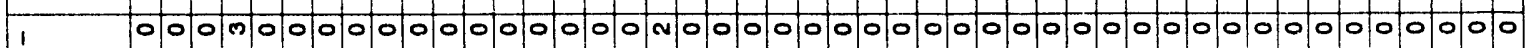
$\frac{1}{6}$ 造枈 近

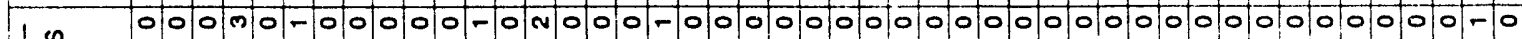
0 w 㹂

iL

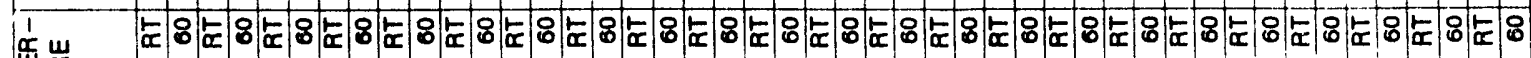
䎹 ii. w

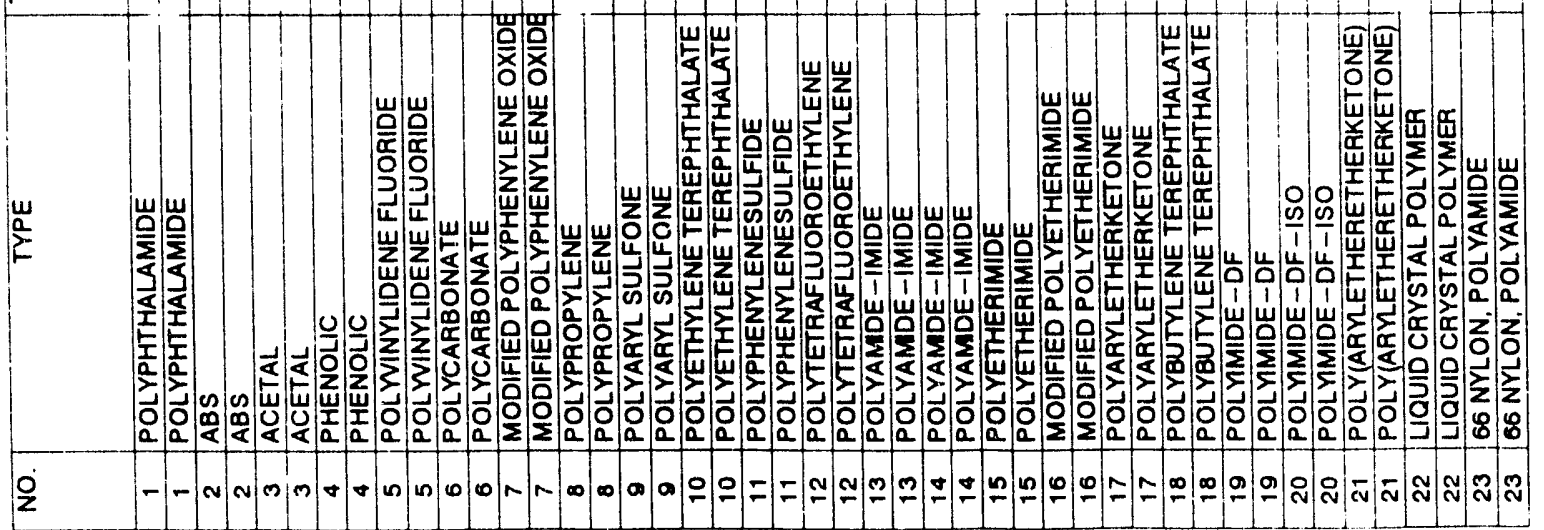



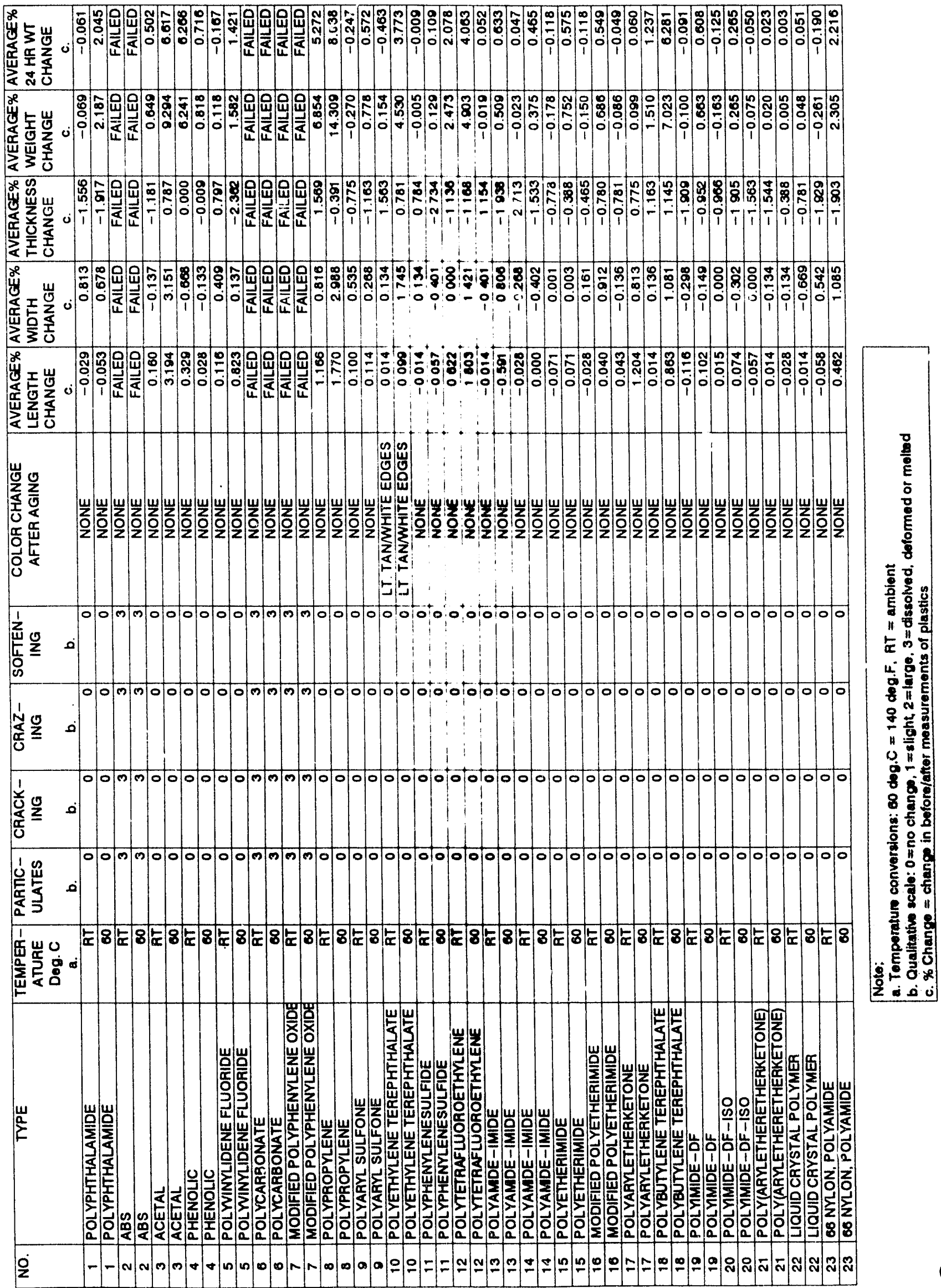


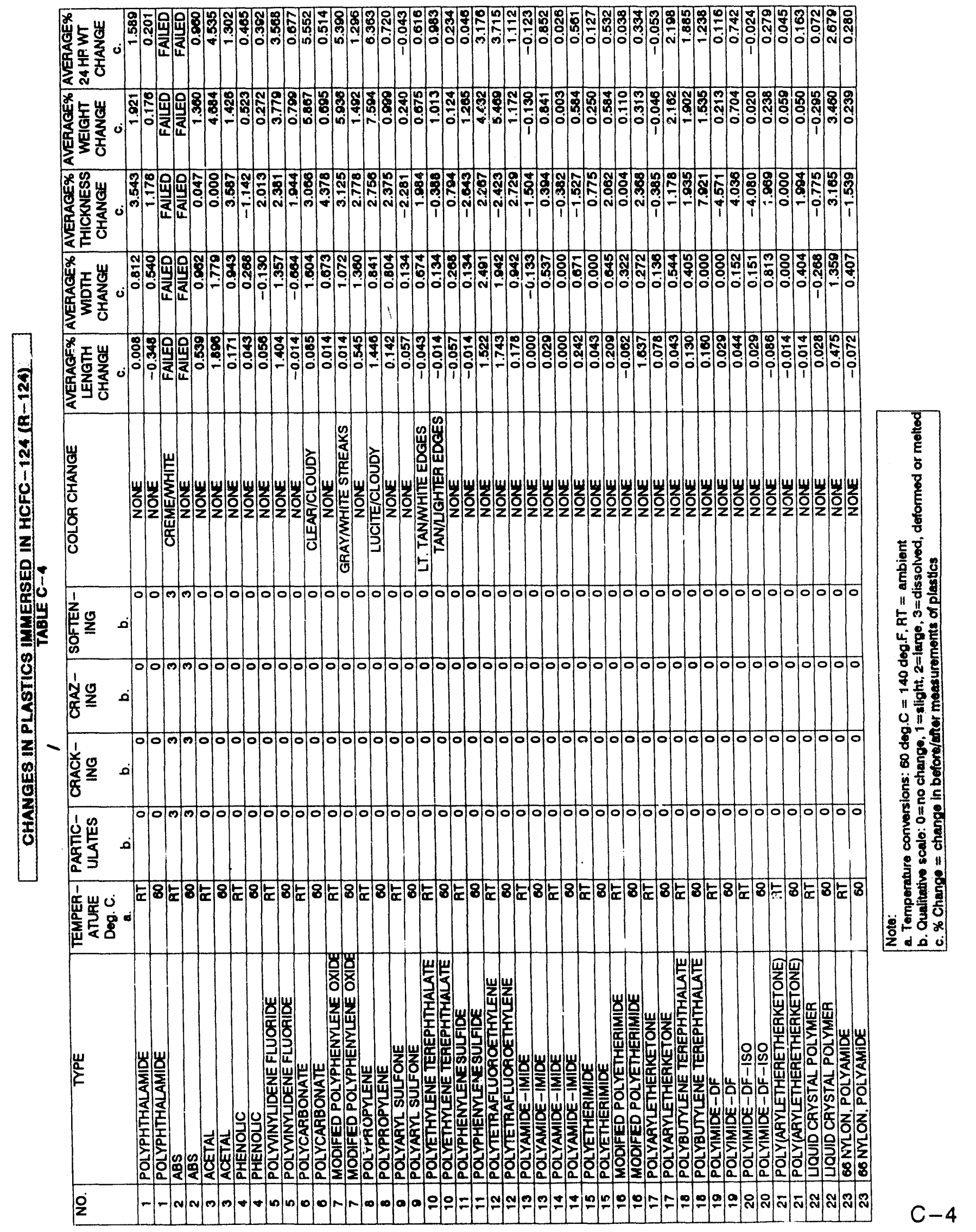




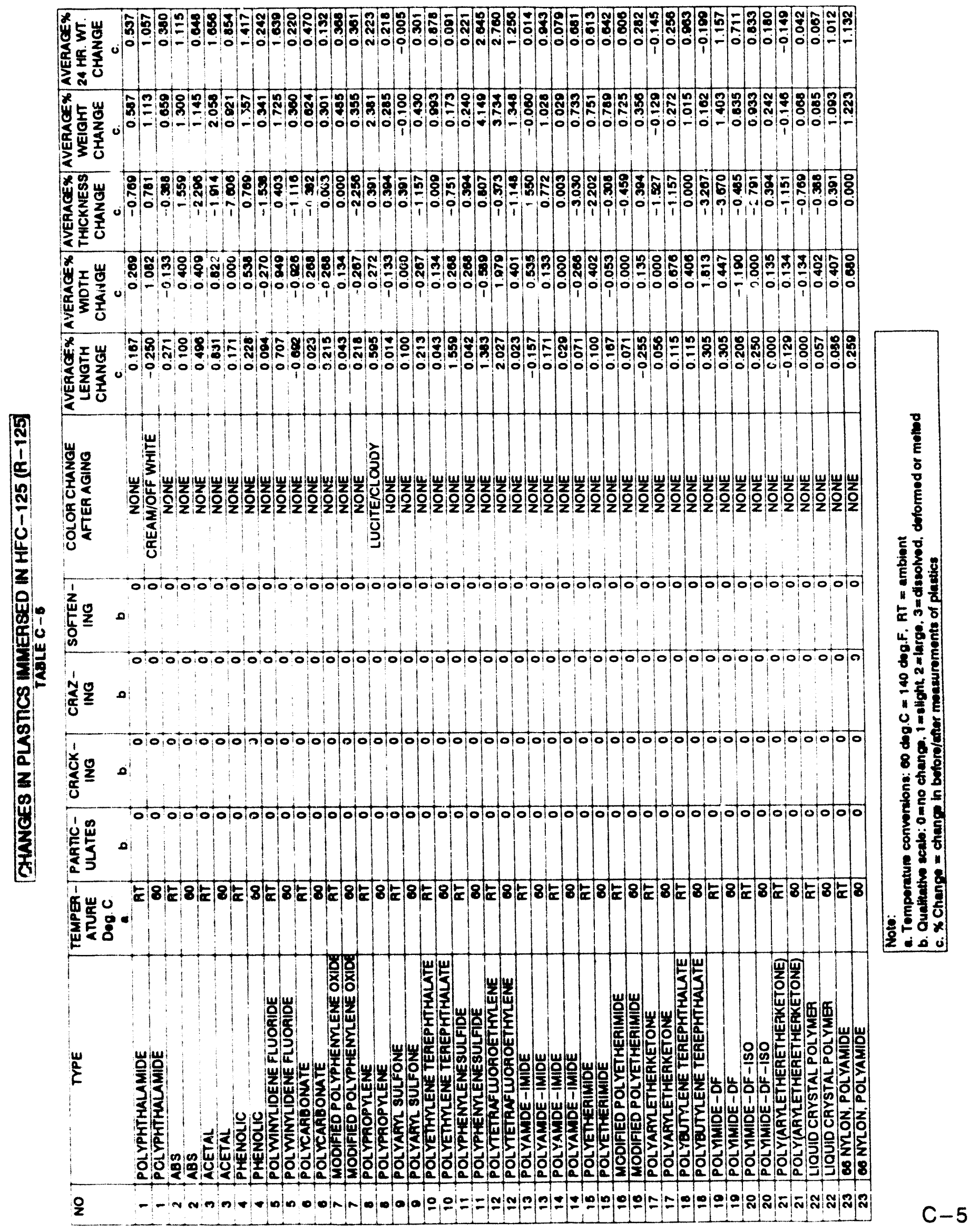




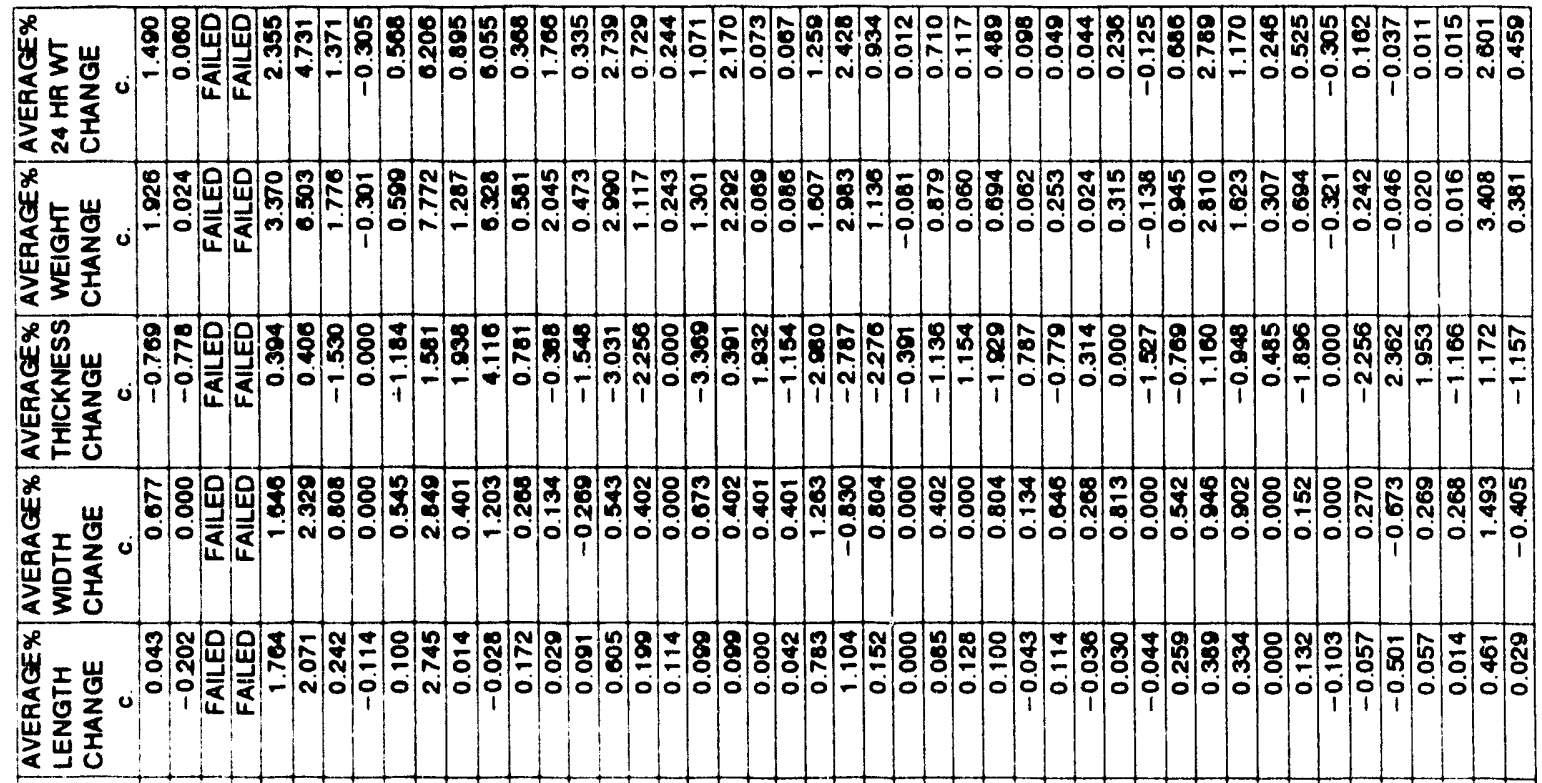

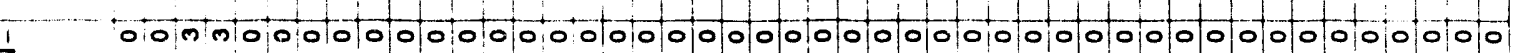
$\sum_{0} \stackrel{0}{0}$

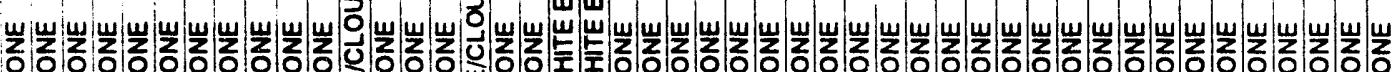
采 家

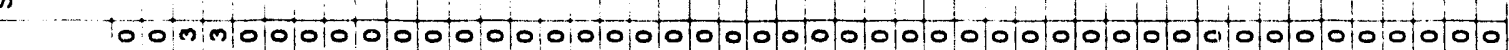

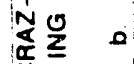

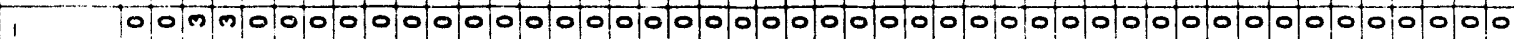
造是:

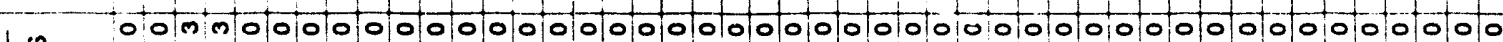

岂

这要

๔ य

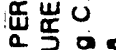
龍星

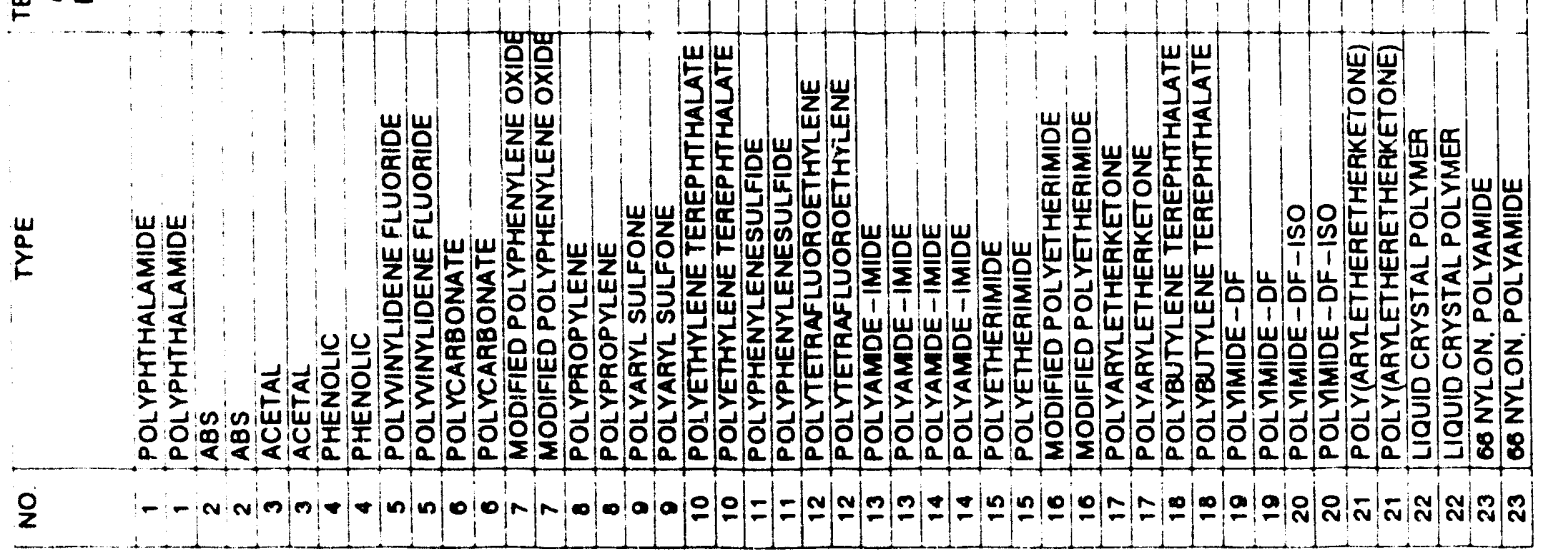




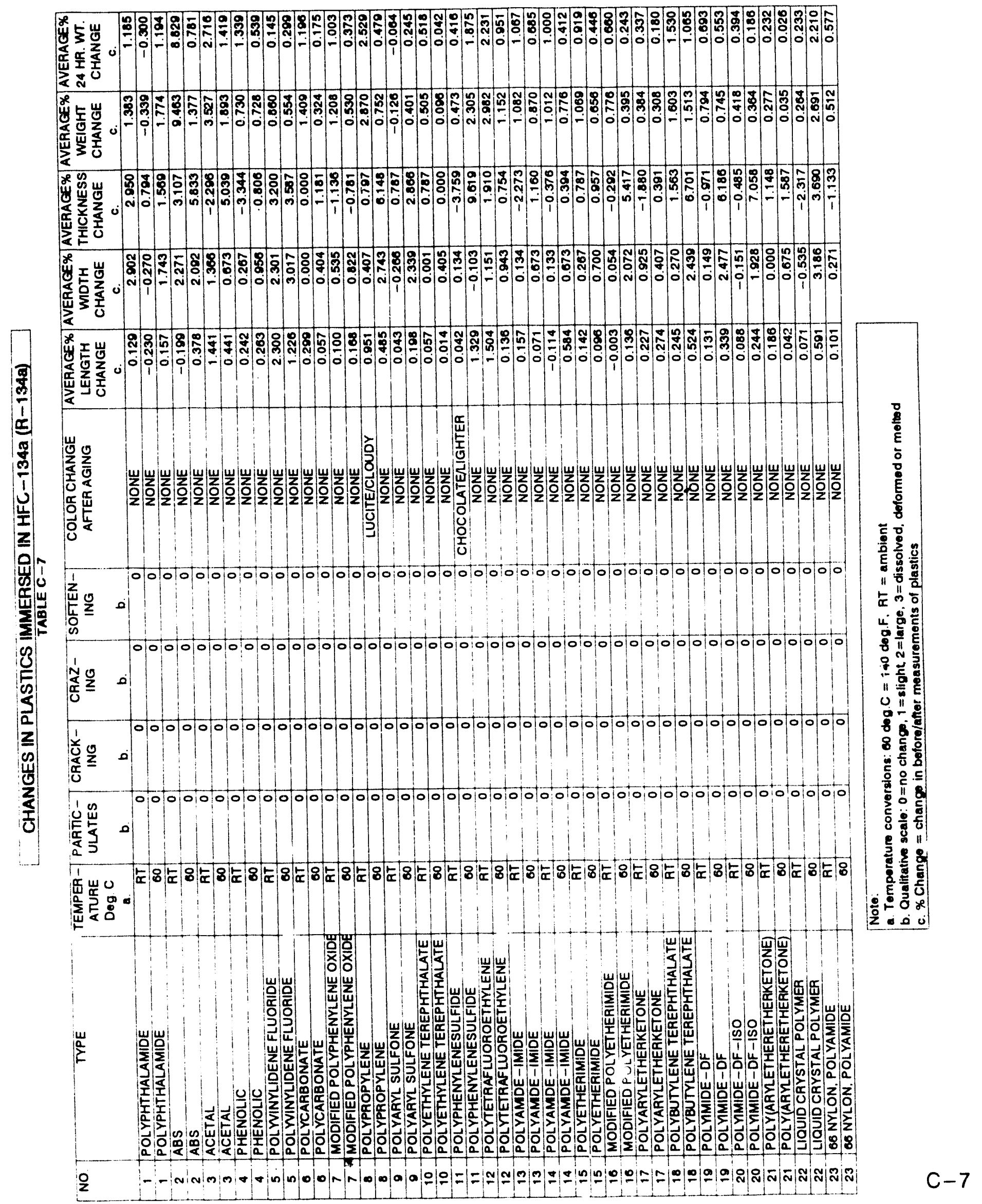




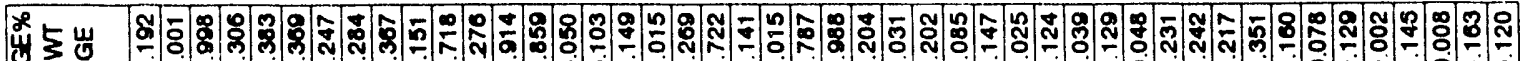

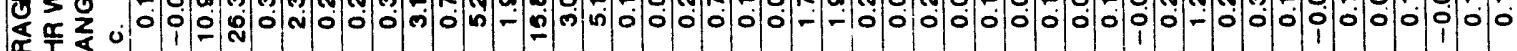
焉要喜

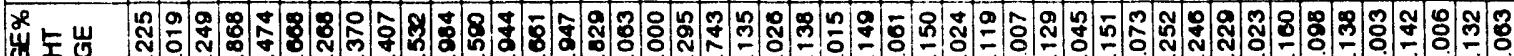

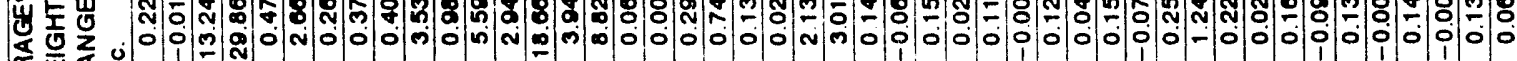
密崖否

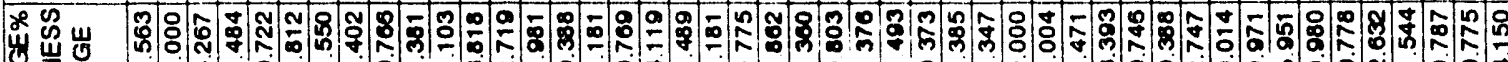

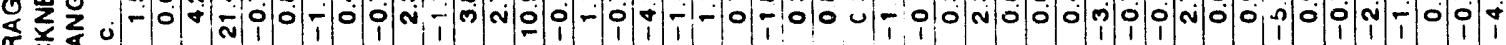
焉昰要

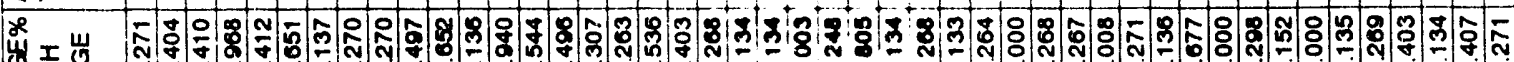

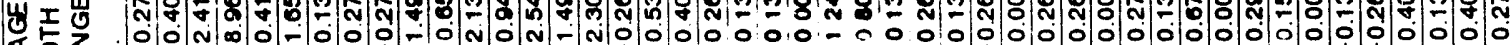

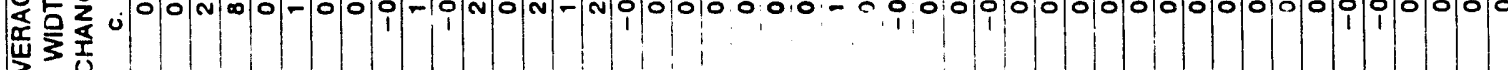

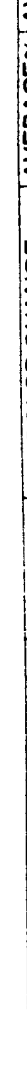
足

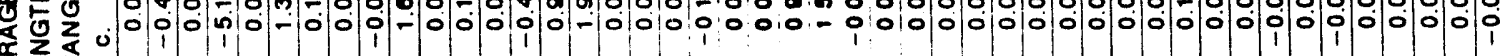

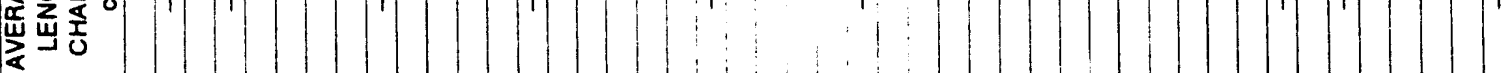

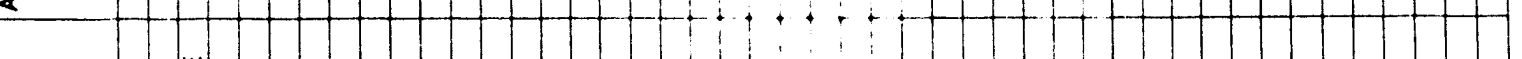

岁罗

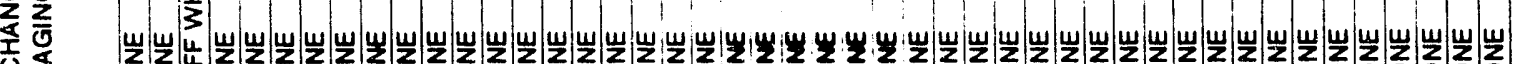

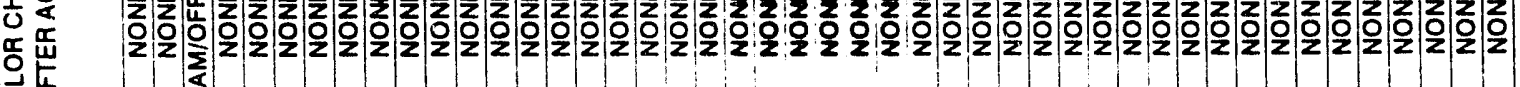

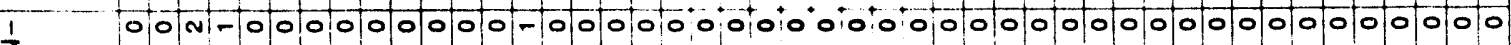

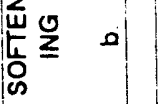

0000000000000000000000000010100000000000000000000

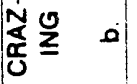

1000000000000000000001000000000000001000000000000

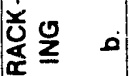

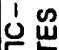

㹂写

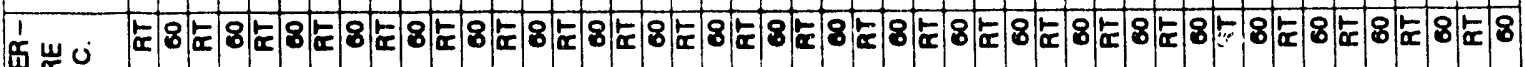

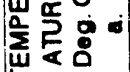

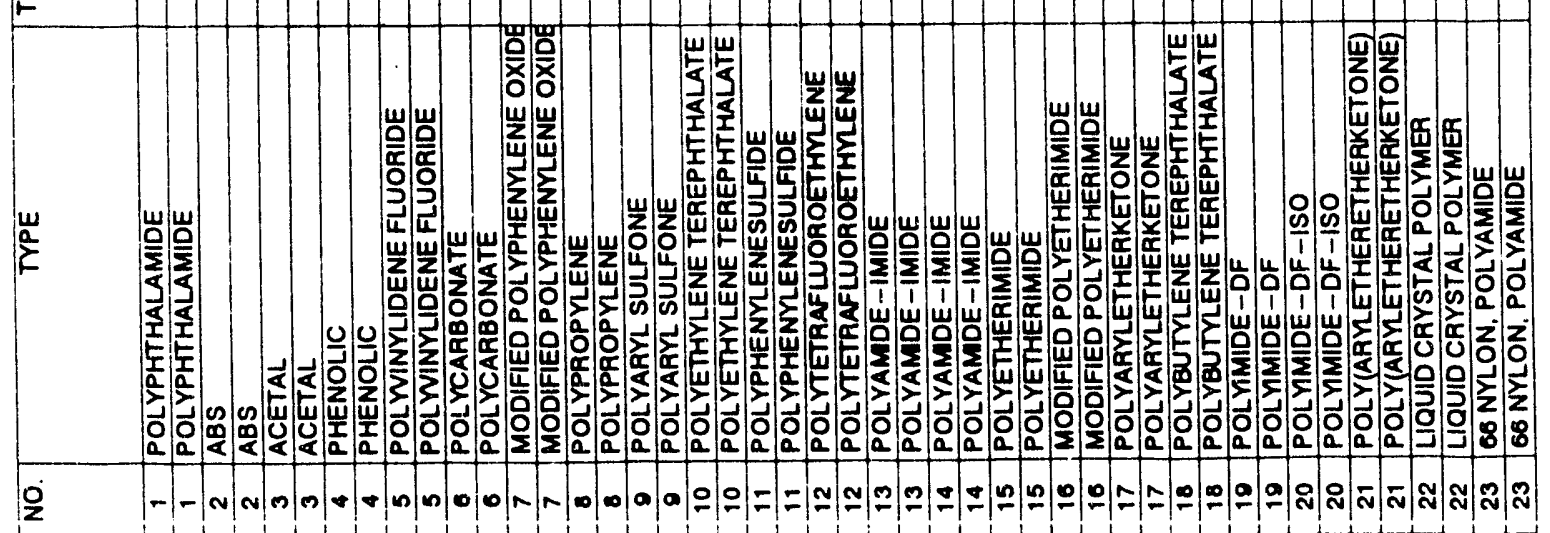




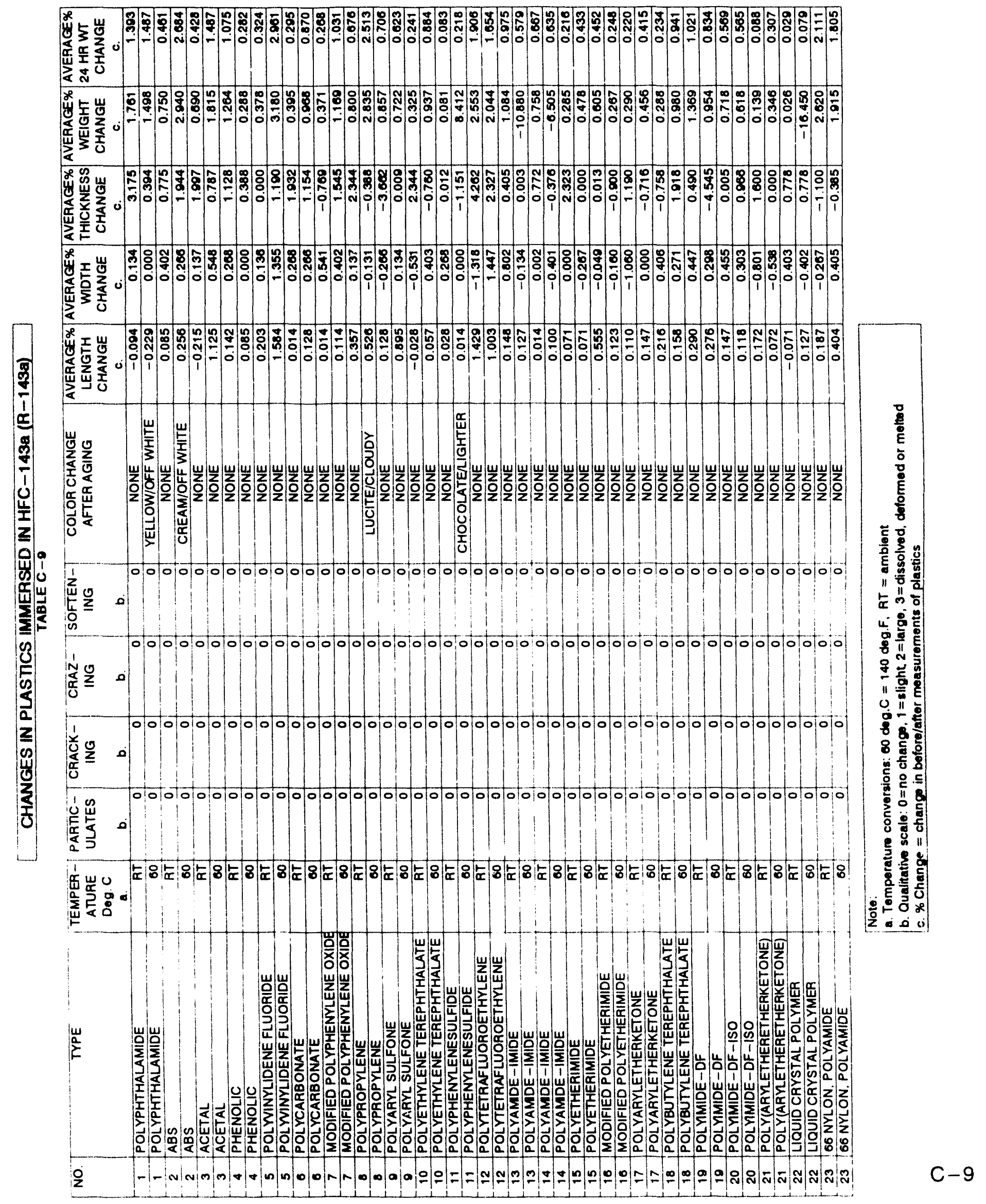




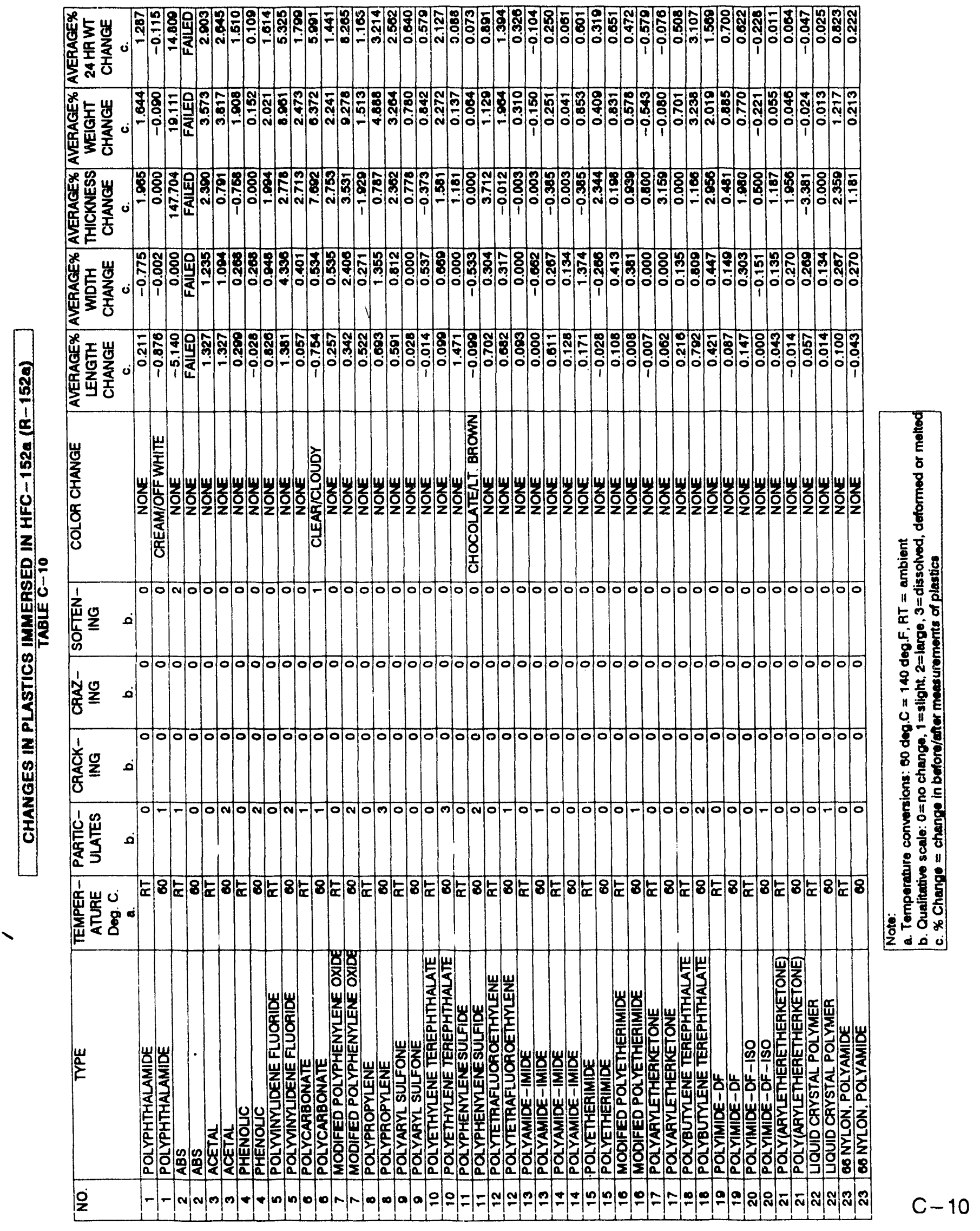




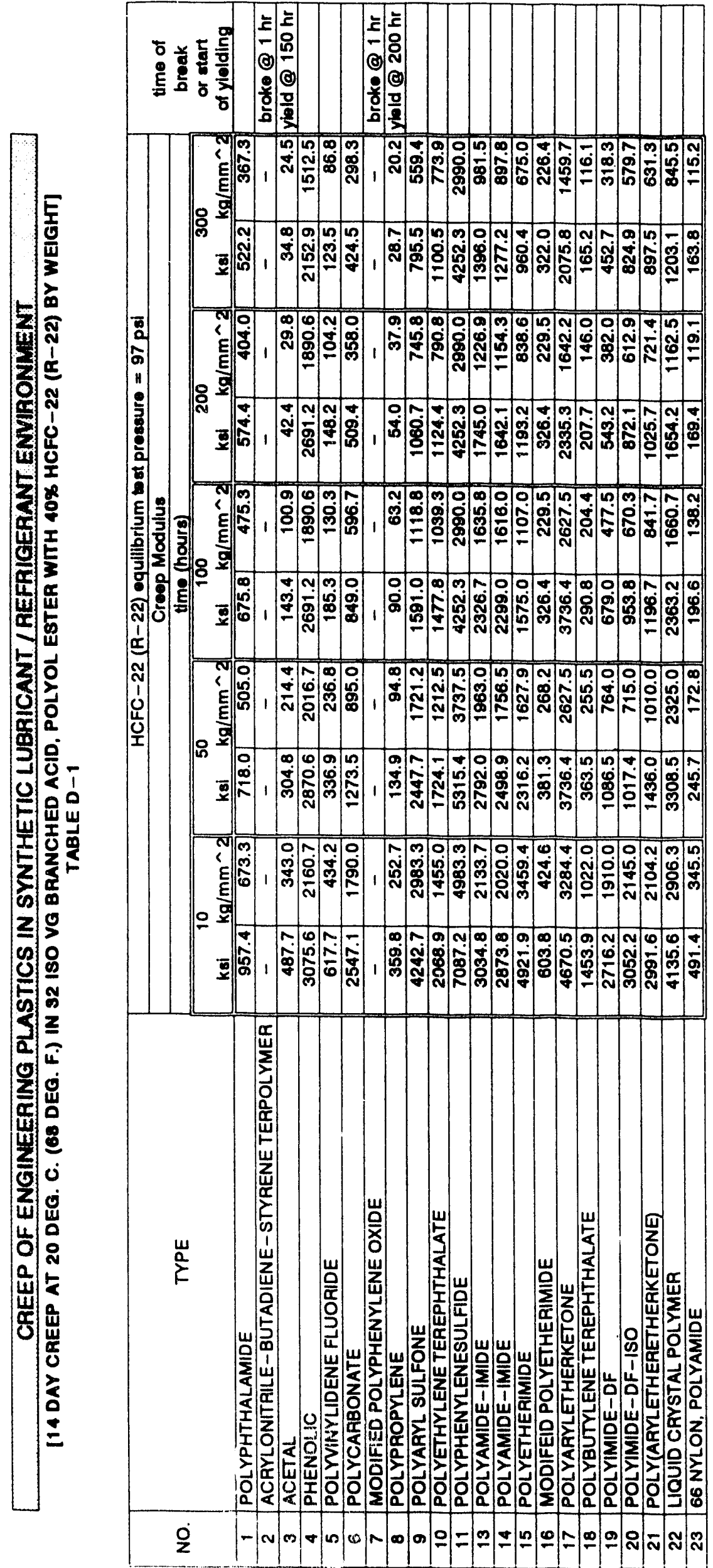




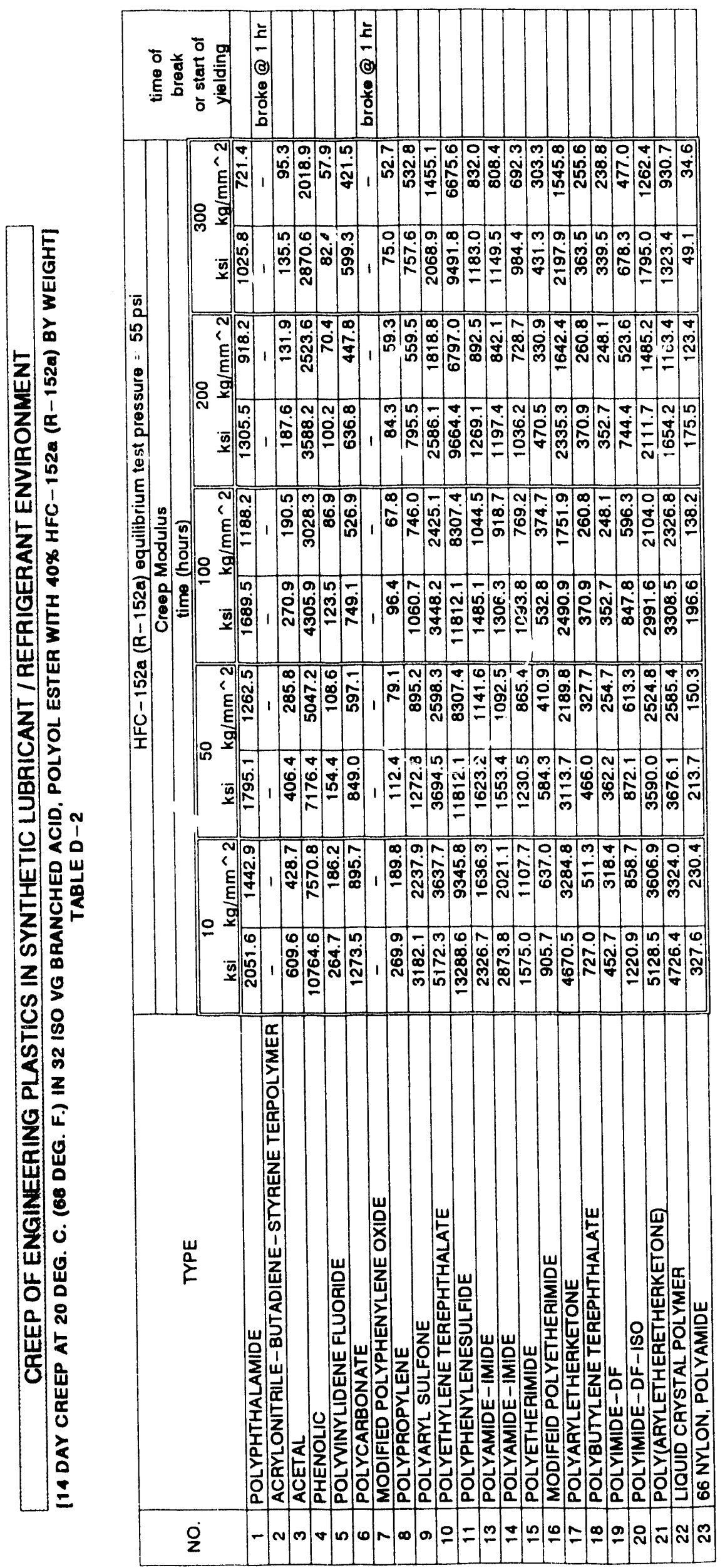




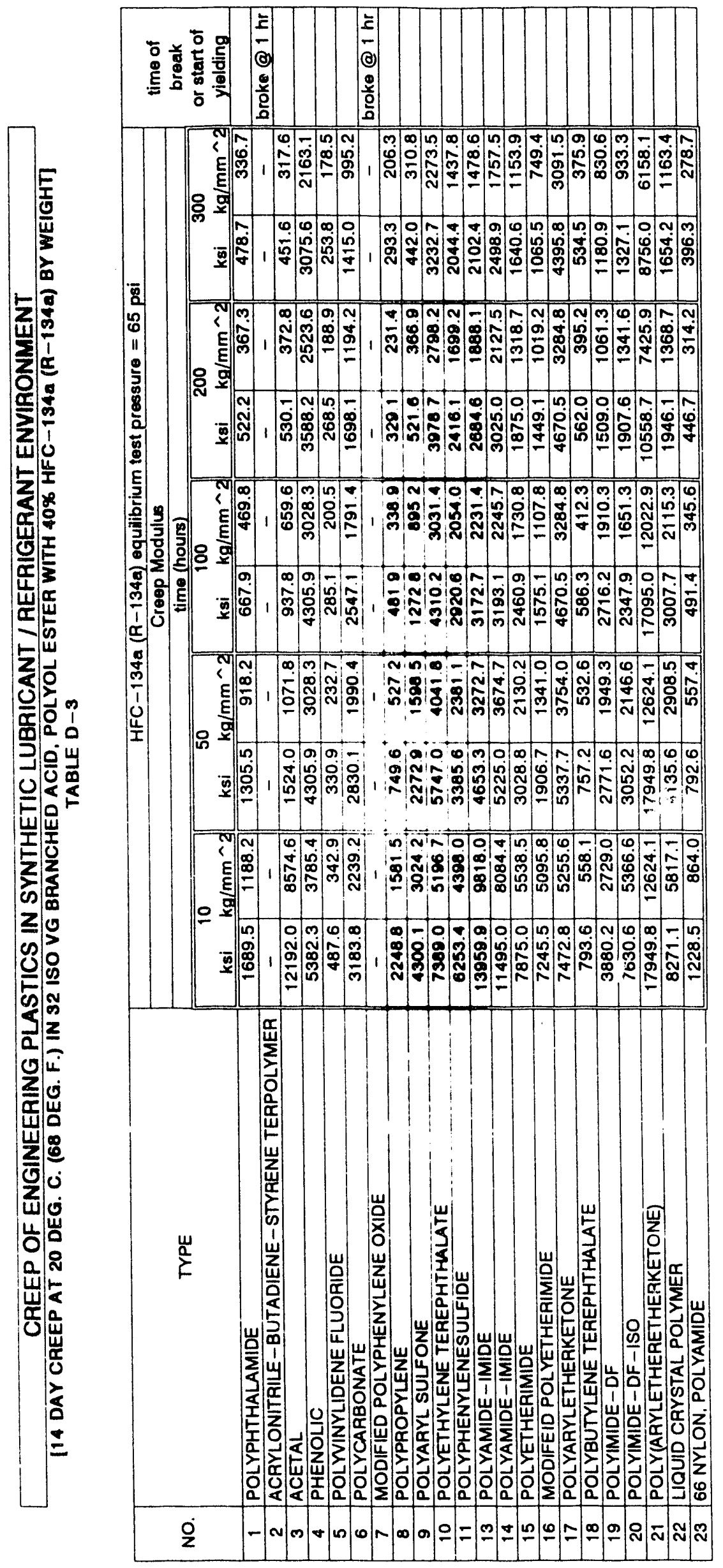




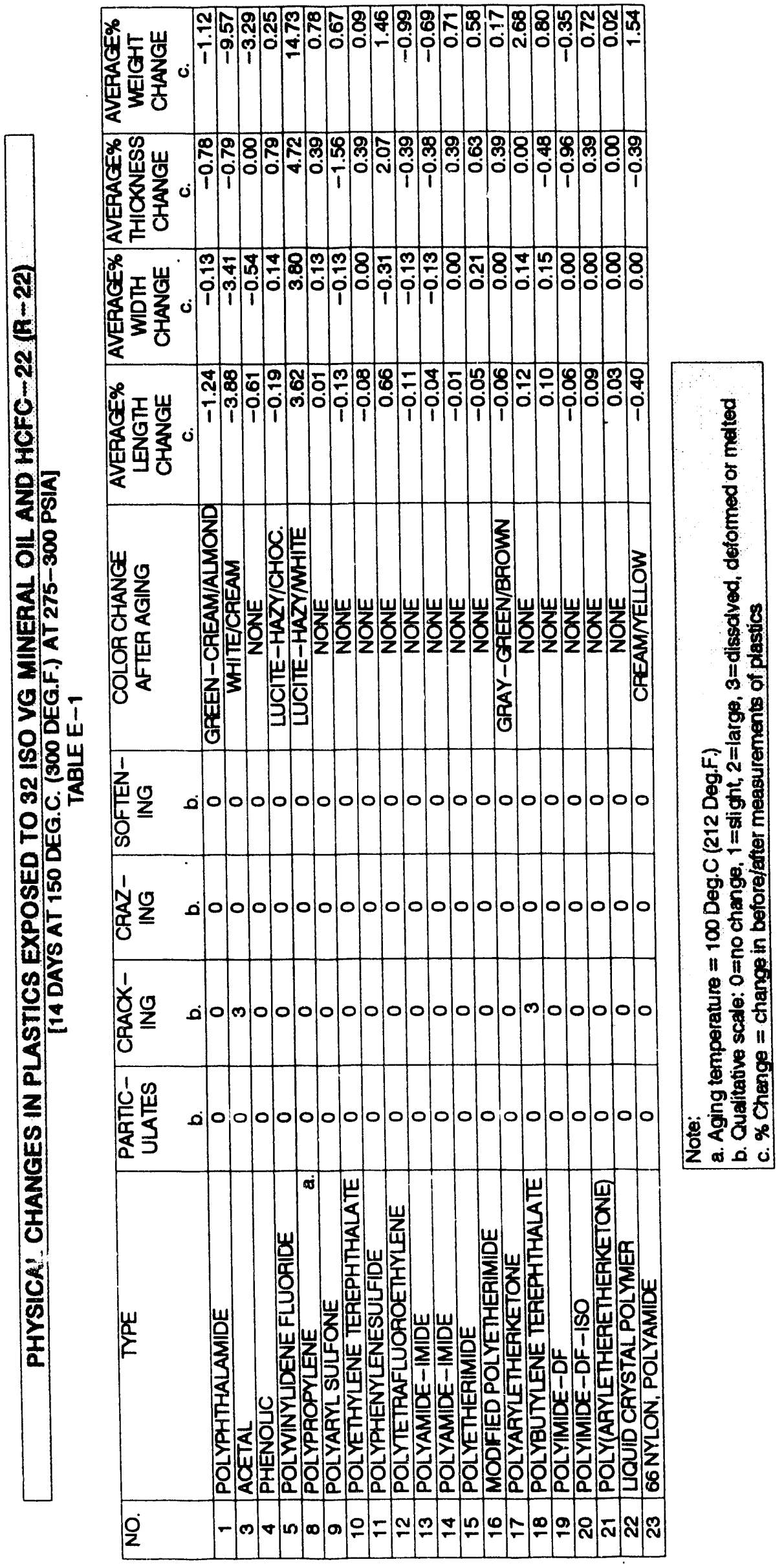




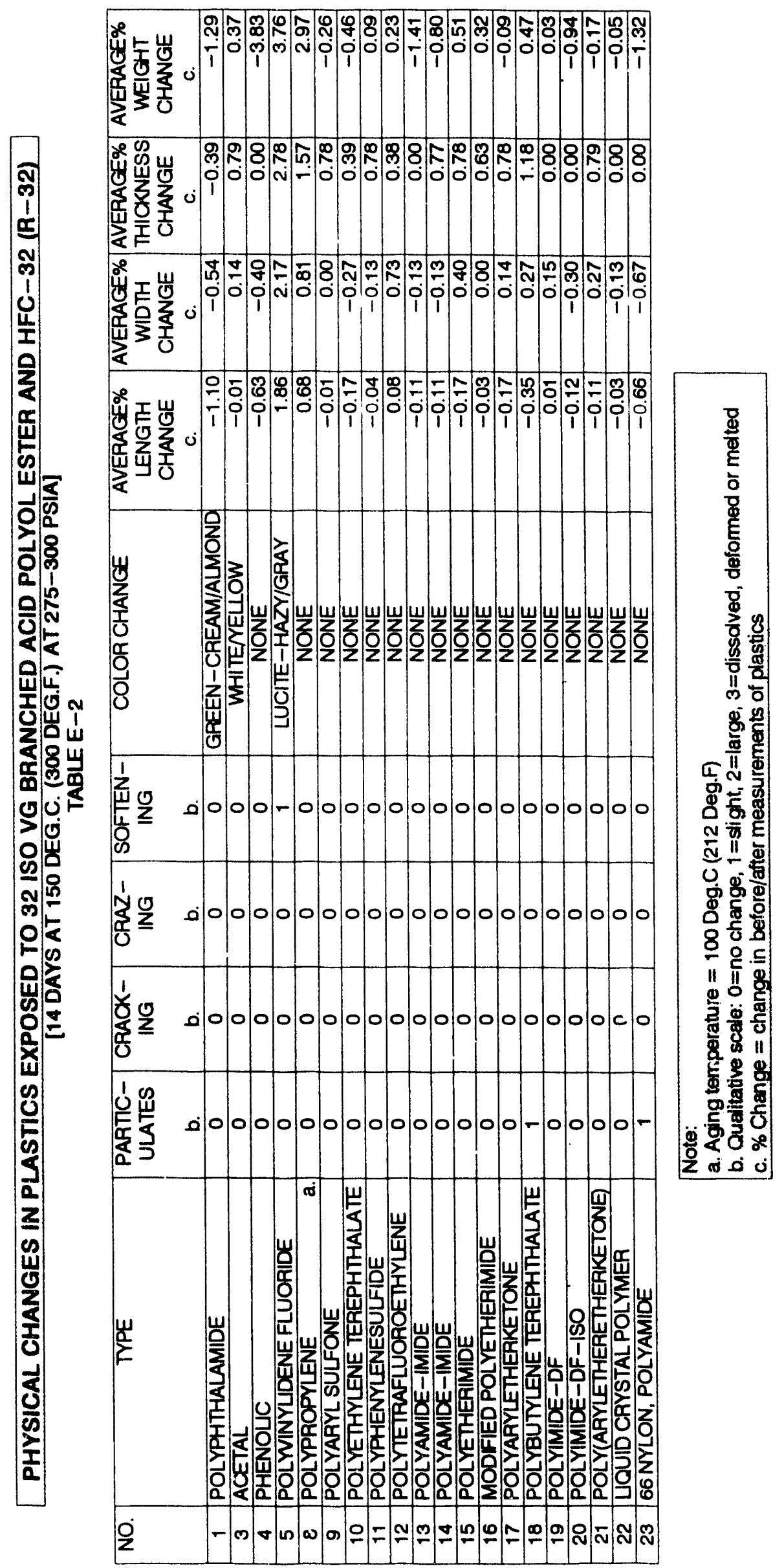




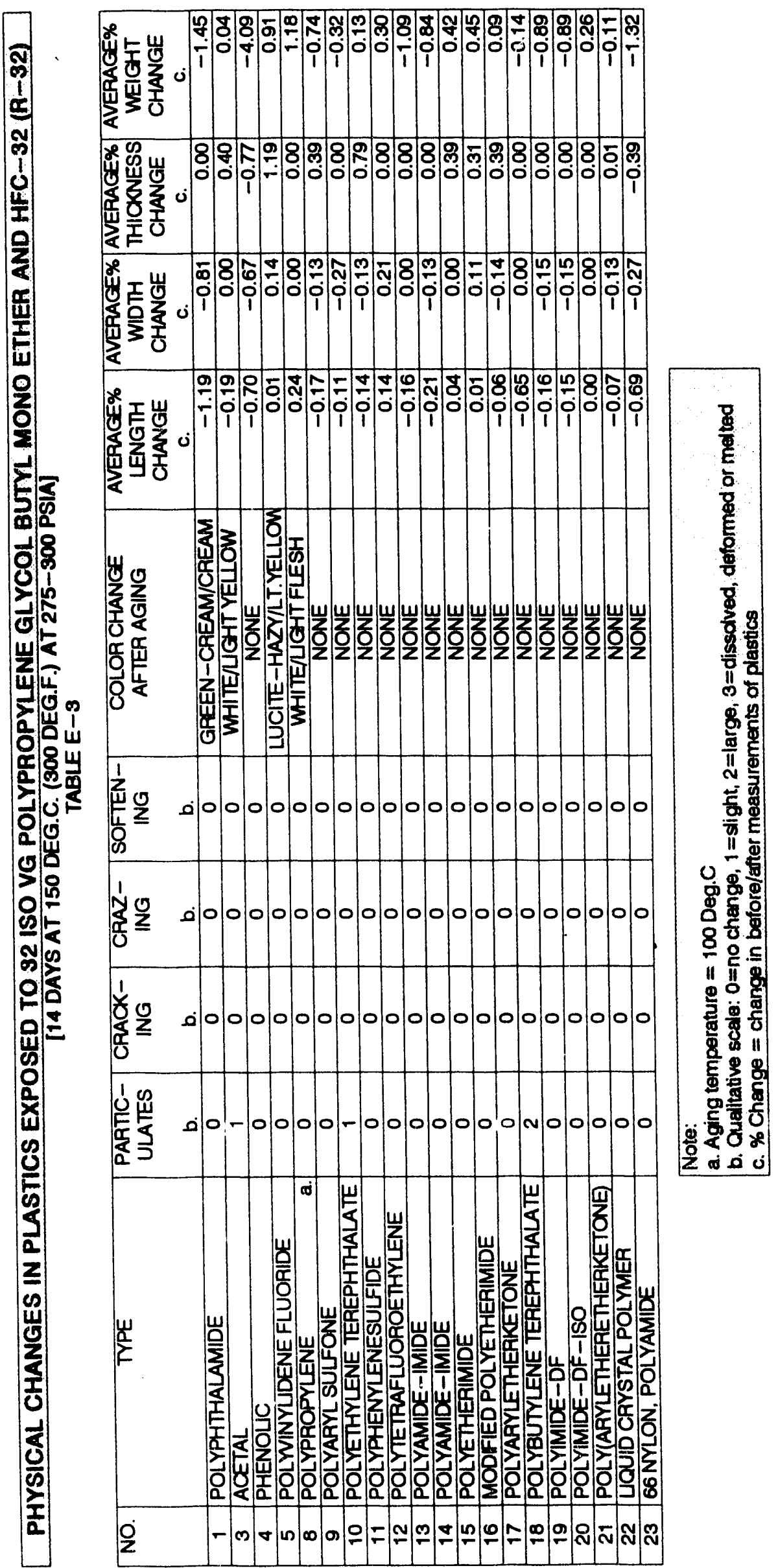




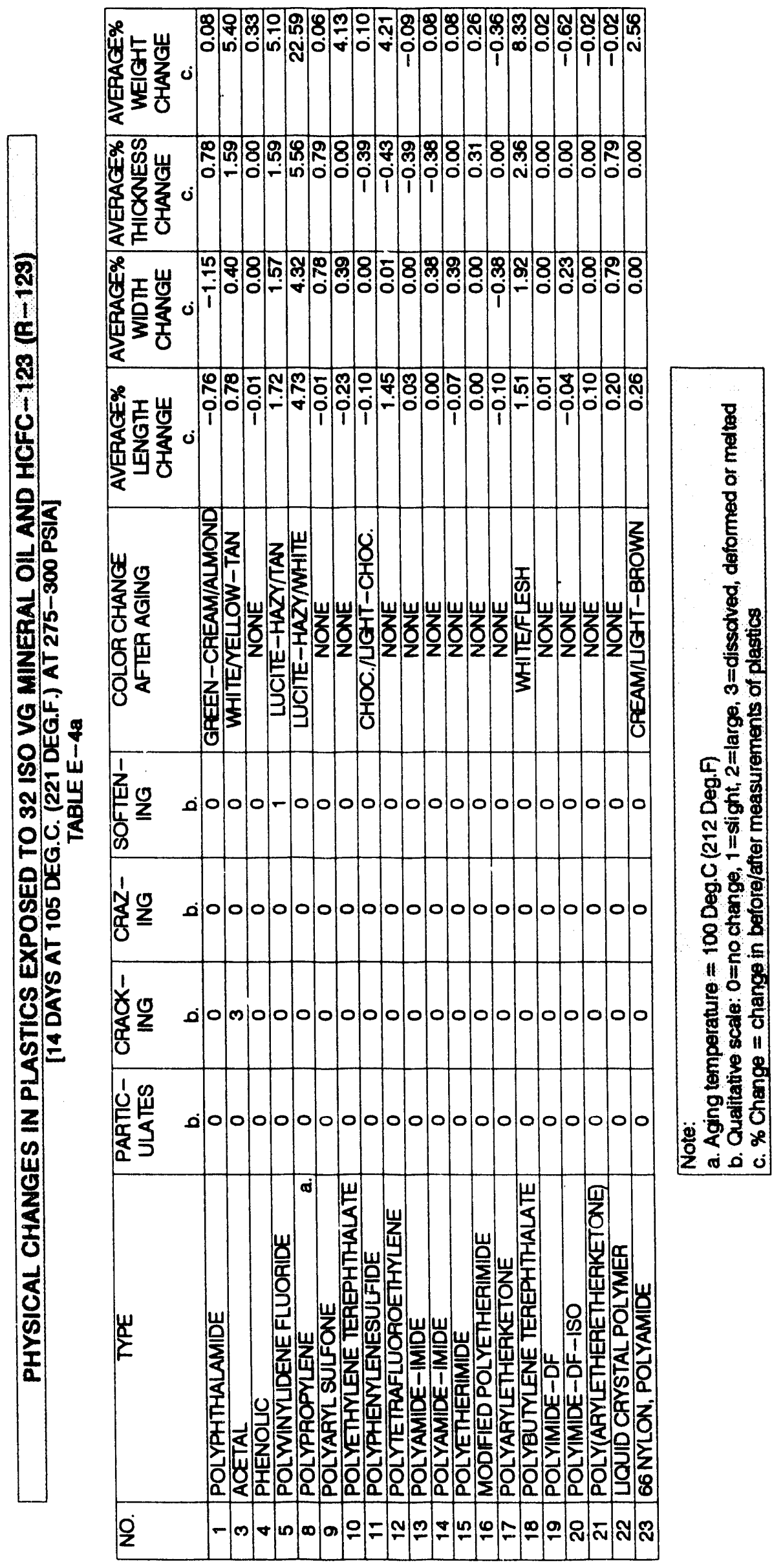




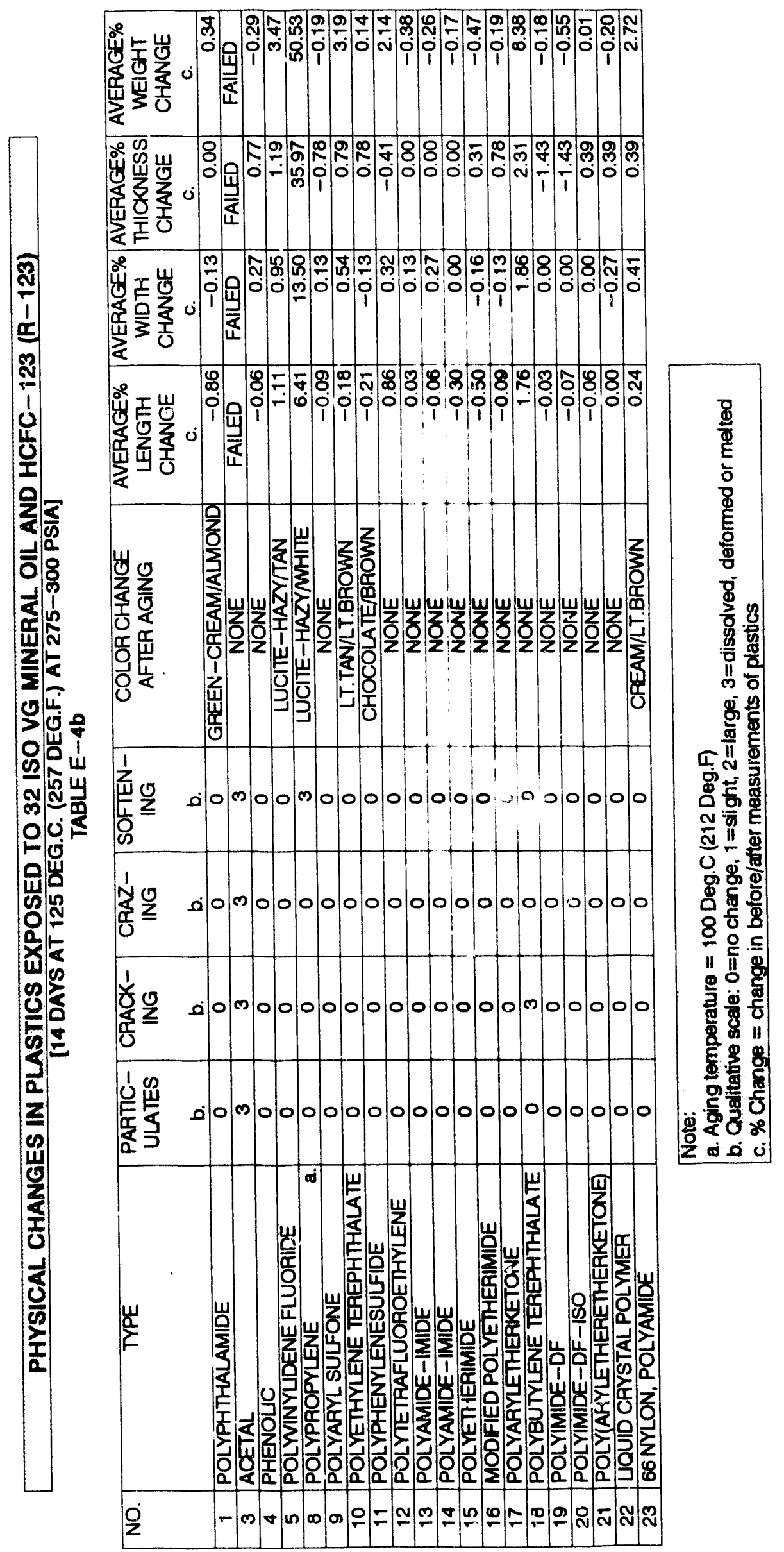




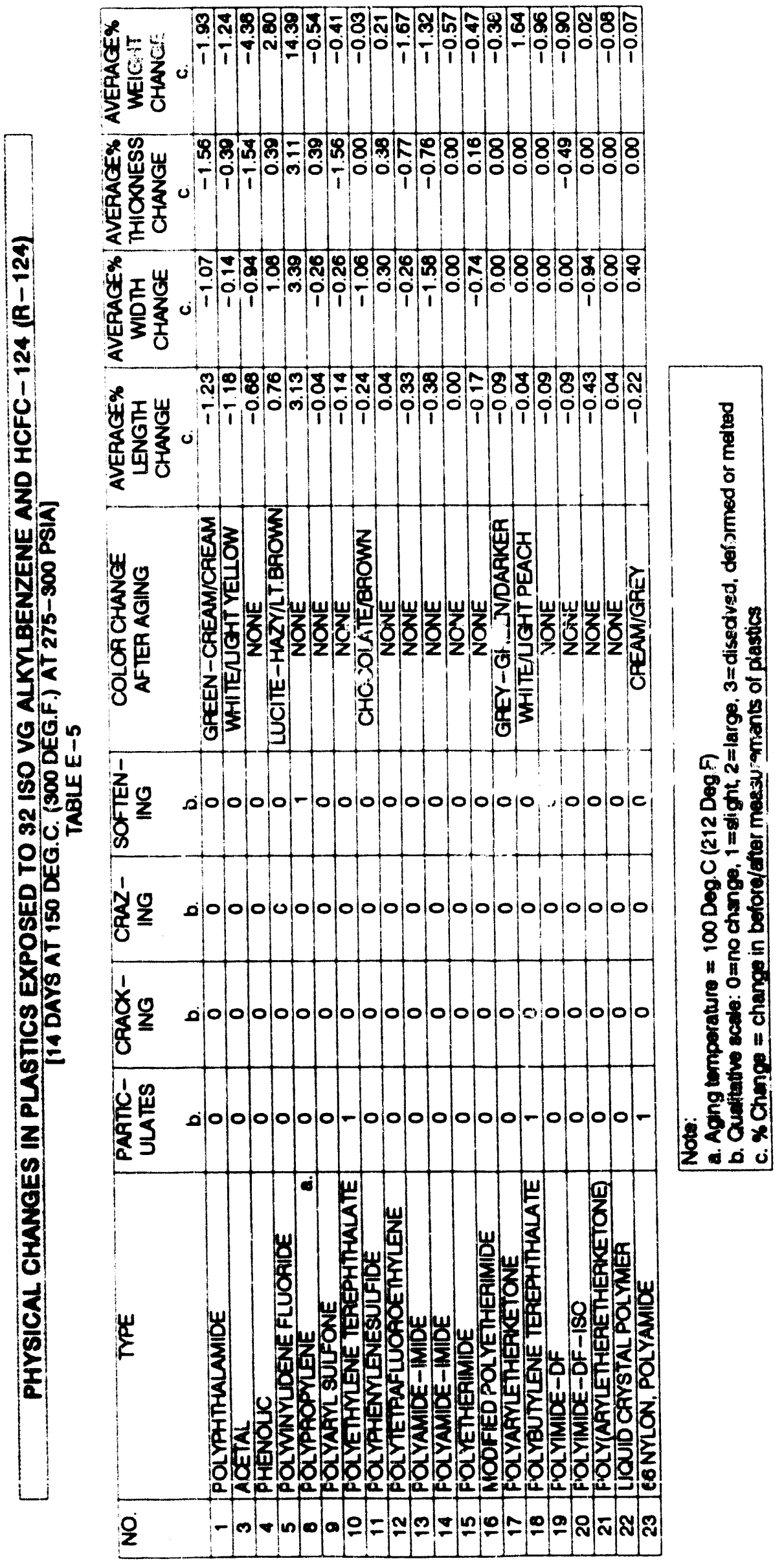




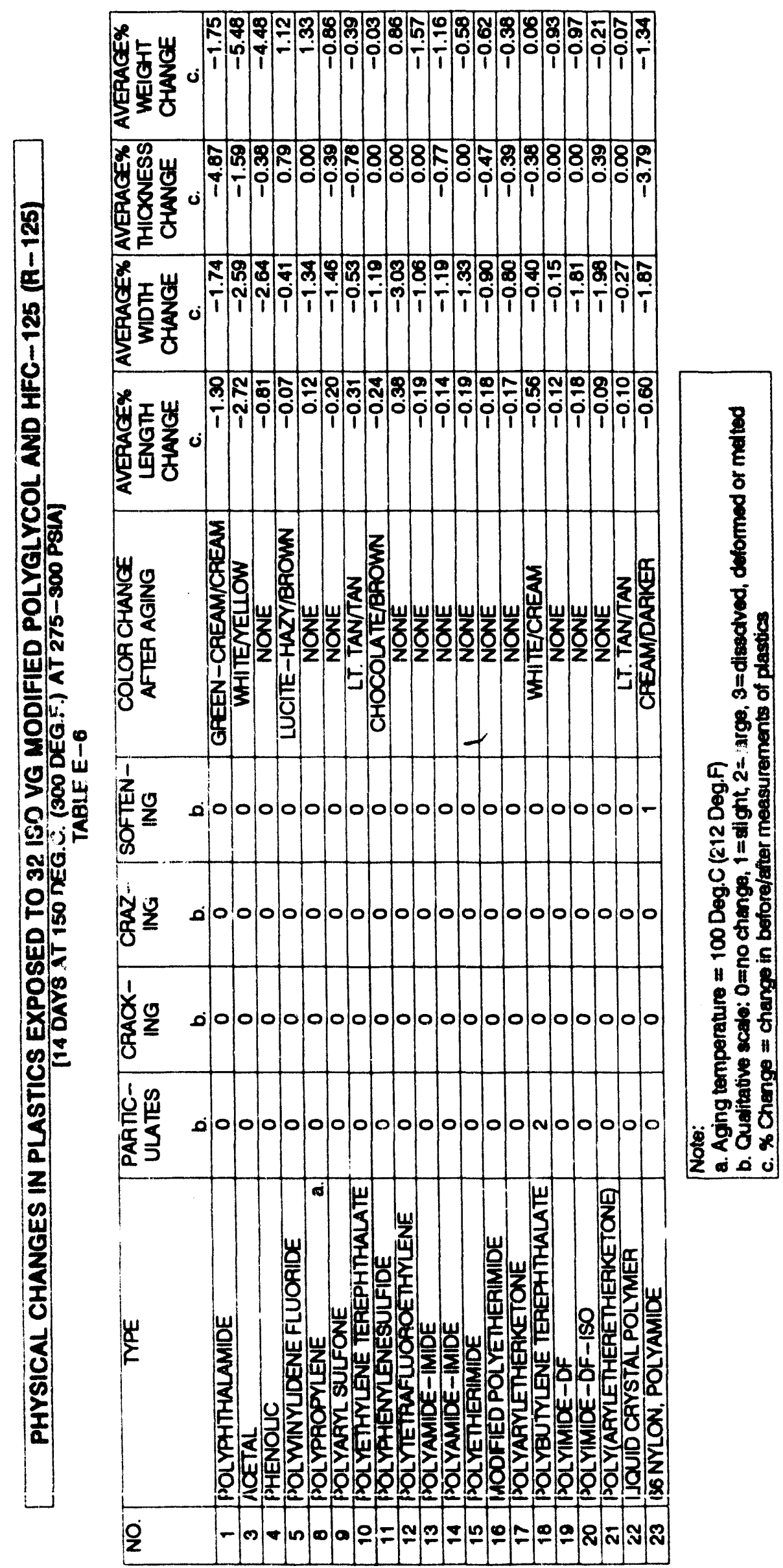




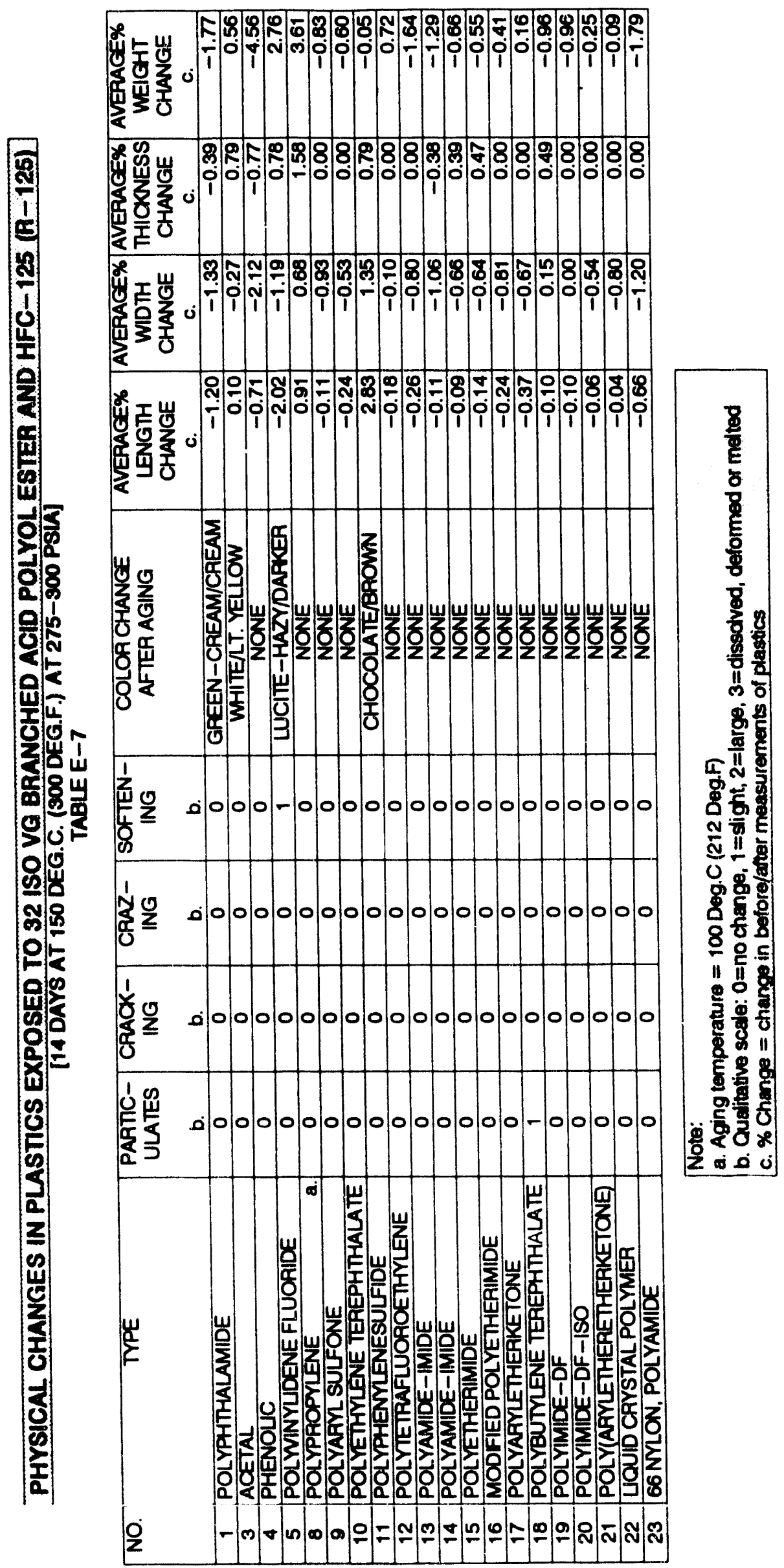




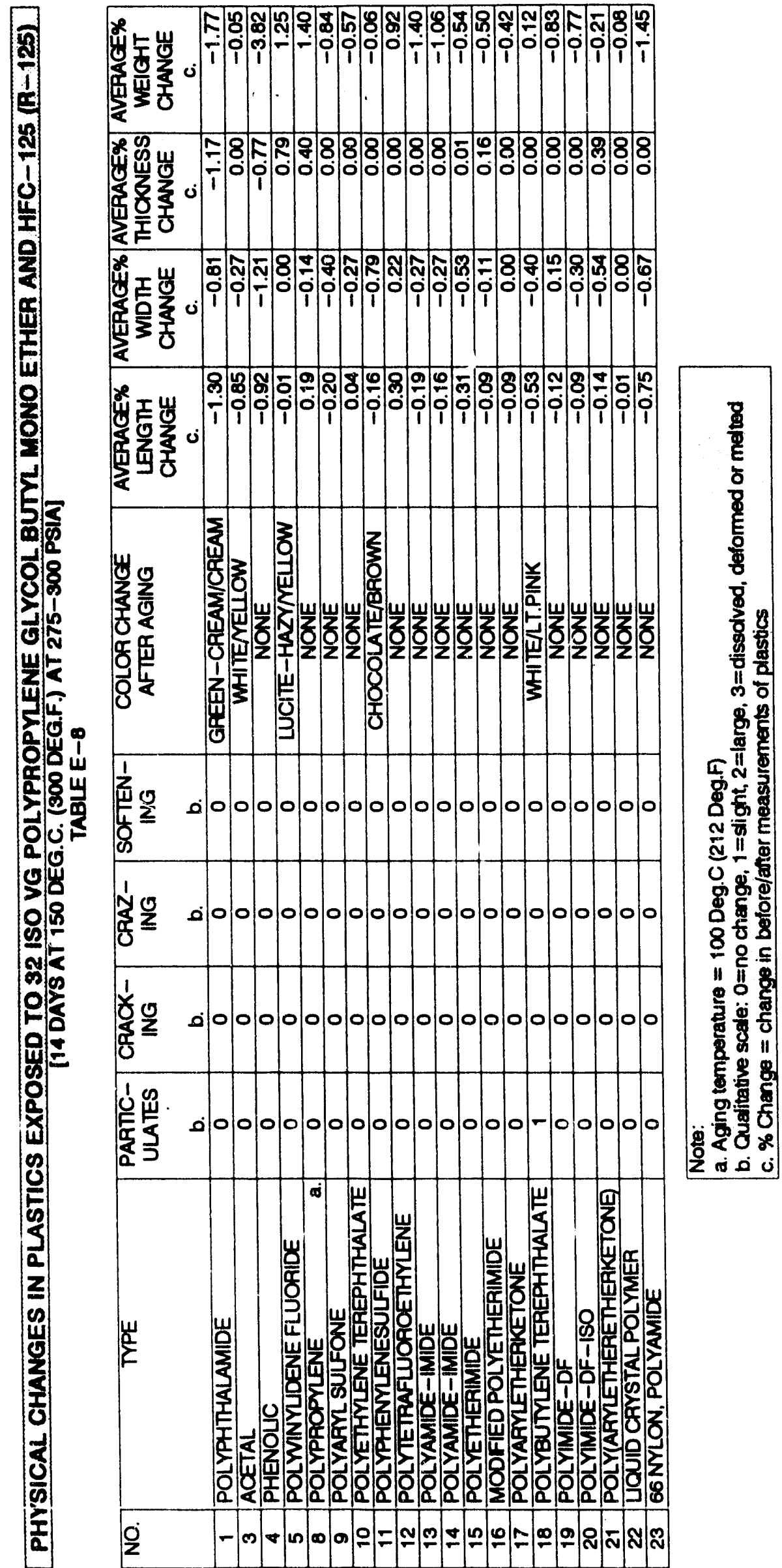




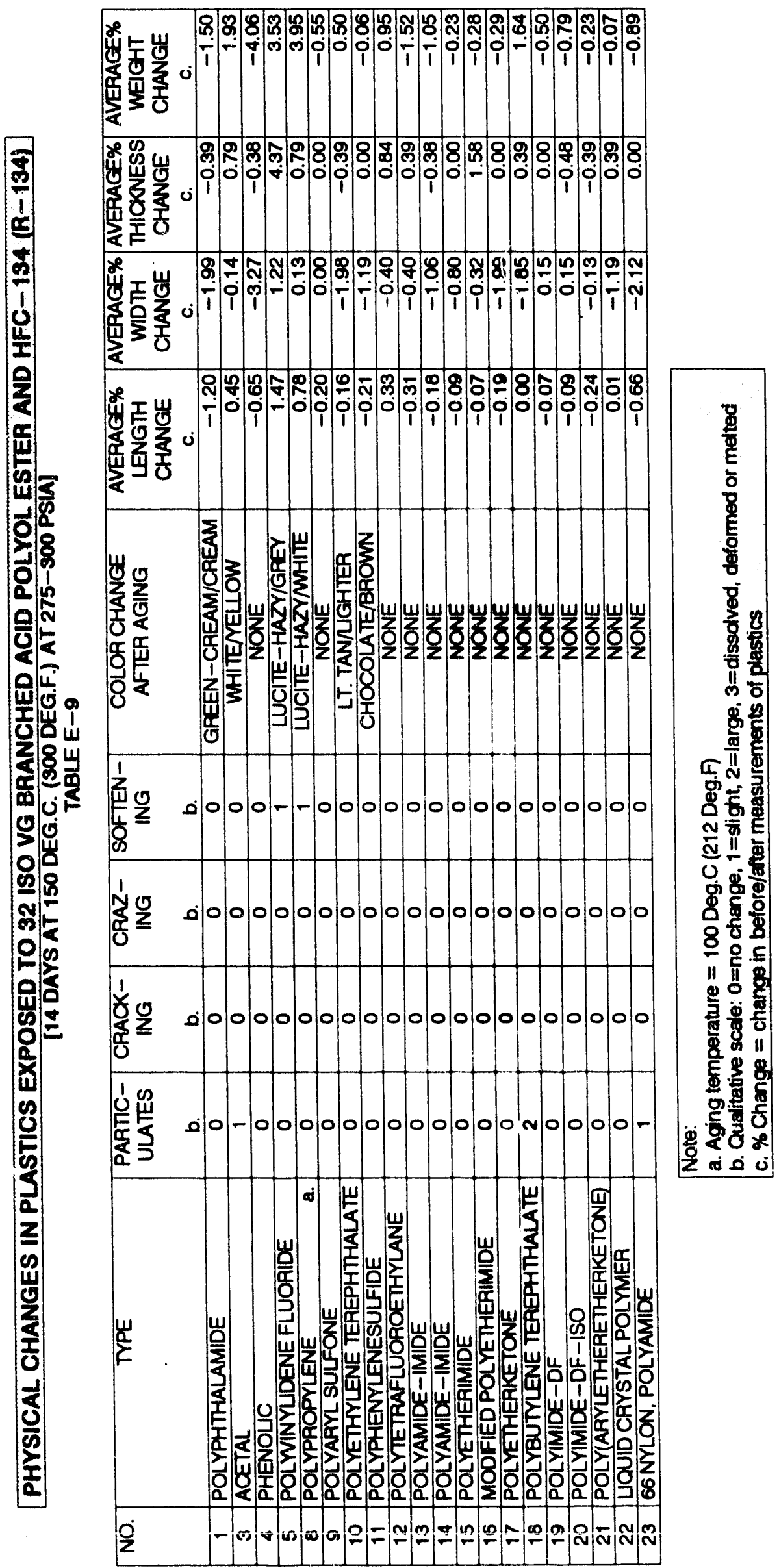




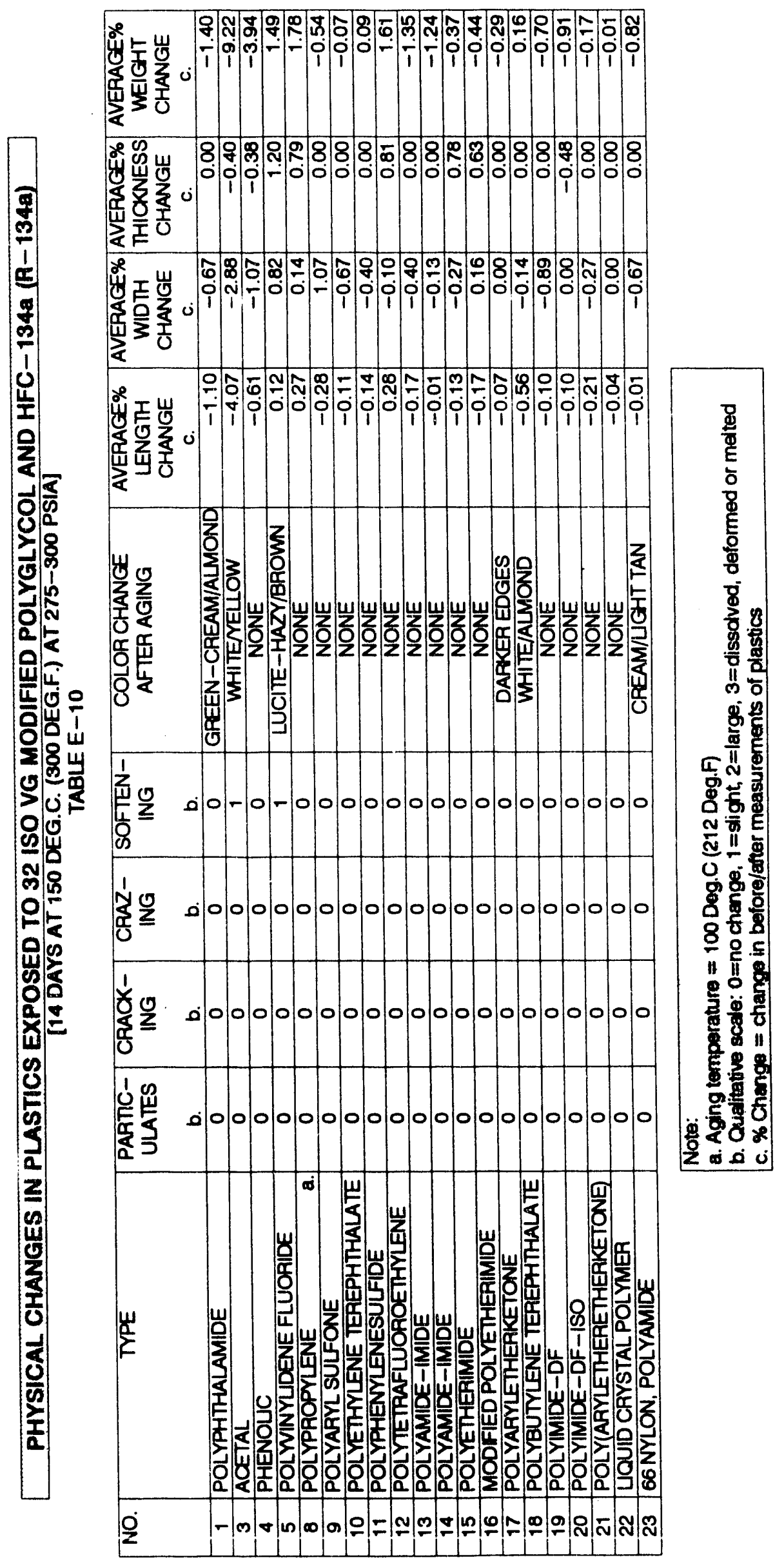

$E-10$ 


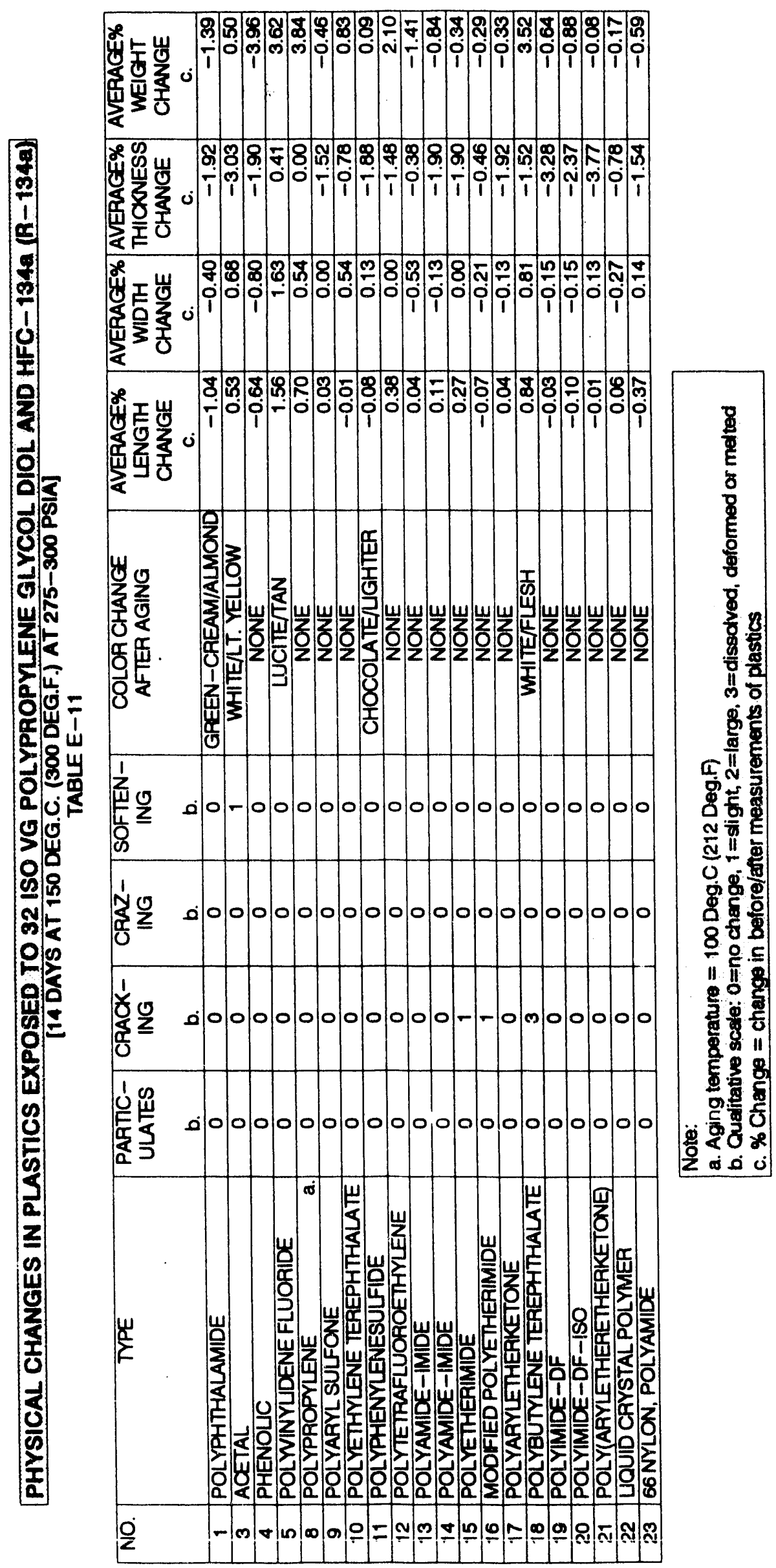




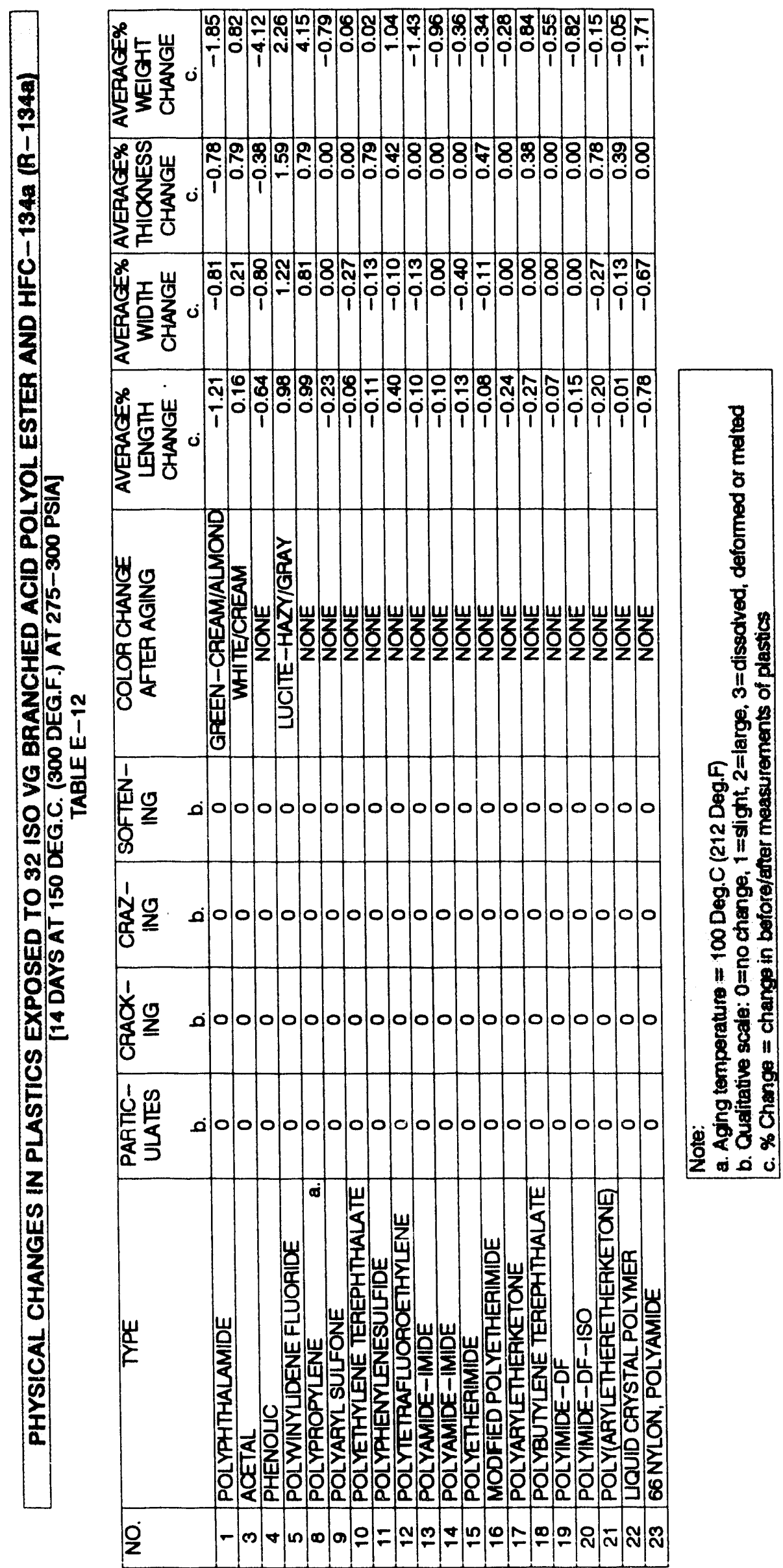




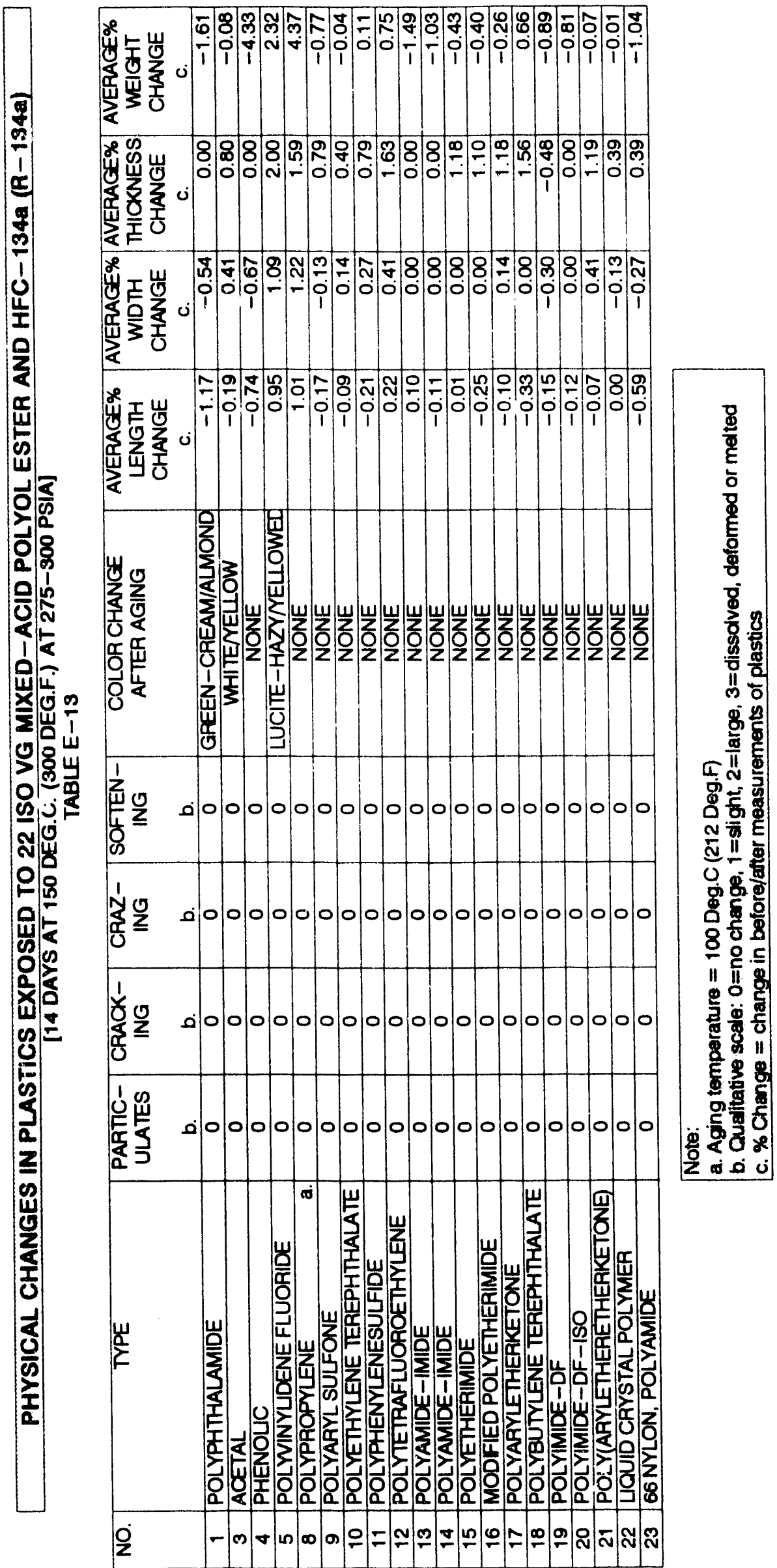




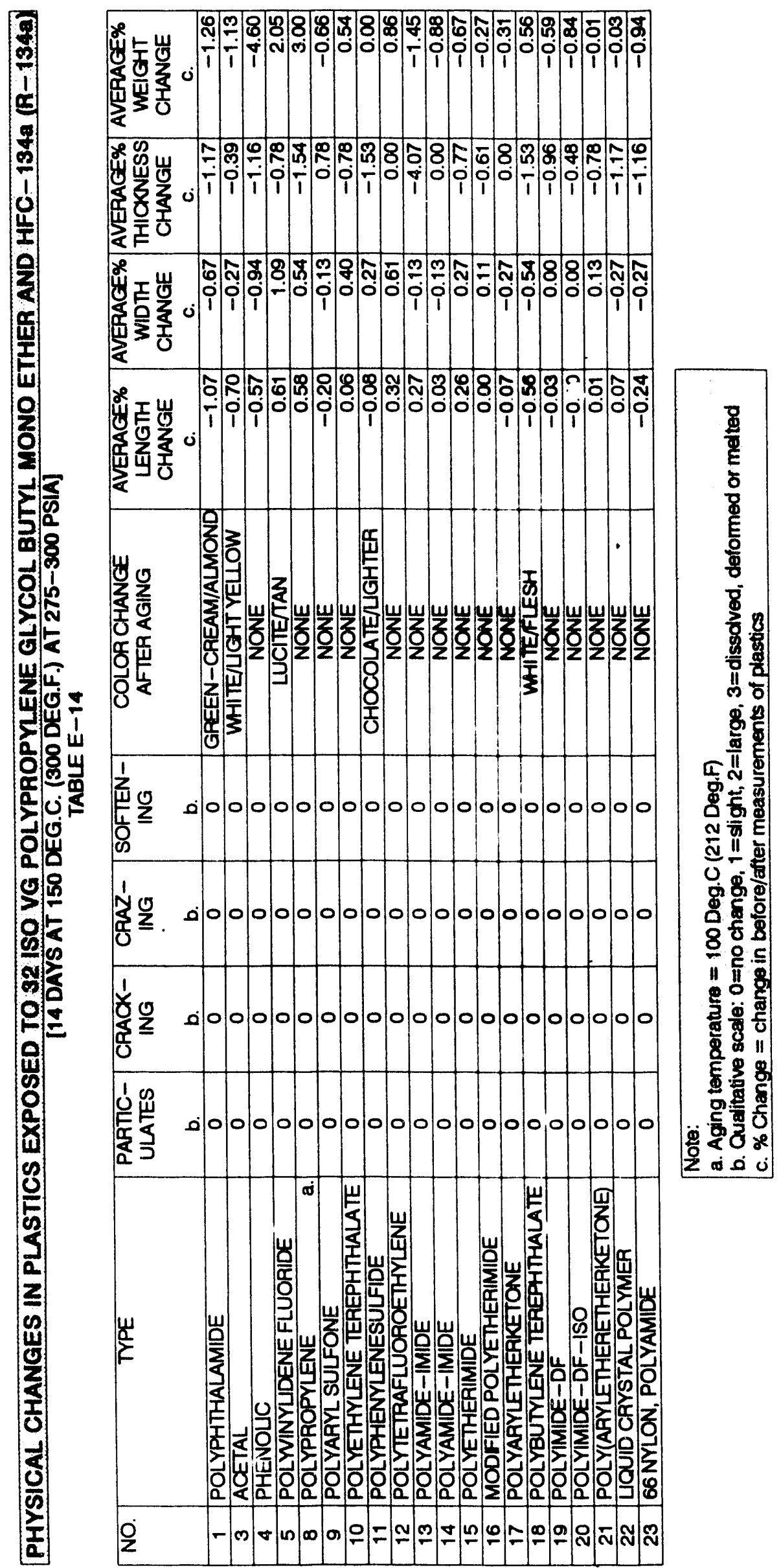




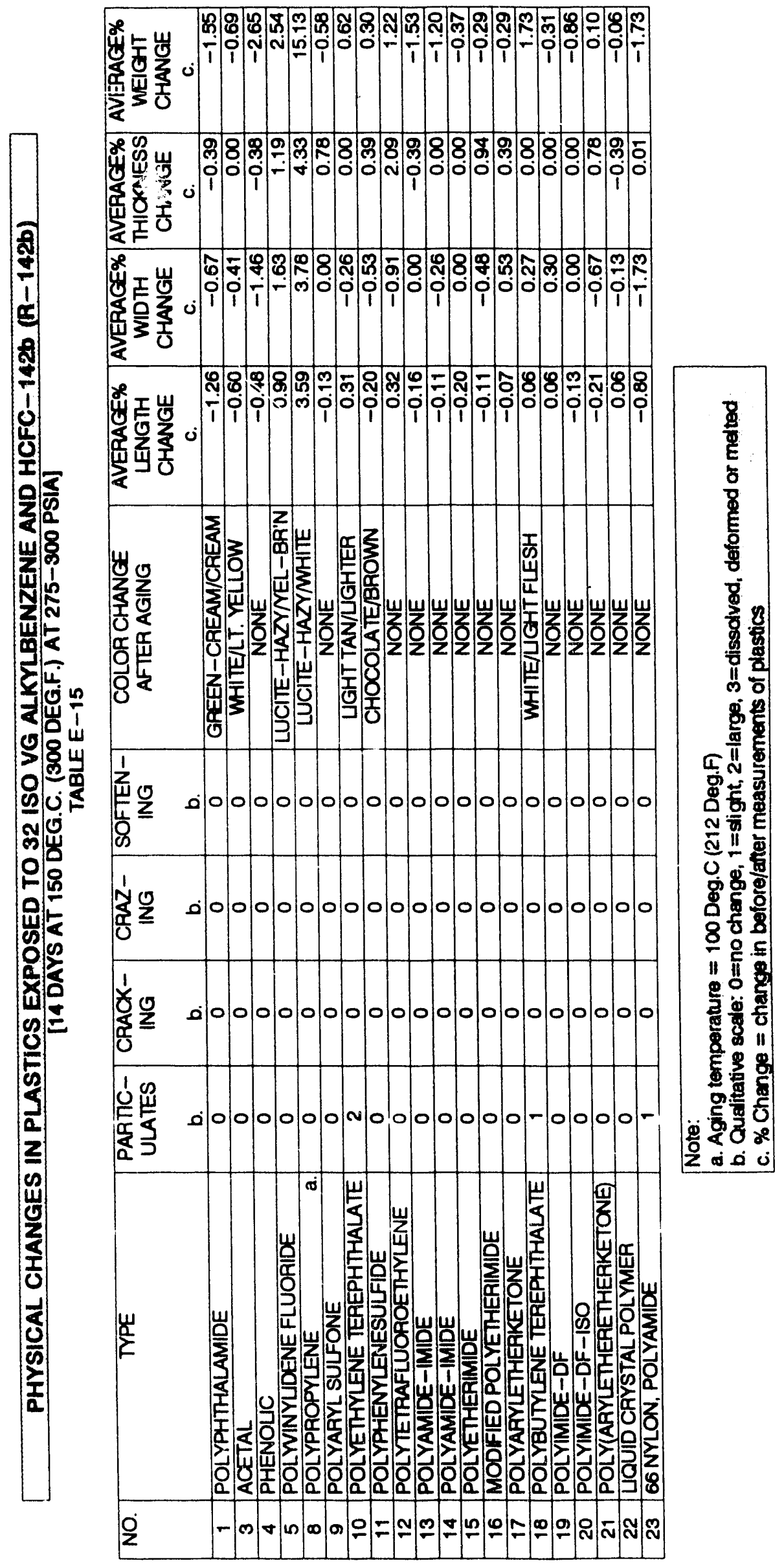




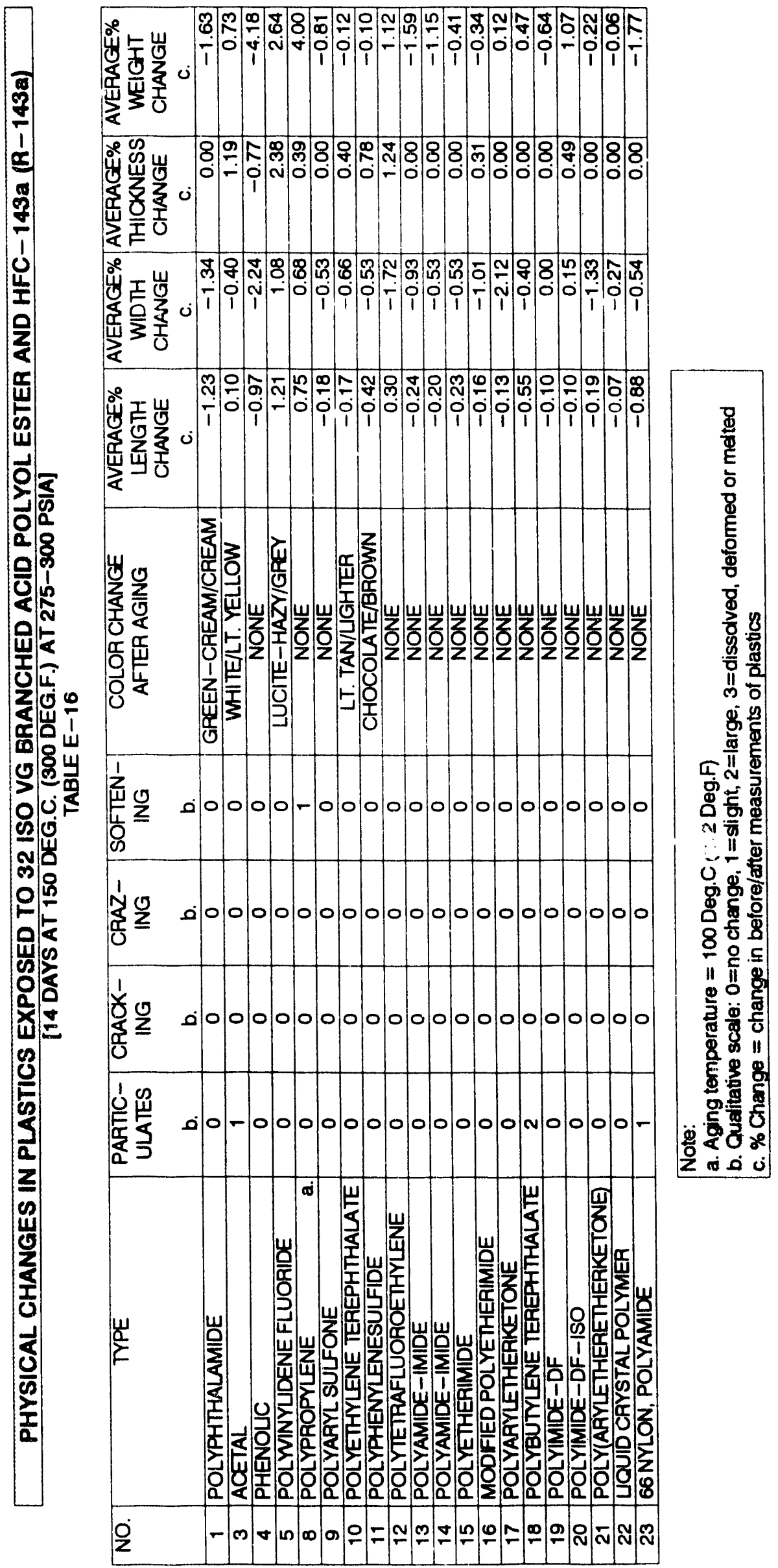




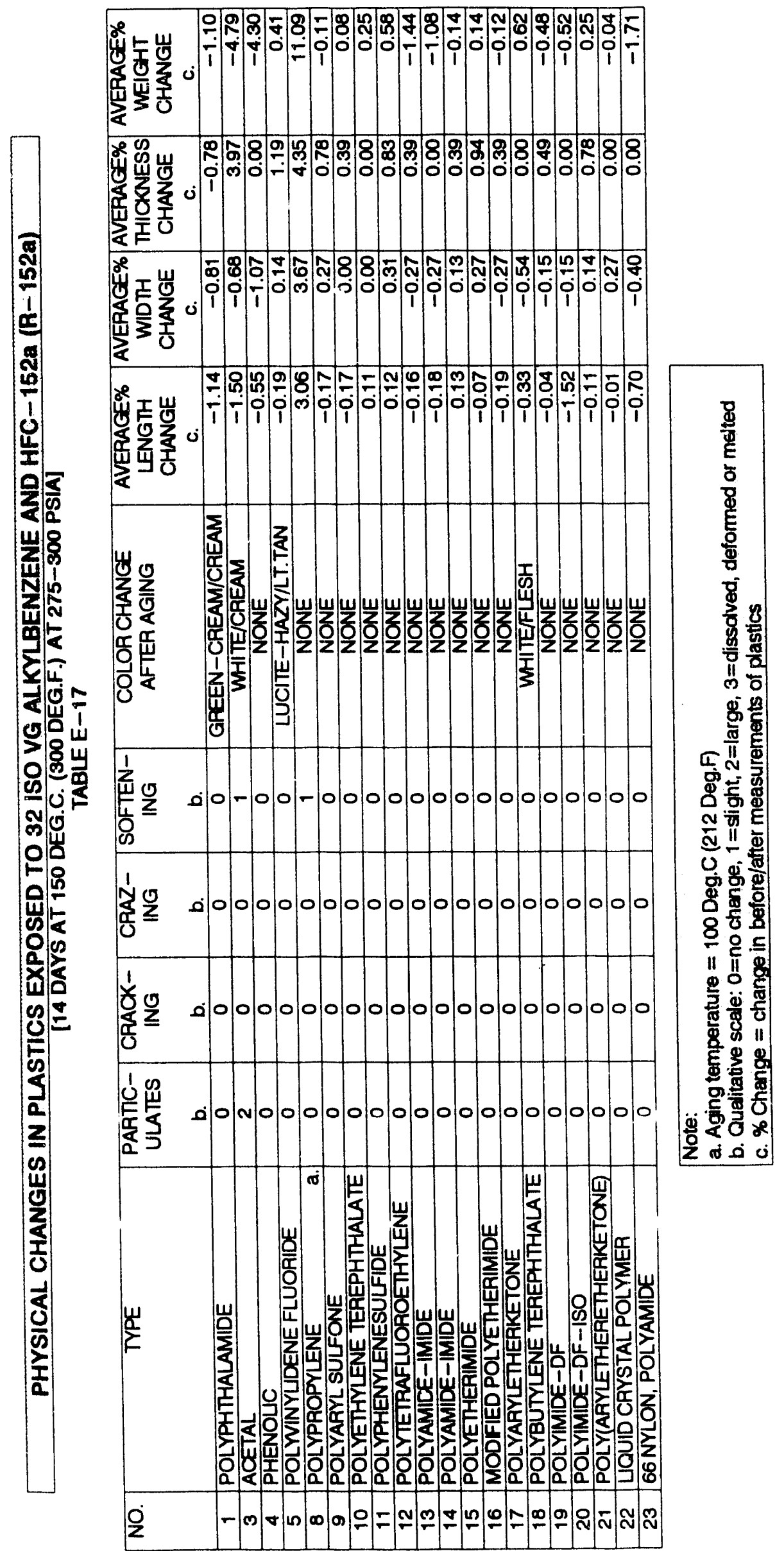




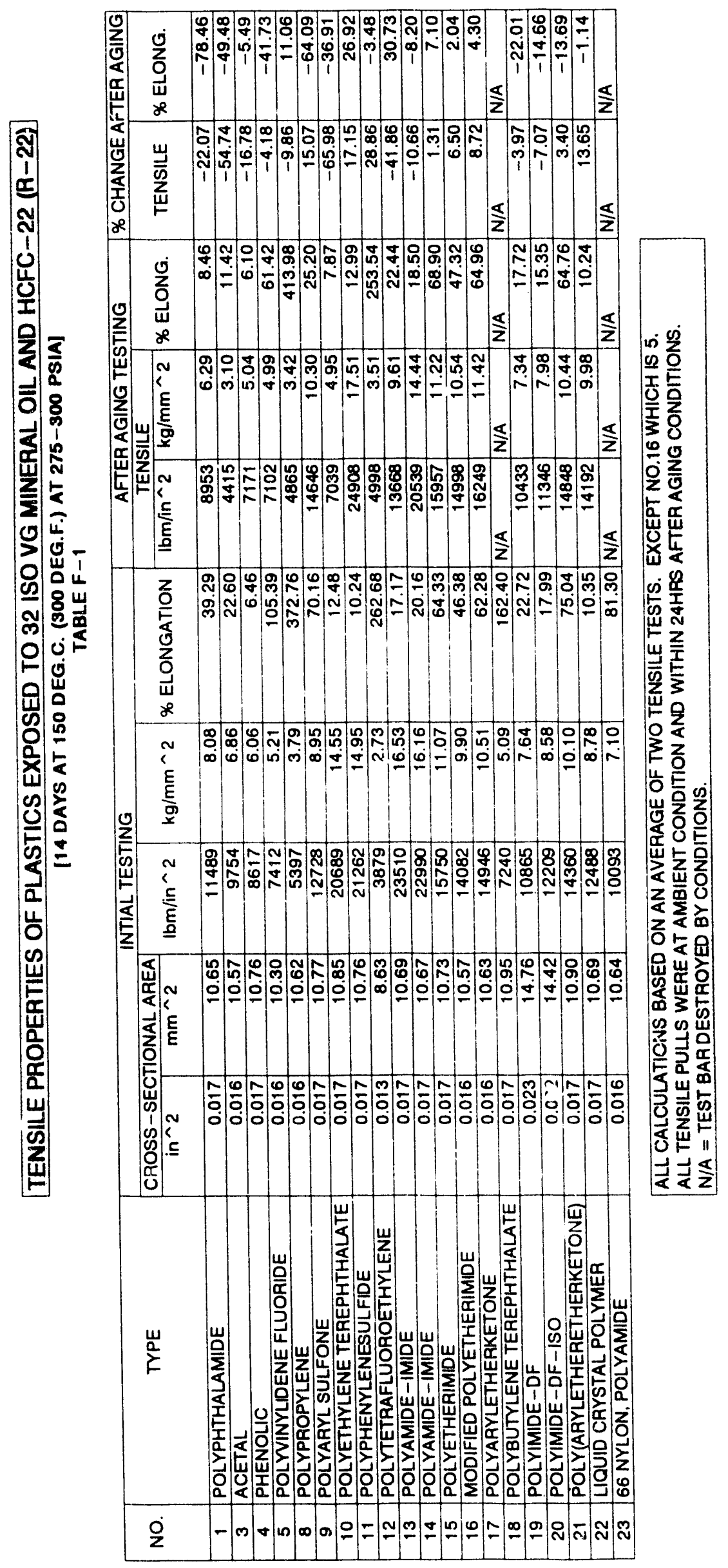




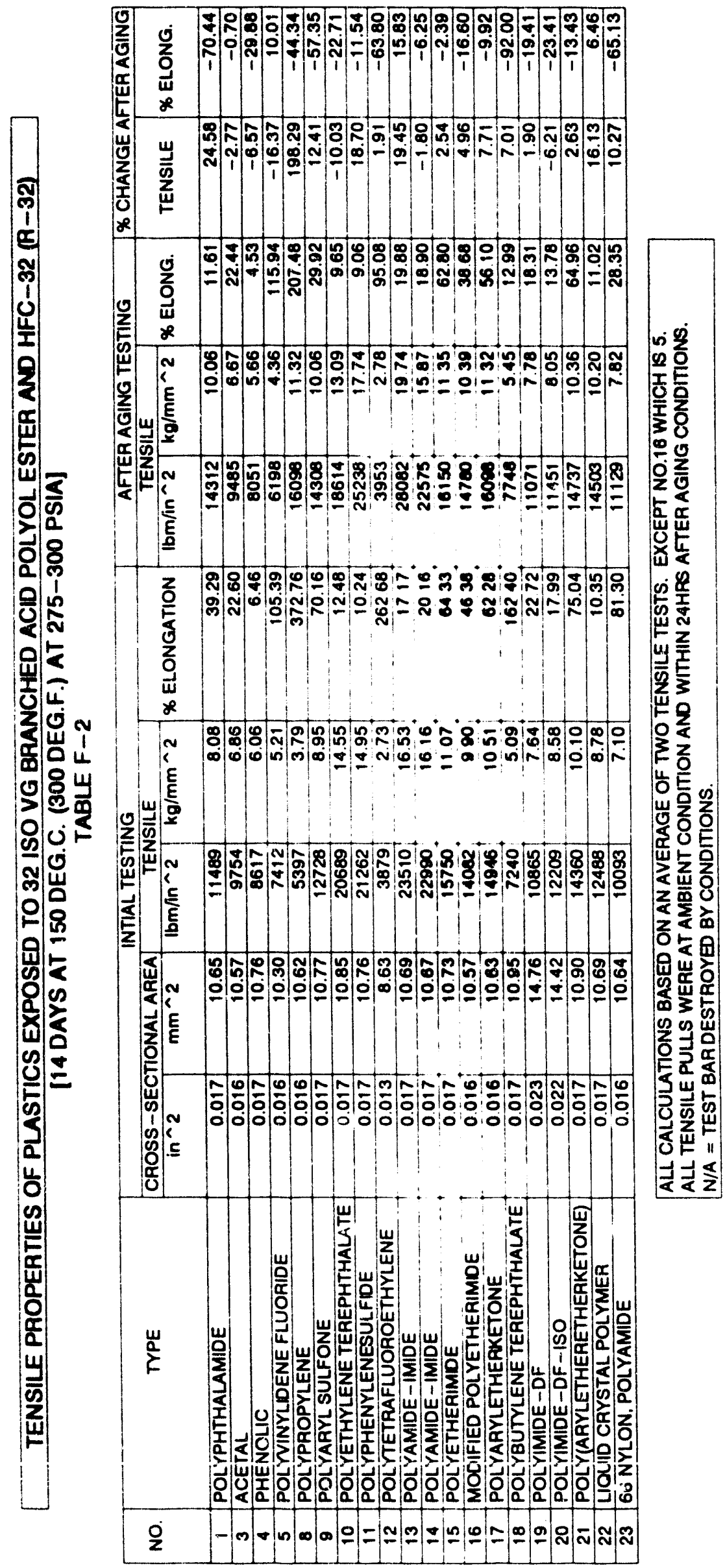




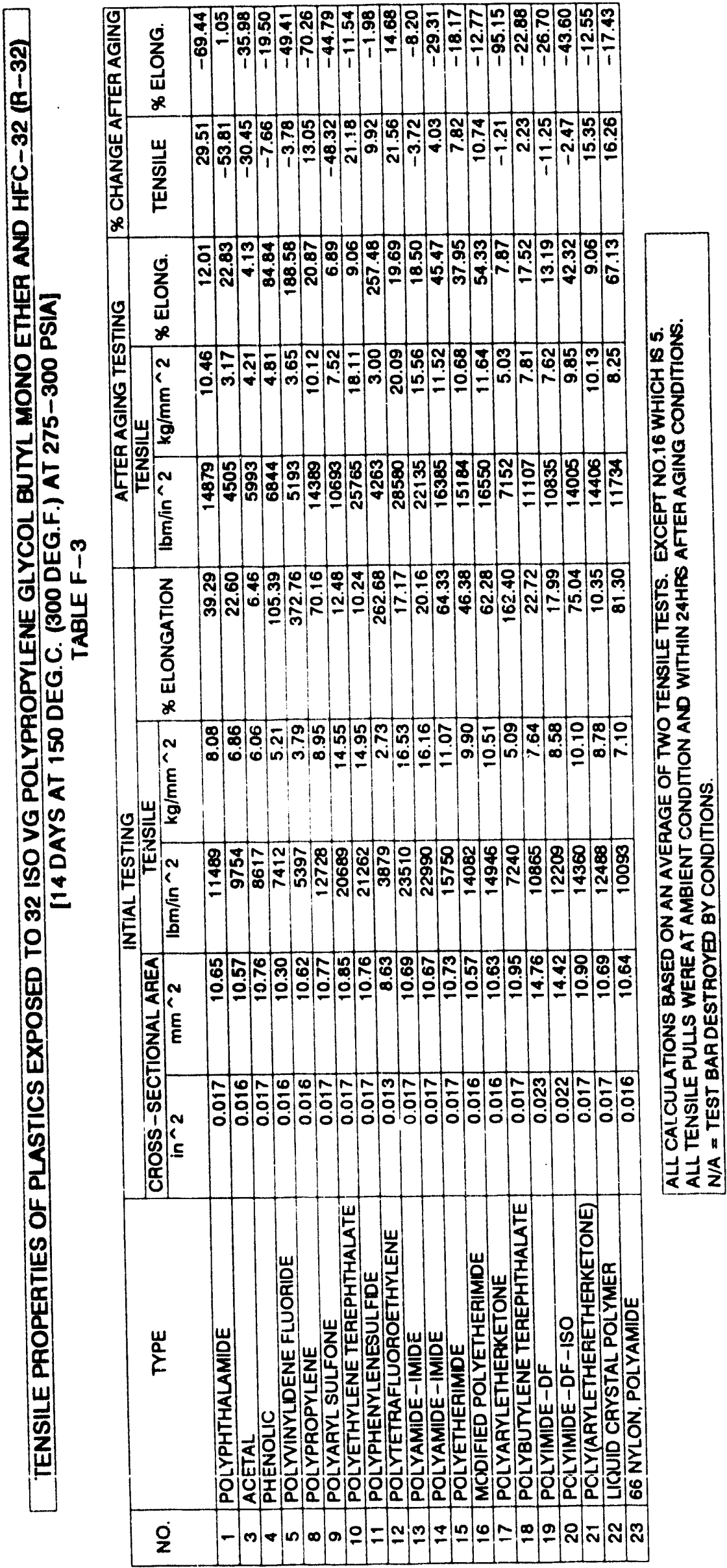



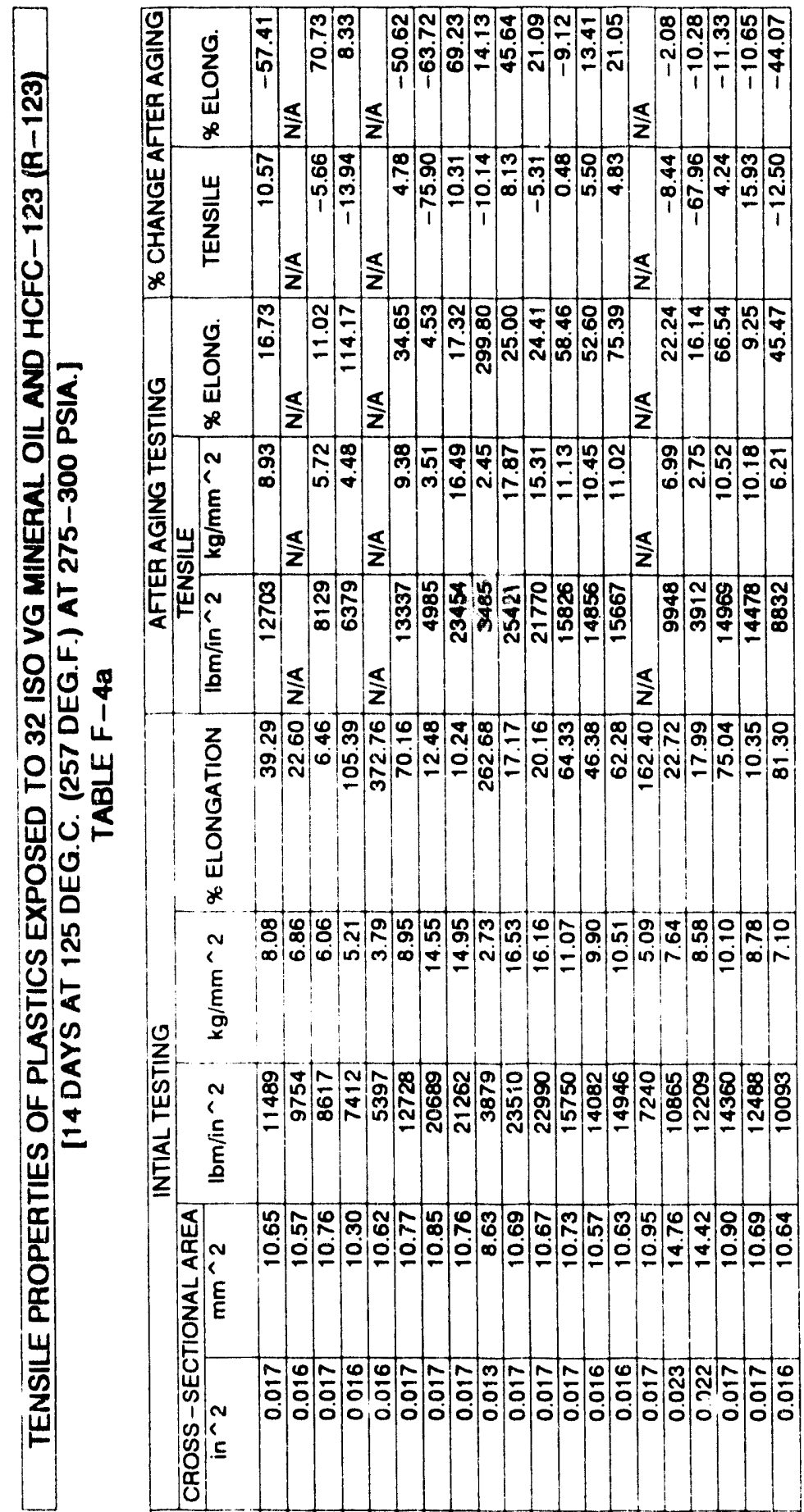

.

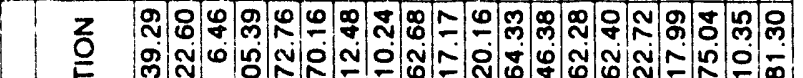

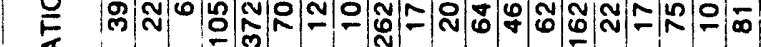
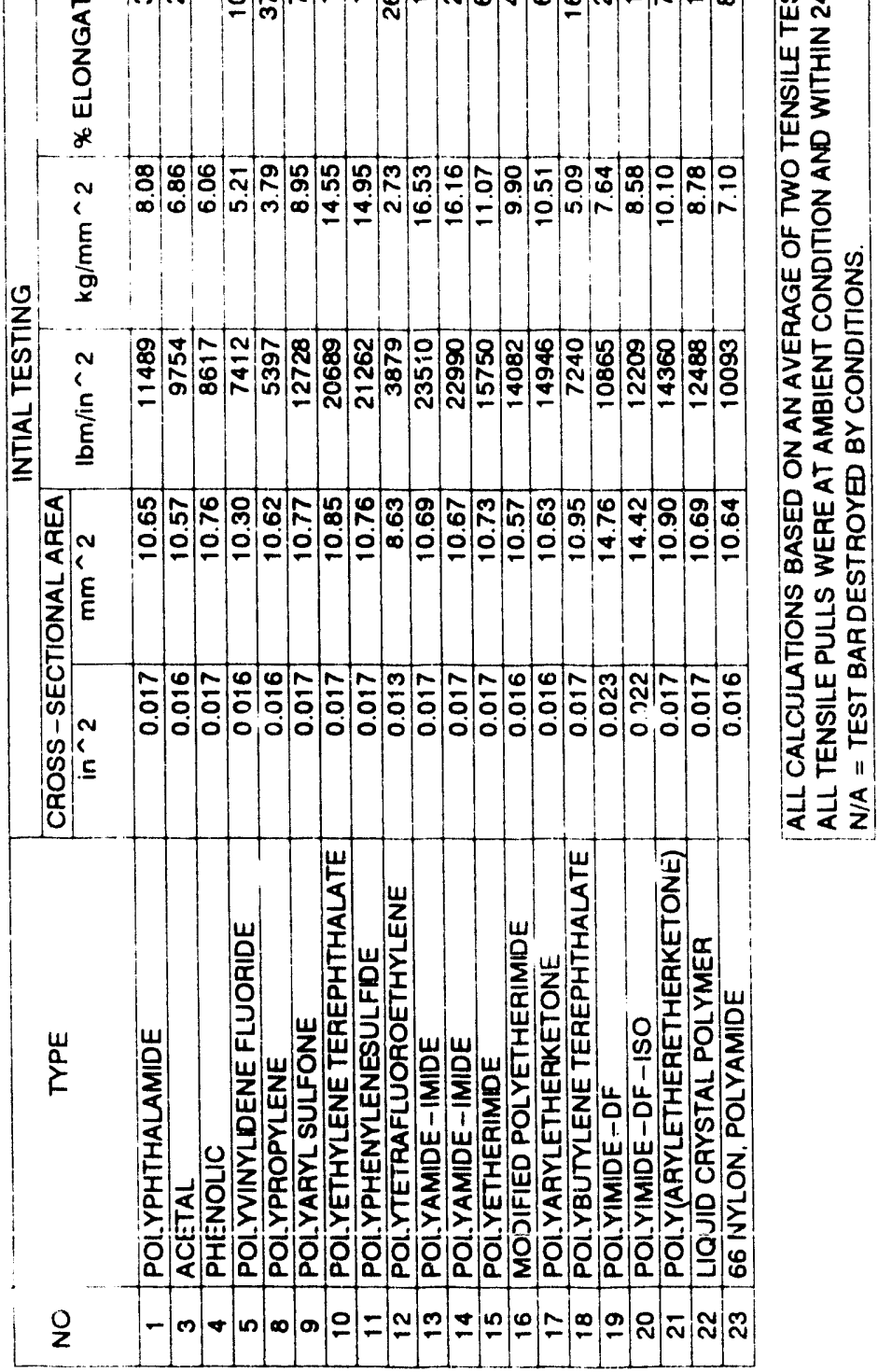

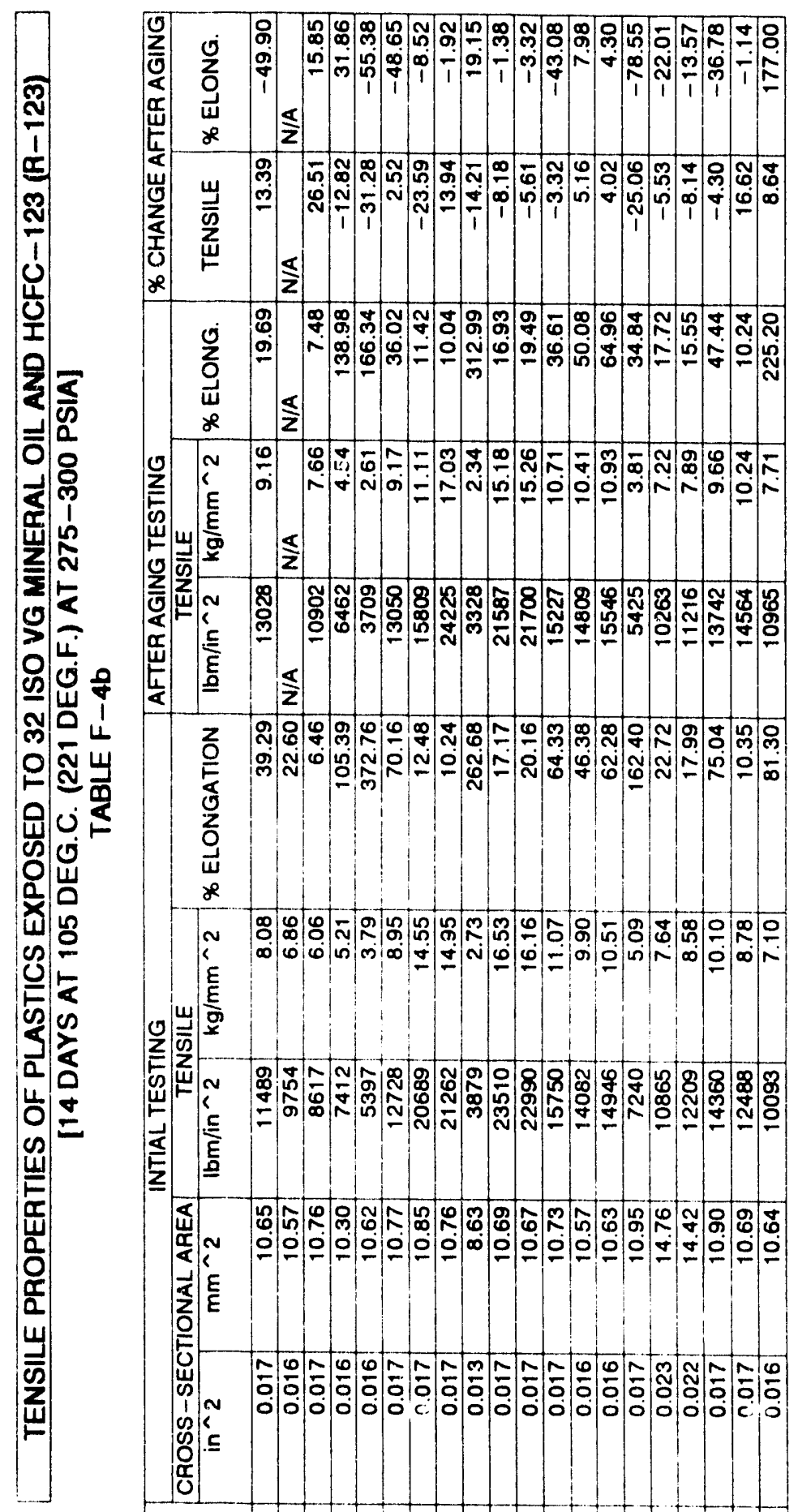
幽

ज政

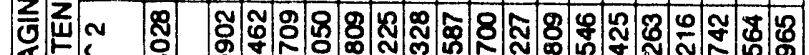

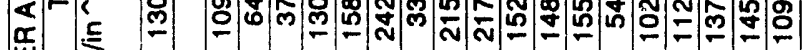

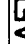

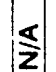

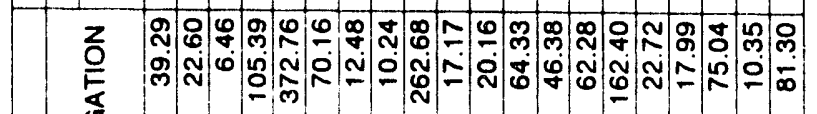

is

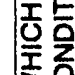

3

인

5

崖在

cis

点

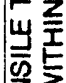

品

证?

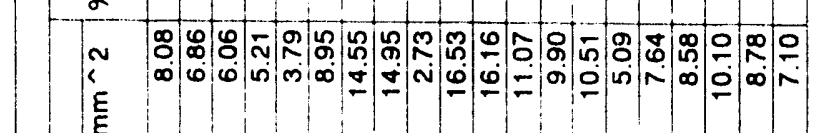

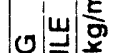

记

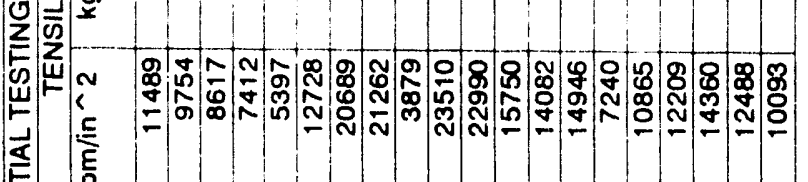

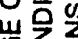

猋之记

䍃证

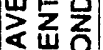

य要方

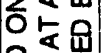

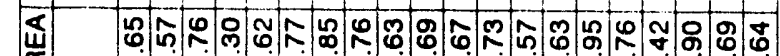

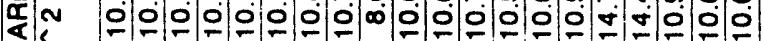

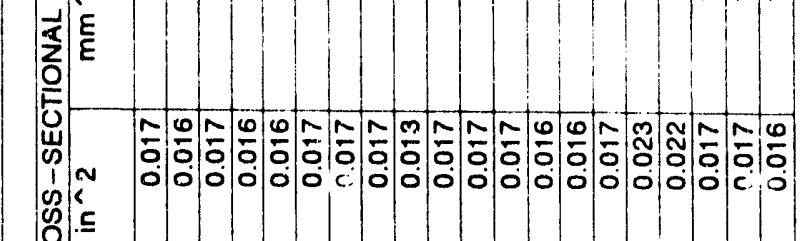

崖焉

35

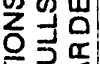

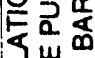

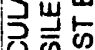

突色"

光軹要

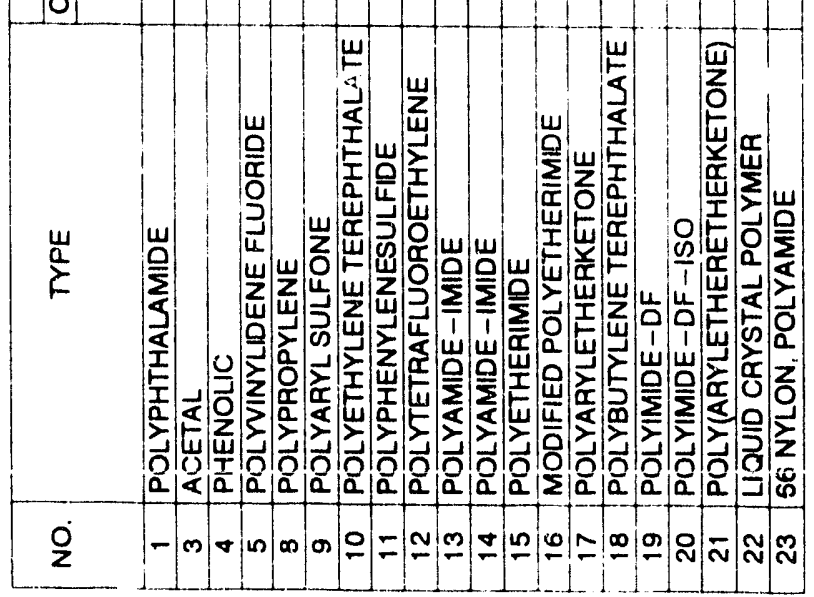




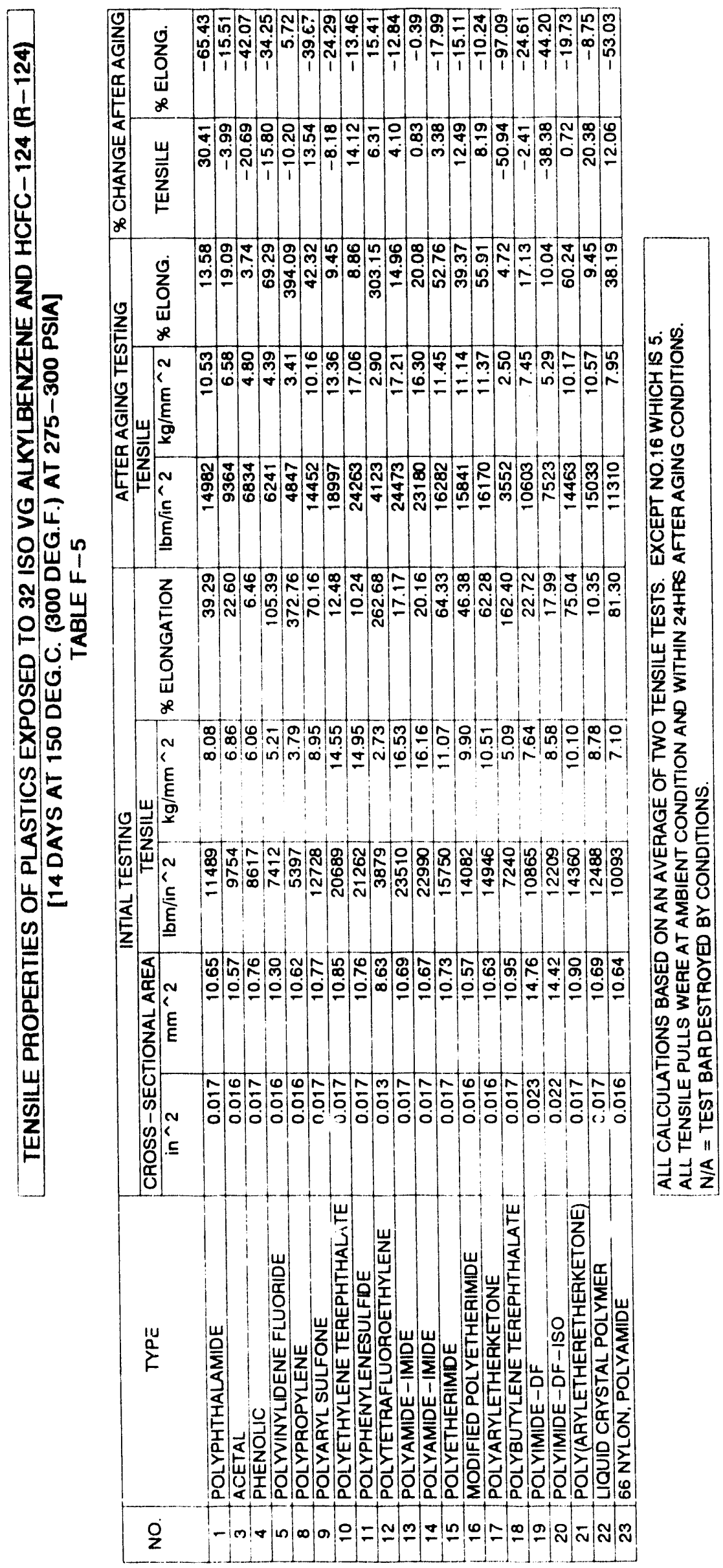




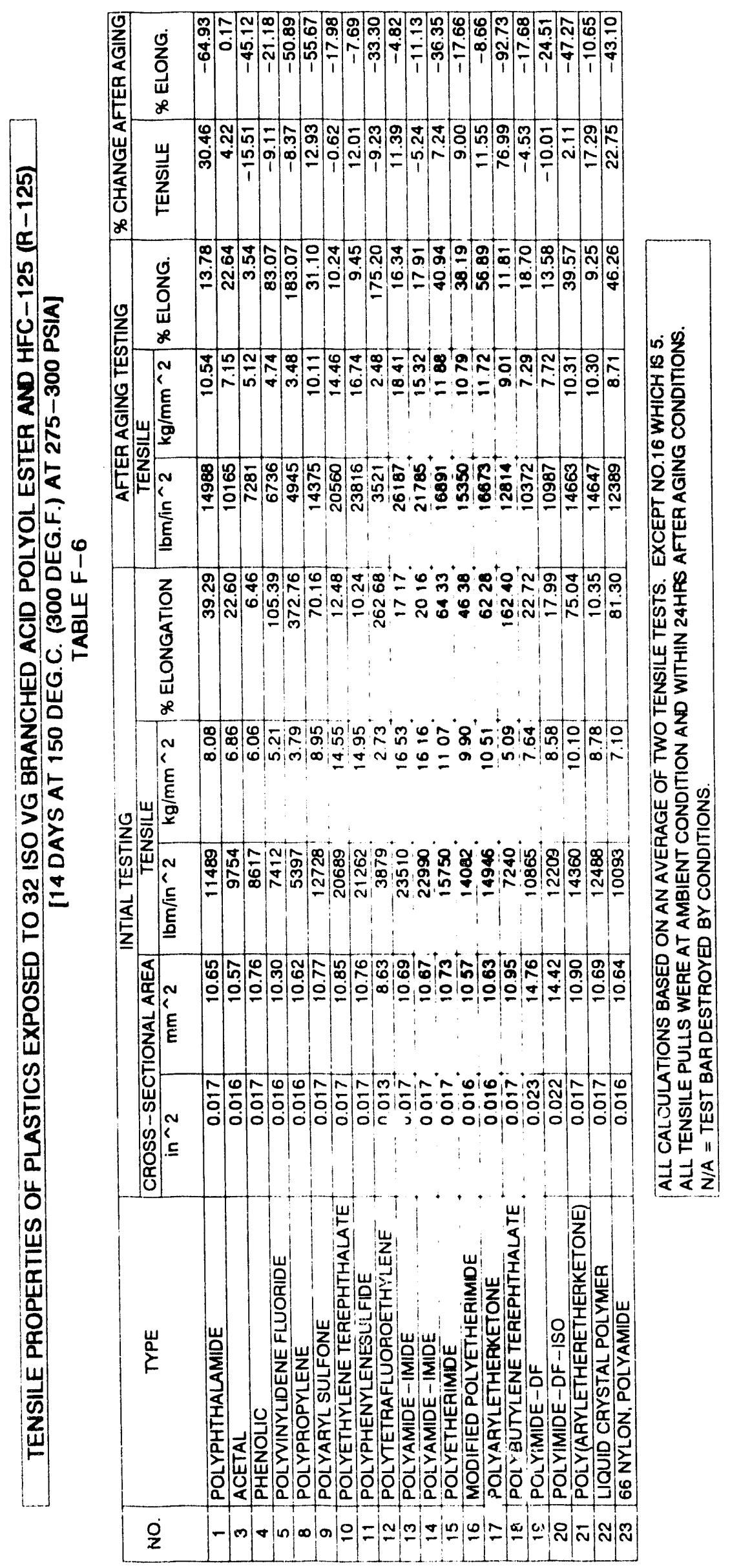




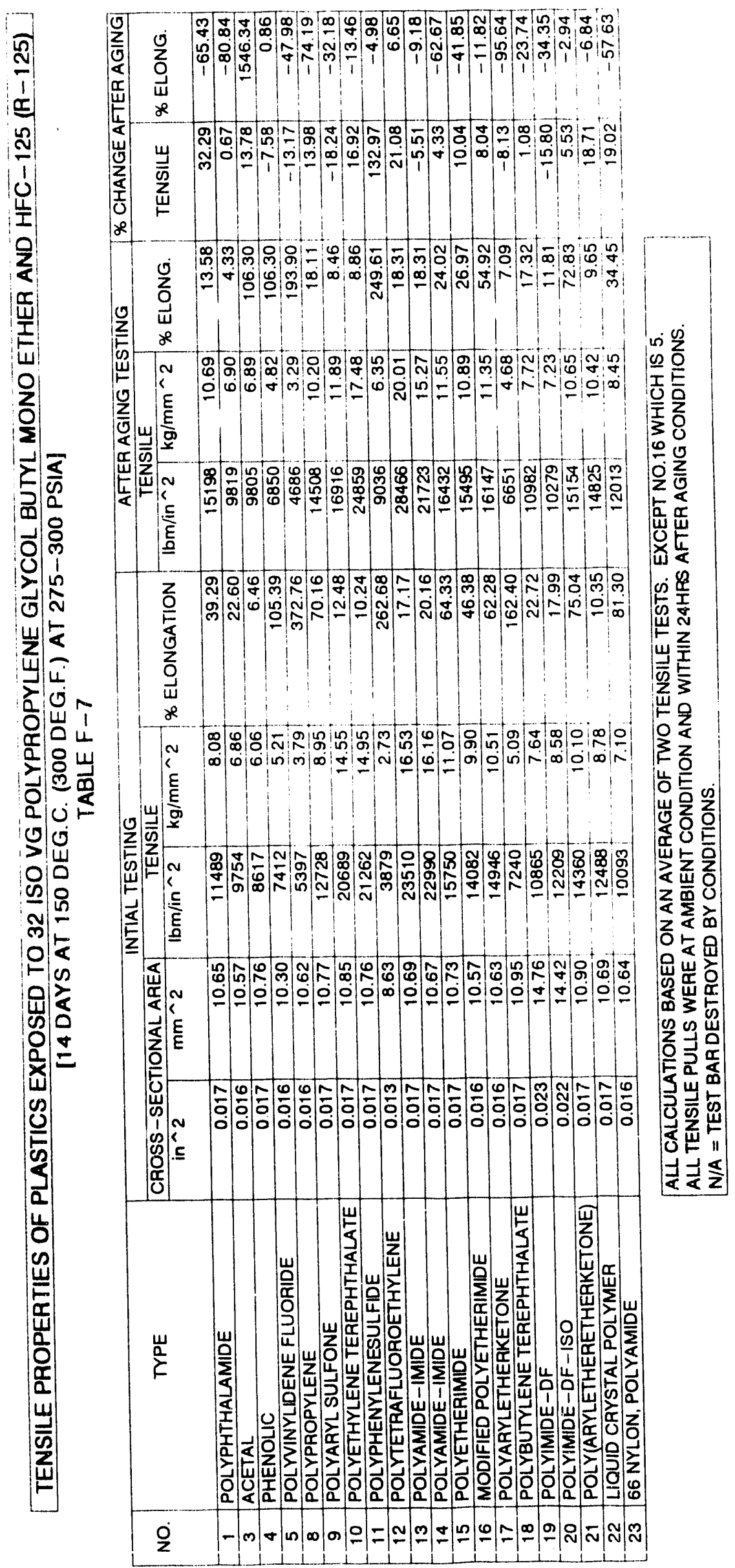




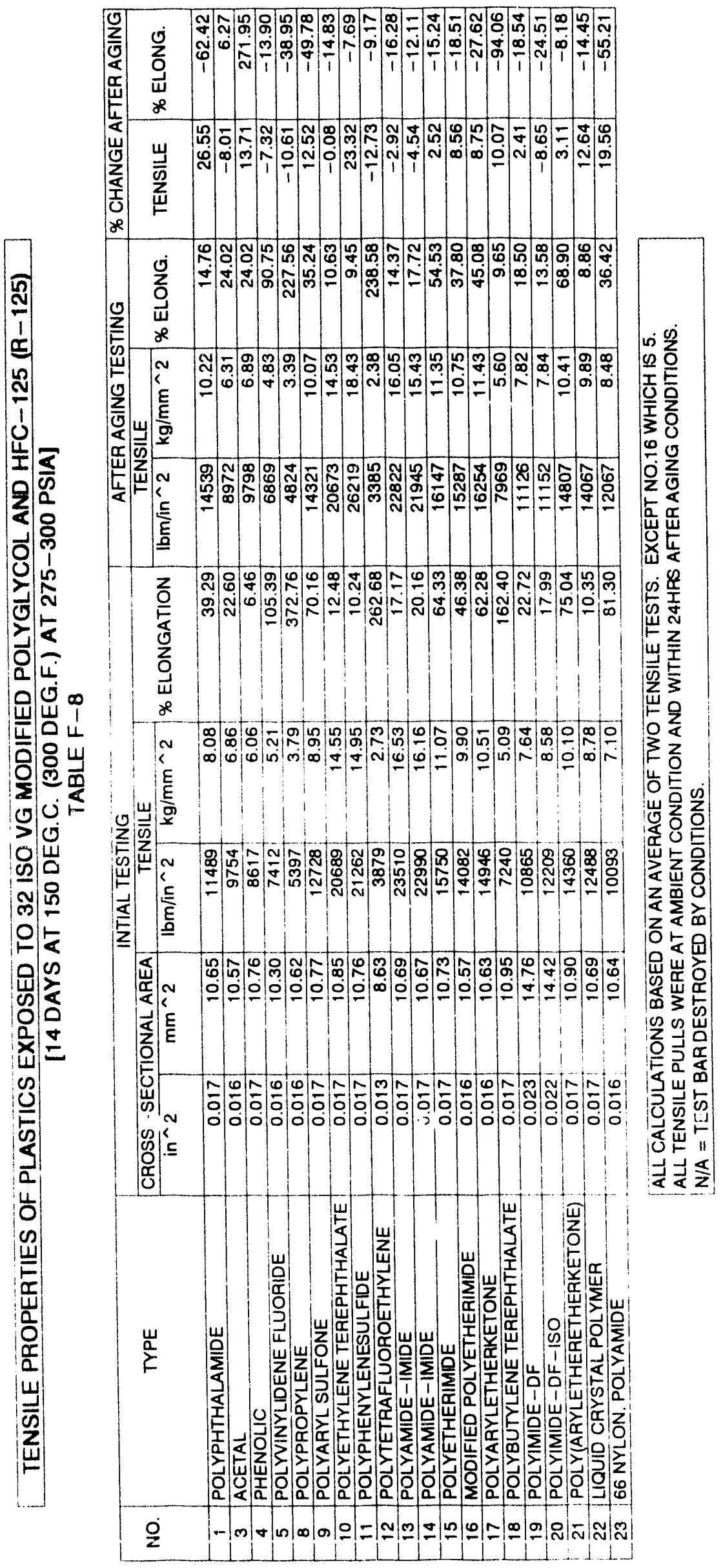




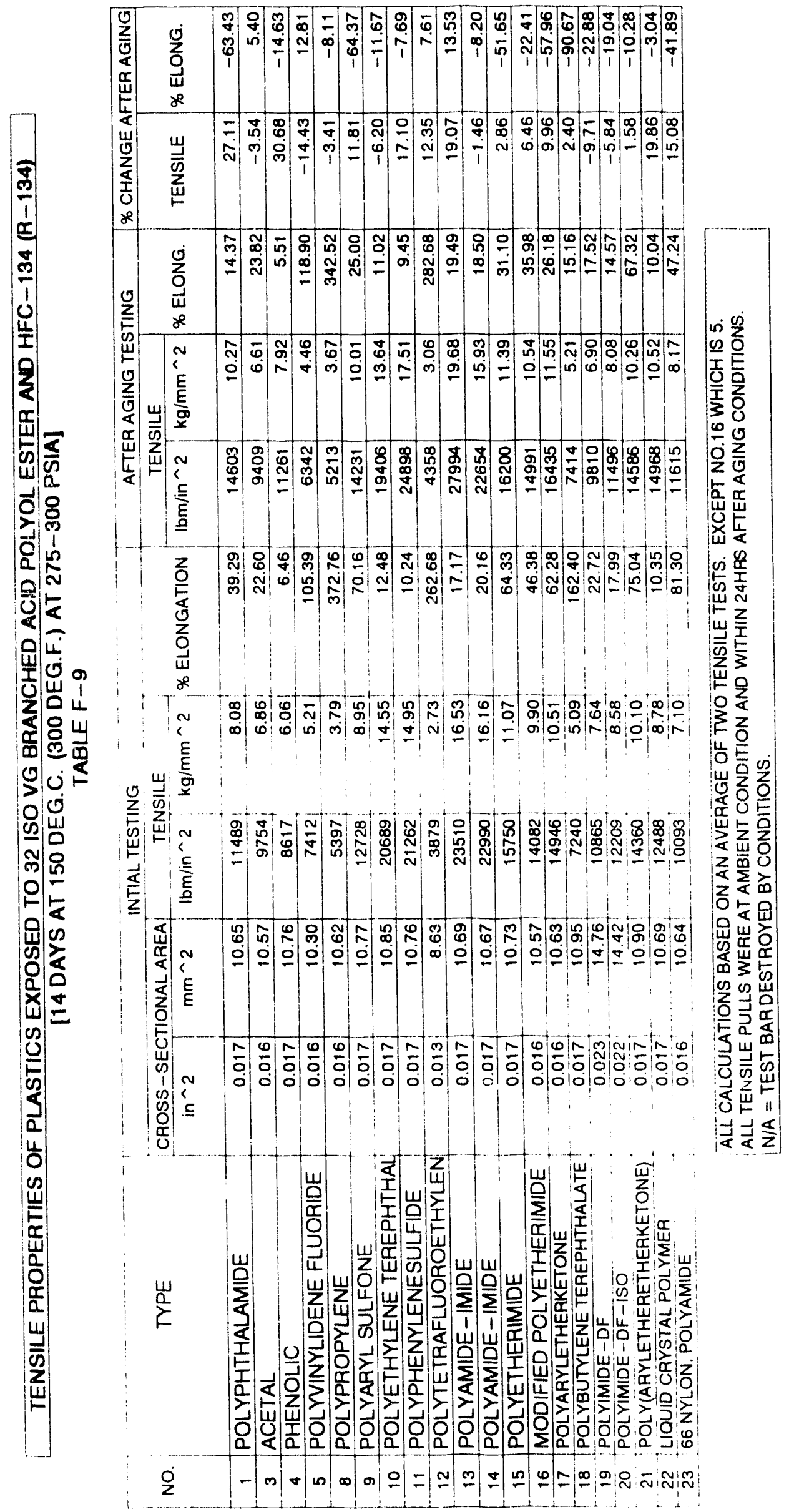




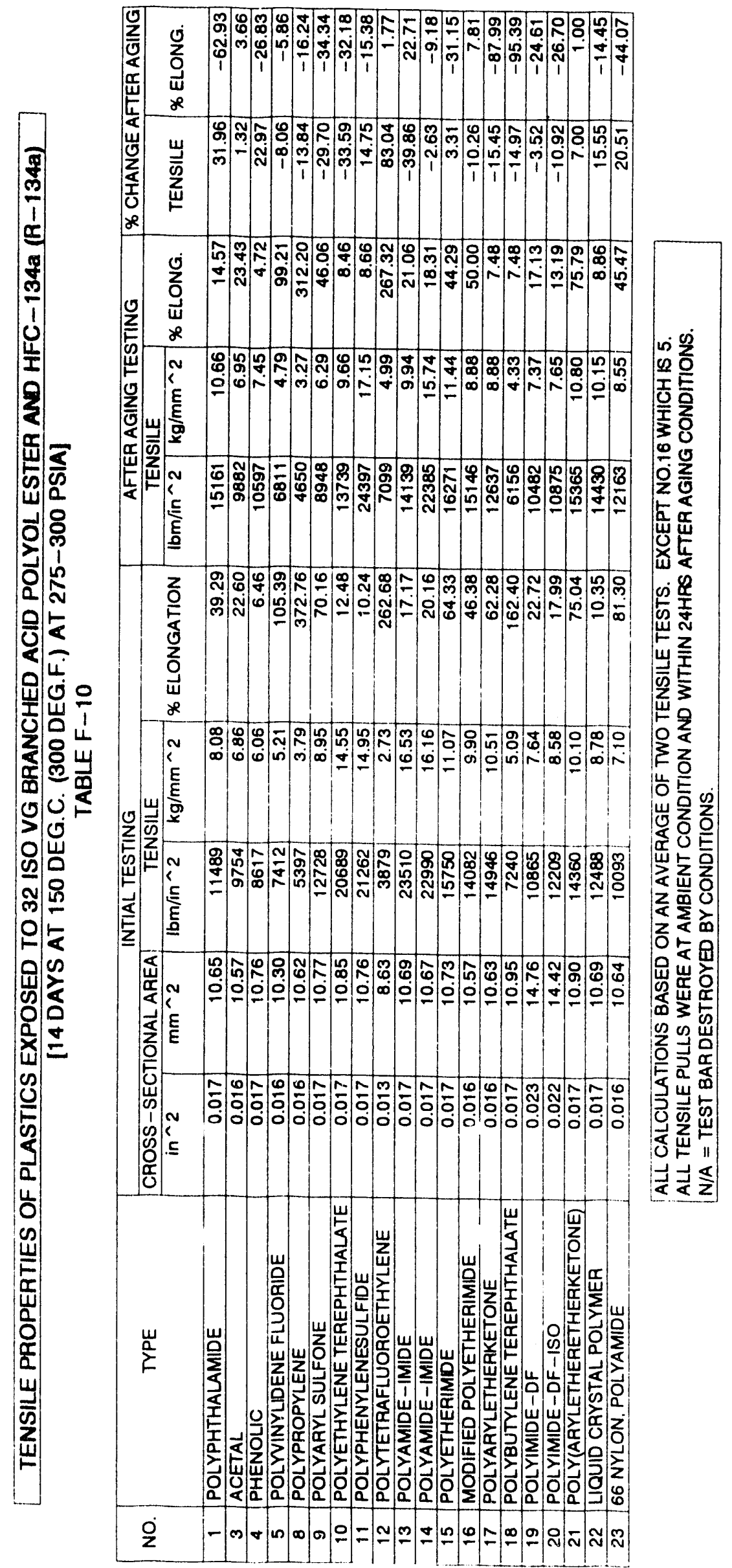




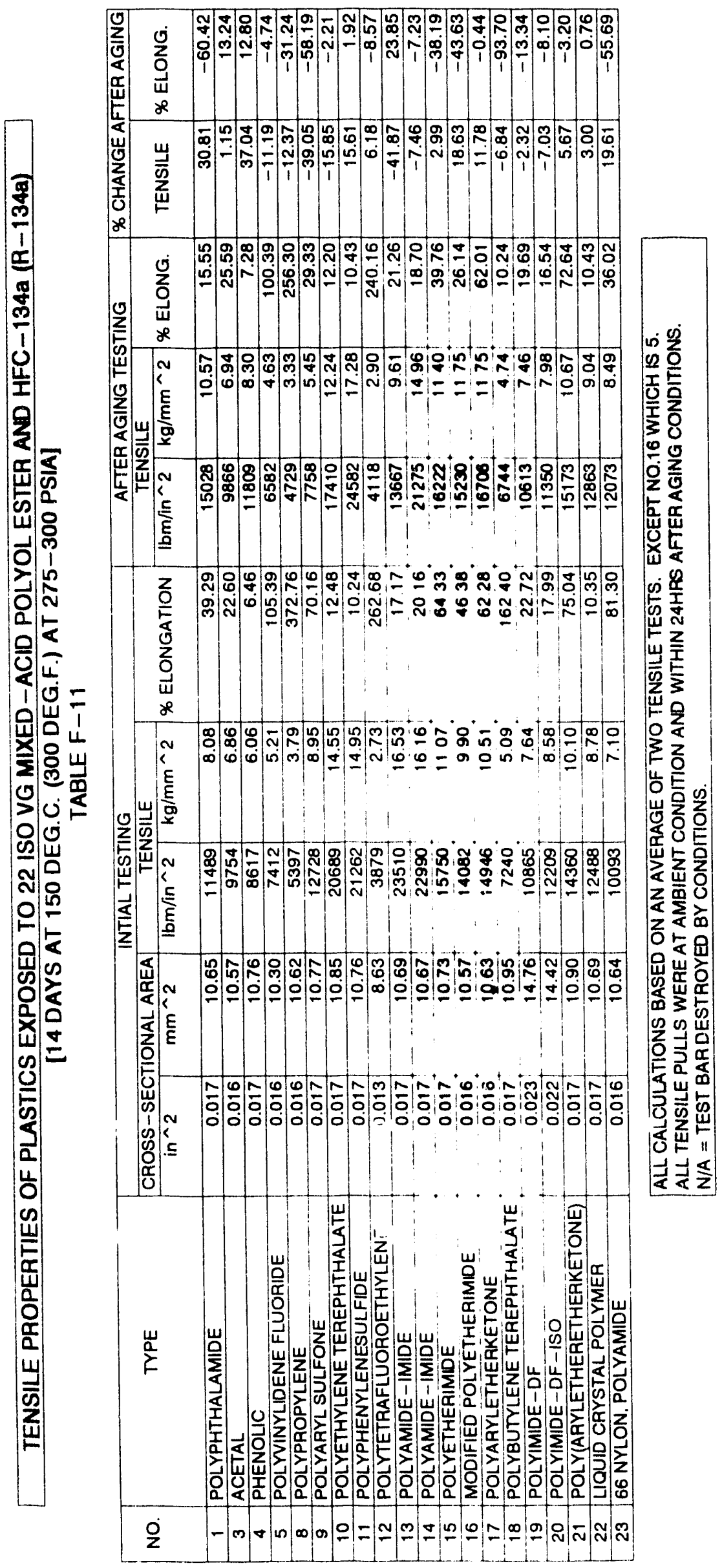




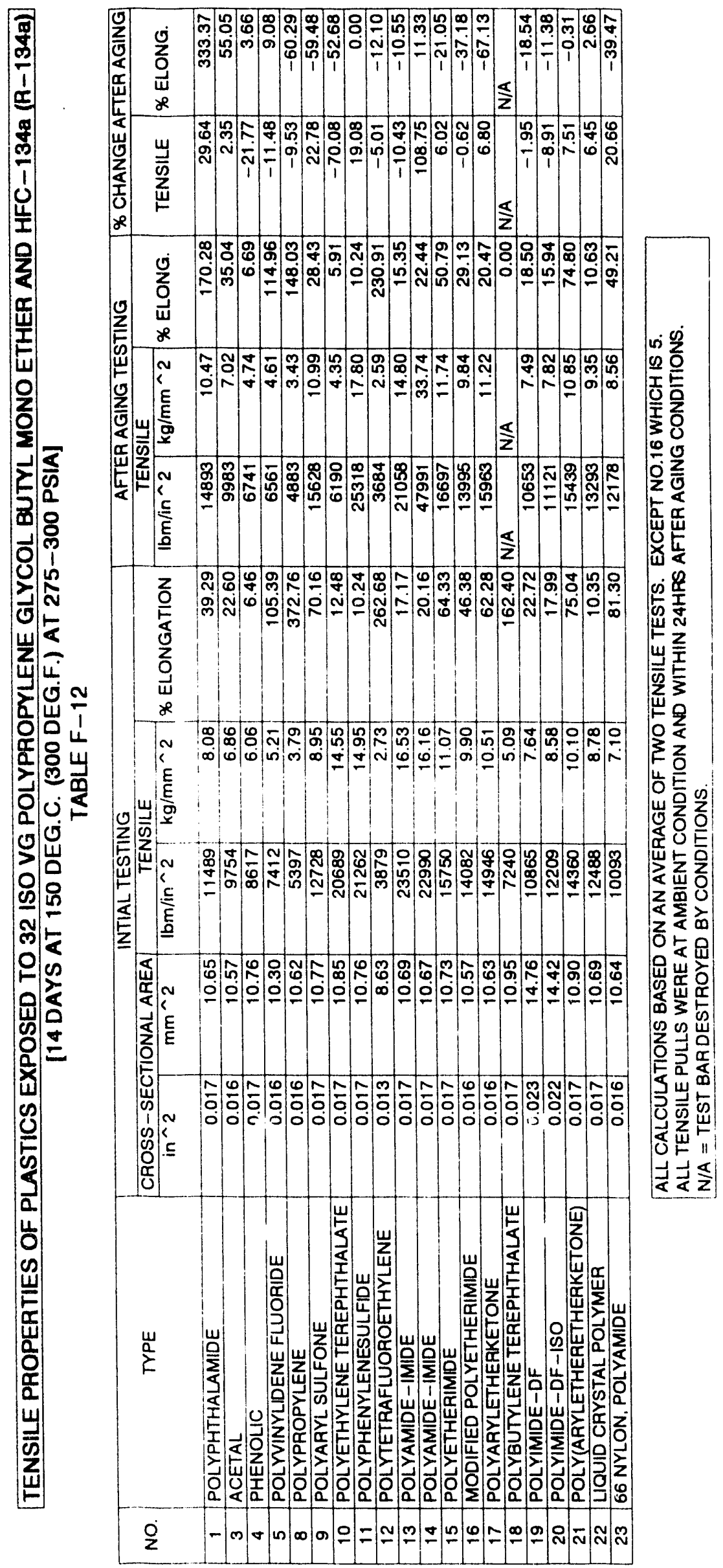




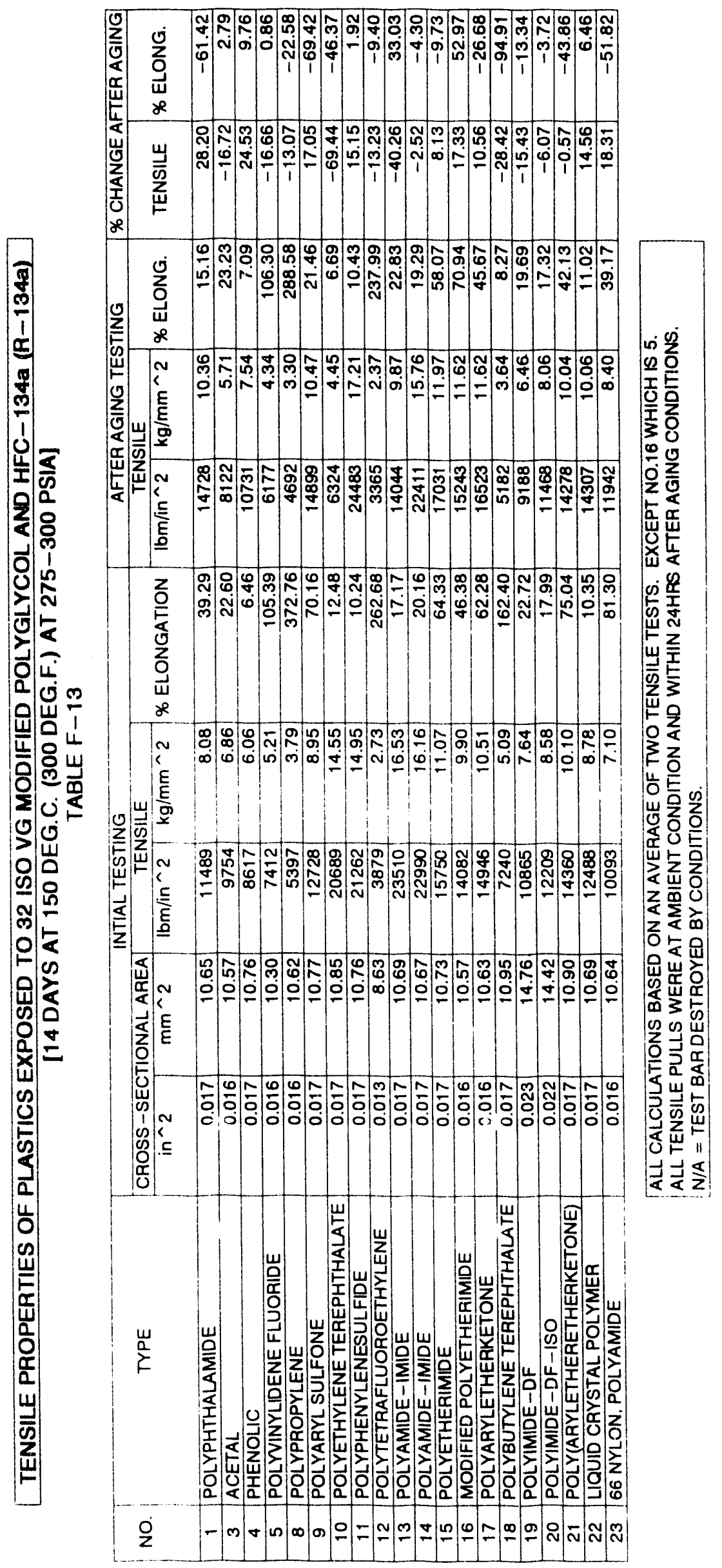




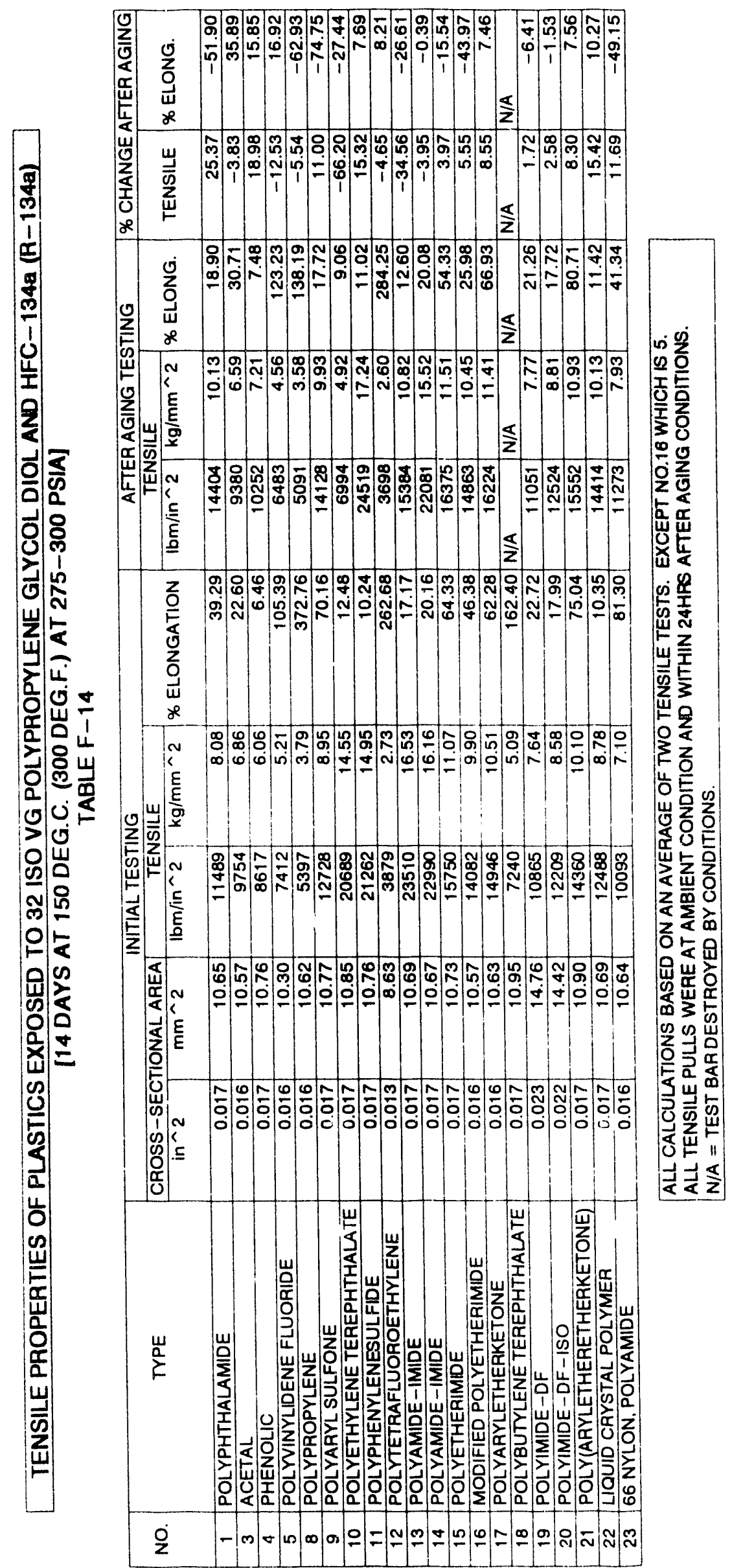




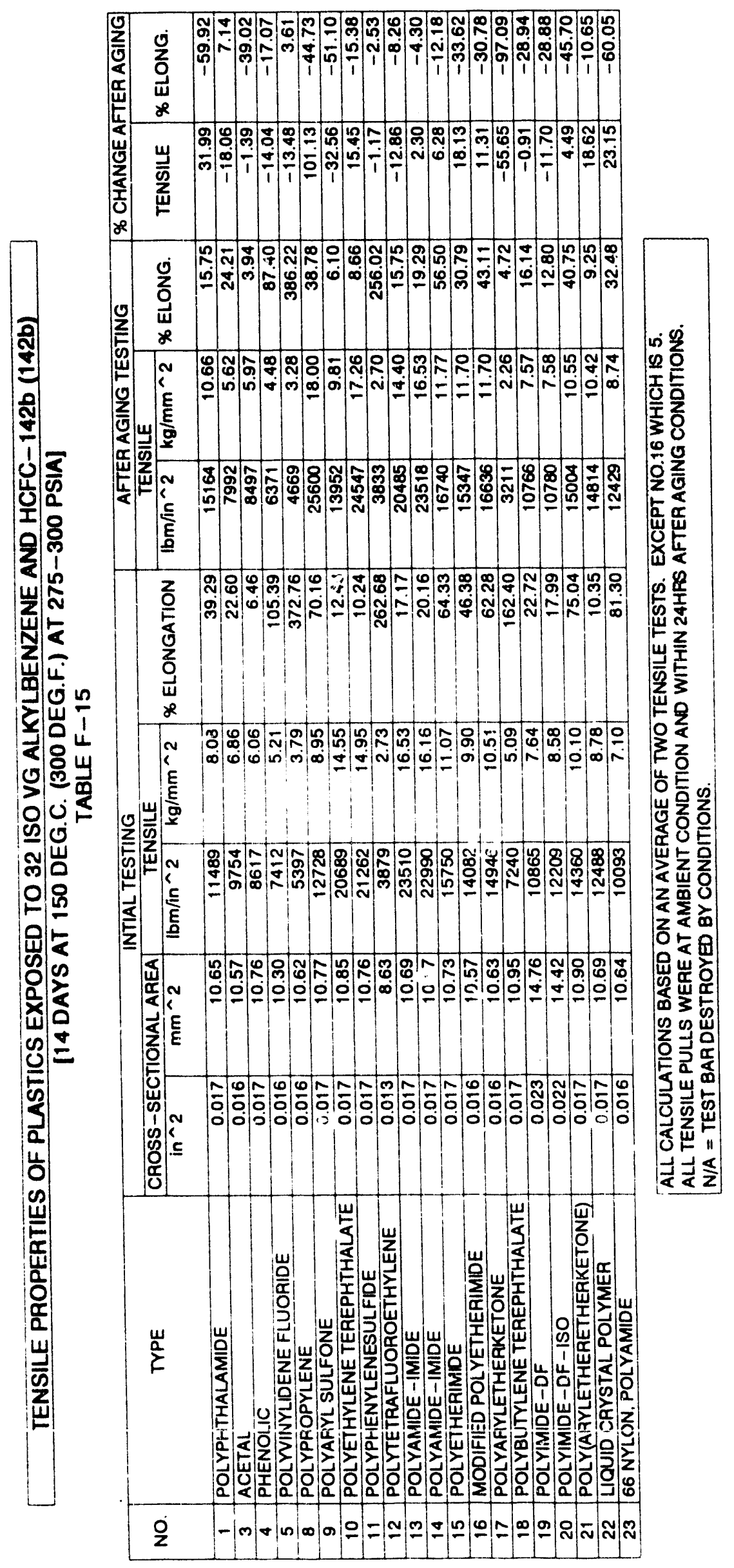




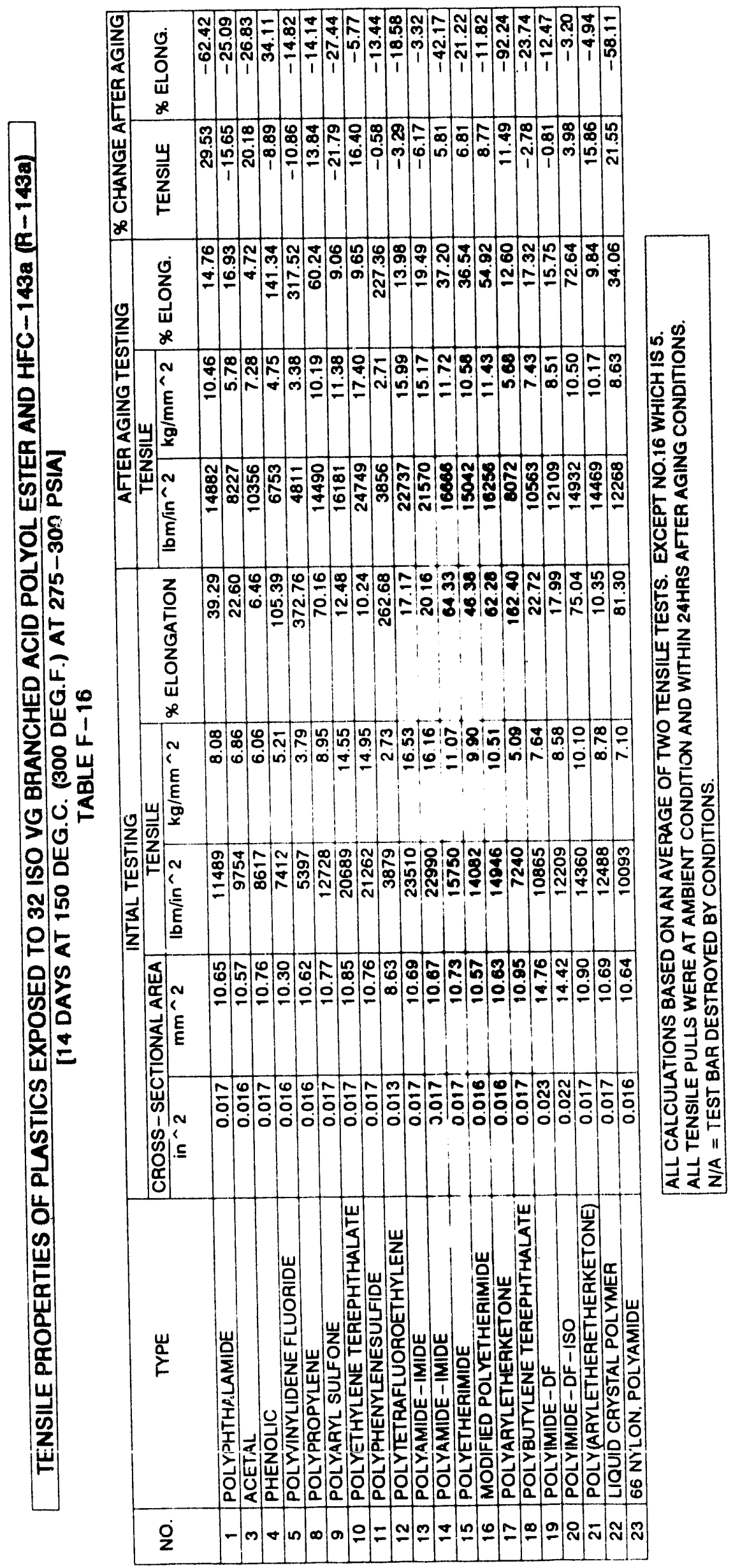




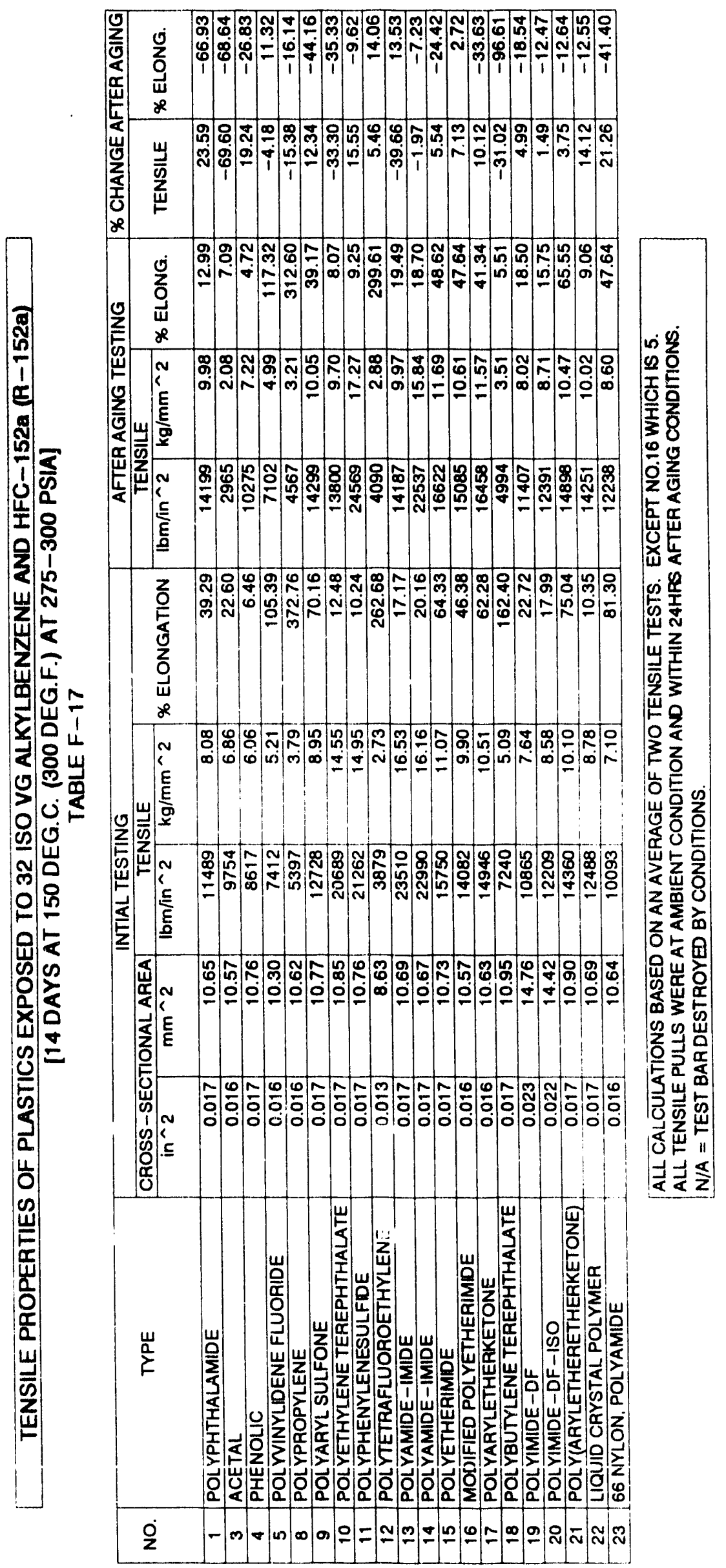



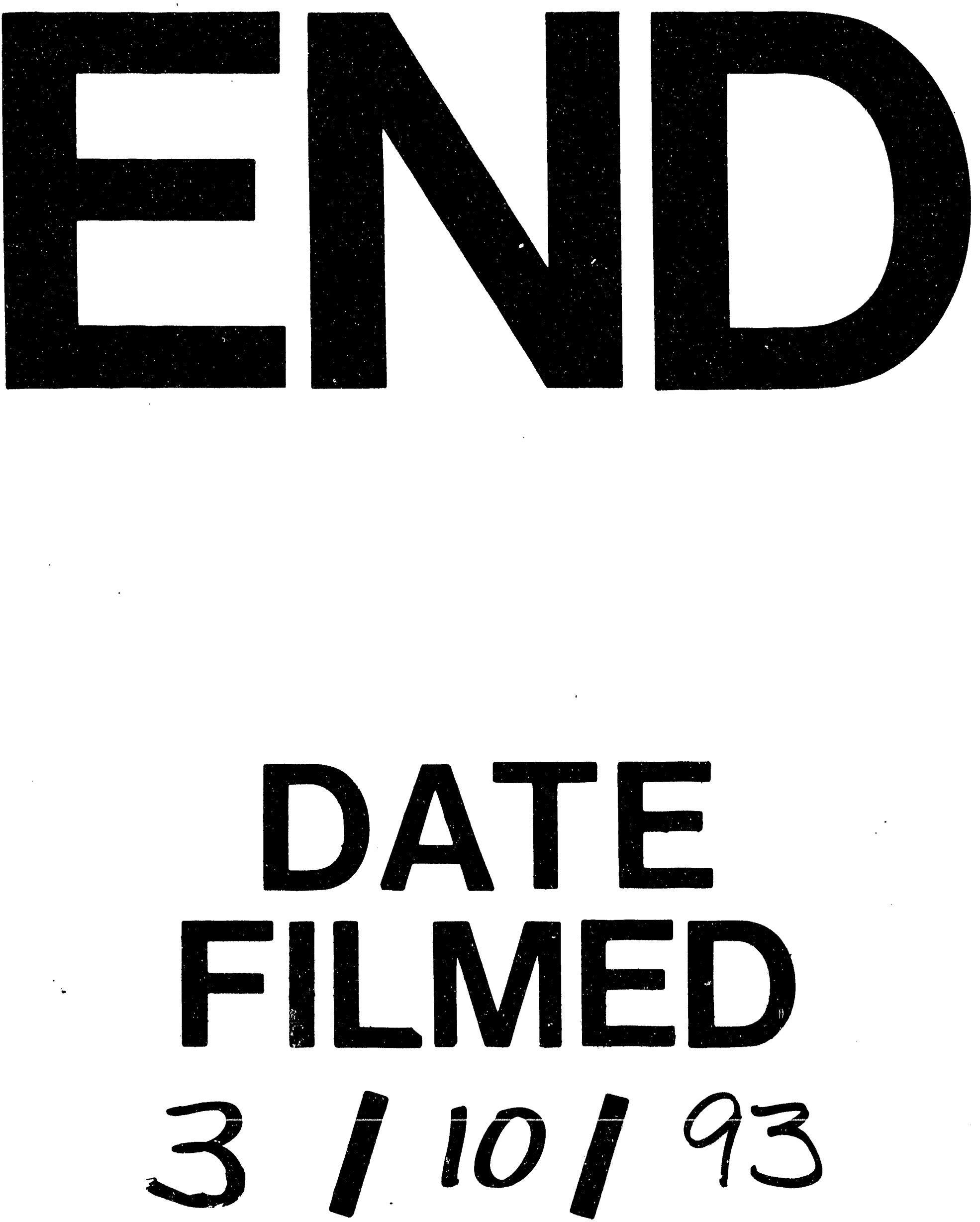
